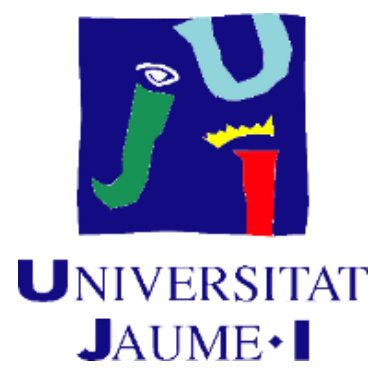

DOCTORAL PROGRAMME IN ECONOMICS AND BUSINESS

DOCTORAL SCHOOL OF UNIVERSITAT JAUME I

\title{
ANALYSIS OF HIGH-FREQUENCY DATA ON INFORMATION TRANSMISSION AND OPTIMAL PORTFOLIO CHOICE
}

\author{
DISSERTATION PRESENTED BY \\ Núria AlEmany Palomo \\ THESIS SUPERVISORS \\ Vicent ARagó Manzana \\ ENRIQUE SALVADOR ARAGó
}

JANUARY, 2018 


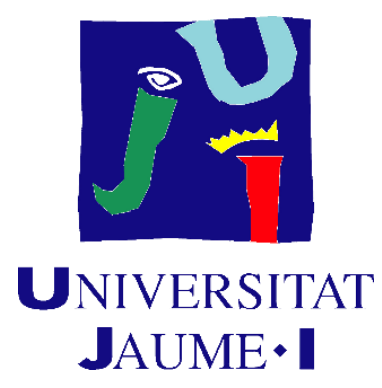

Programa de Doctorat en ECONOMIA I EMPRESA

Escola de Doctorat de la Universitat Jaume I

\title{
ANÀLISIS DE DADES D'ALTA FREQÜÈNCIA EN LA TRANSMISSIÓ D’INFORMACIÓ I L'ELECCIÓ ÒPTIMA DE CARTERES
}

\begin{abstract}
Memòria presentada per Núria Alemany Palomo per optar al grau de doctor/a per la Universitat Jaume I.
\end{abstract}

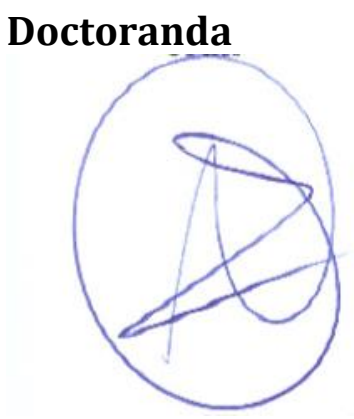

Núria Alemany Palomo

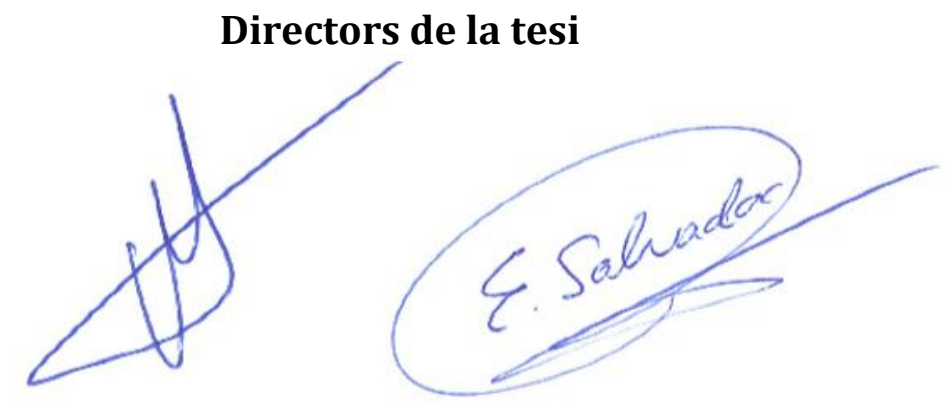

Vicent Aragó Manzana i Enrique Salvador Aragó 


\section{Agraïments Institucionals}

Aquesta tesi ha estat possible gràcies al finançament rebut pel programa predoctoral PREDOC/2014/14 per a la formació de personal investigador de la Universitat Jaume I, i pel projecte EC02014/55221-P del Ministeri d'Economia i Competitivitat d'Espanya. 


\section{ACKNOWLEDGEMENTS}

I take this great opportunity to sincerely thank a number of people and institutions who have made possible that my thesis becomes a reality.

First and foremost I would like to thank my thesis supervisors Professor Vicent Aragó and Enrique Salvador for their commitment, confidence, and for suggesting me the original idea developed in this thesis. In particular, I appreciate their endless guidance and valuable contribution, which have greatly improved the quality of this thesis and whose continued support has been crucial to accomplish this task. I would also want to express my gratitude to Professor Andreas Kaeck, my tutor while I was doing my doctoral stay at Sussex University, for his comments regarding the third chapter of this dissertation.

I am sincerely thankful to the members of the Accounting and Finance Department at Jaume I University for providing a comfortable, motivating and rewarding working atmosphere. During these three years, I have really enjoyed working with them.

I really appreciate the financial support received by Universitat Jaume I of Castellon through the Research Personal Program (PREDOC/2014/14) and Spanish Ministerio de Economía y Competitividad project ECO2014/55221-P.

I also owe a special thanks to my husband Santi Oliver, for his encouraging support and patience to endure my divided attention between my family and the demanding studies and giving me the opportunity to fulfil my ambitions; to my father and siblings because every time I needed their help, no matter neither the day nor the time, they have always been there; and to my mum who will remain present in my mind forever.

My utmost love goes to my beloved children, Marc and Paula, for being really sympathetic, for their understanding and successfully adapting to the new circumstances. I hope I make you all proud.

I thank you by heart. 
1. INTRODUCTION

1.1 Motivation of this thesis ……………...............................................................

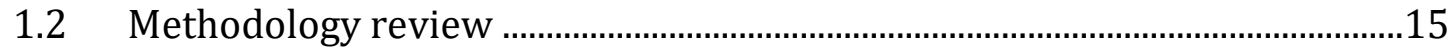

1.2.1 Markov Switching Models ................................................................................16

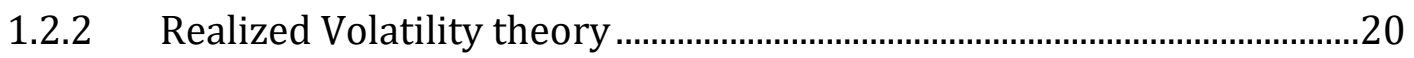

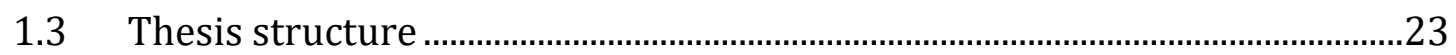

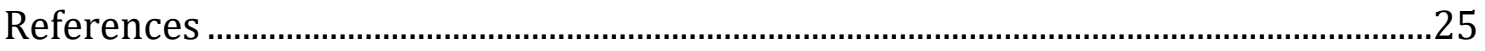

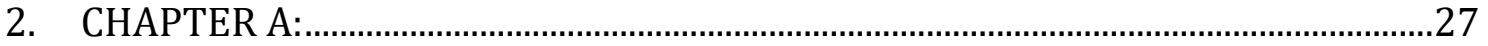

LEAD-LAG RELATIONSHIP BETWEEN SPOT AND FUTURES STOCK INDEXES: INTRADAY DATA AND

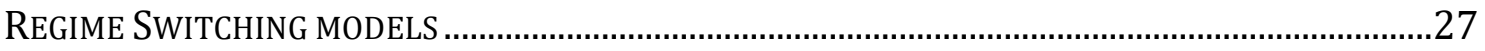

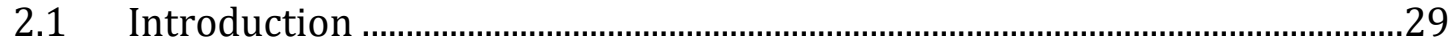

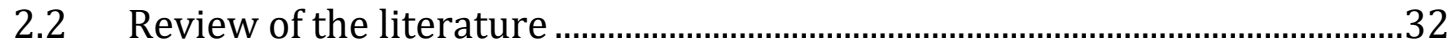

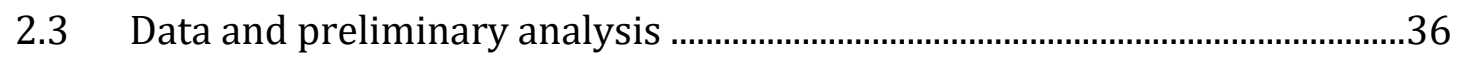

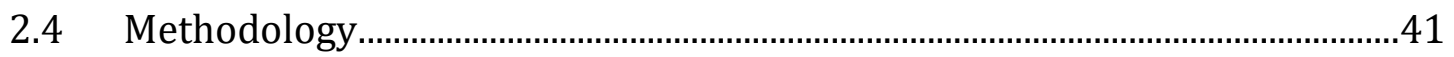

2.4.1 Traditional VECM......................................................................................... 41

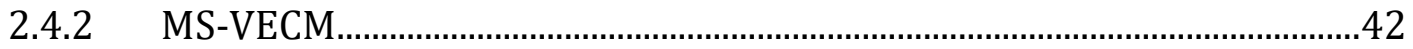

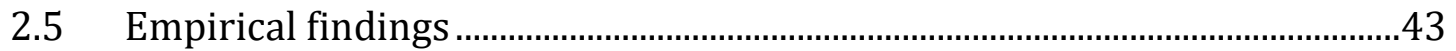

2.5.1 Estimations for linear models....................................................................4

2.5.2 Estimations for nonlinear models (MS-VECM) ...........................................46

2.6 Regime dependent impulse response function ................................................50

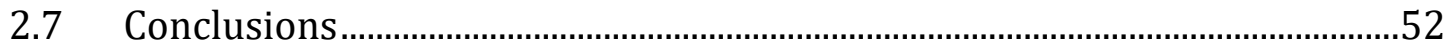

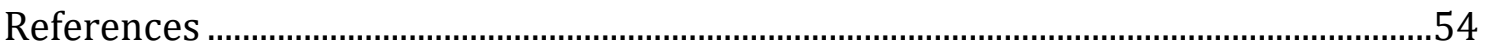

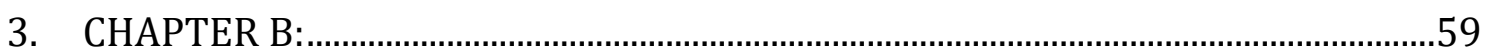

THE INFLUENCE OF INTRADAY SEASONALITY ON VOLATILITY TRANSMISSION PATTERN ..................59

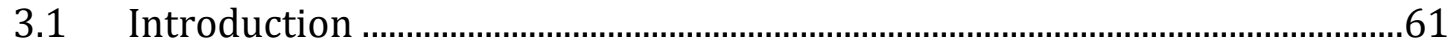

3.2 Flexible Fourier Form for deseasonalized volatility .........................................65

3.3 Data: Descriptive statistic for raw and standardized data .............................68

3.4 Empirical Results: Volatility transmission, Impulse Response Function and Directional Measurement of Volatility Spillovers............................................................77

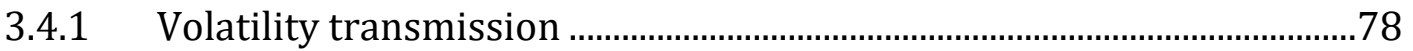

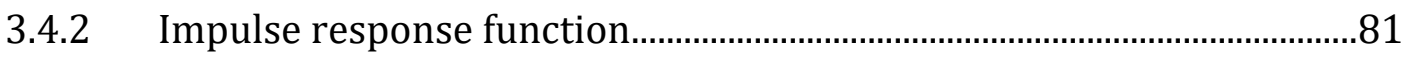


3.4.3 Directional measurement of volatility spillovers.....................................86

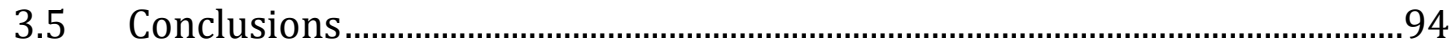

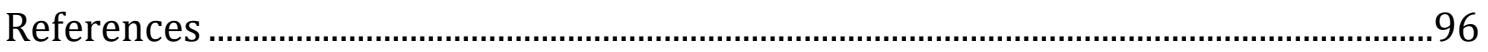

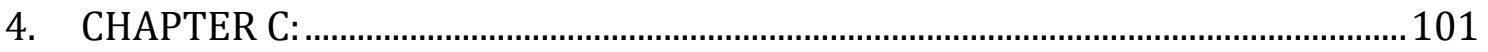

AN APPLICATION OF HIGH-FREQUENCY DATA TO OPTIMAL PORTFOLIO CHOICE.............................101

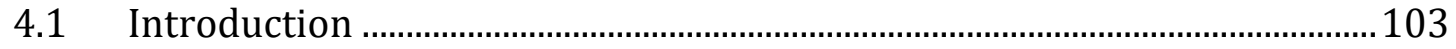

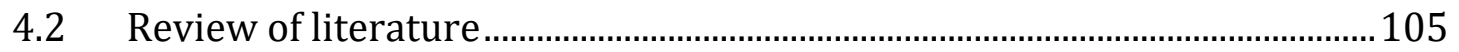

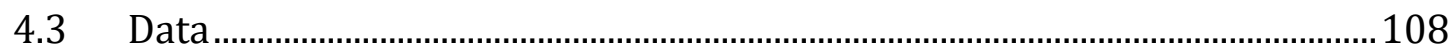

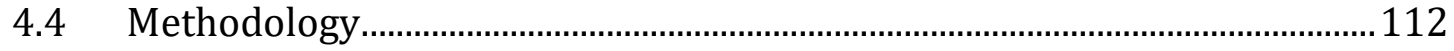

4.4.1 Portfolio strategies.................................................................................... 112

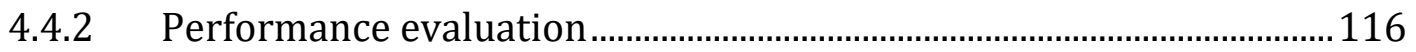

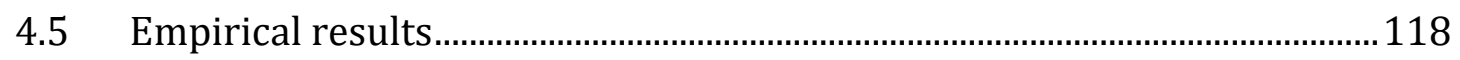

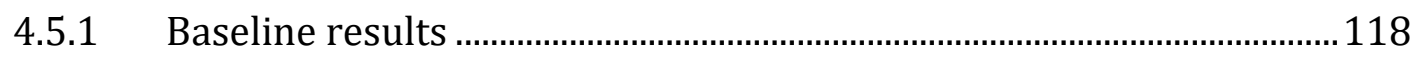

4.5.2 Breakeven transaction cost ………........................................................... 123

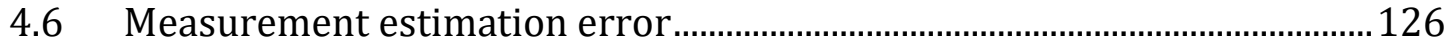

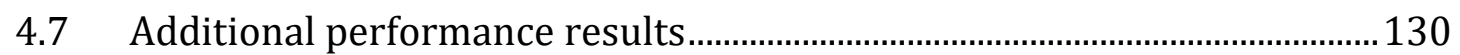

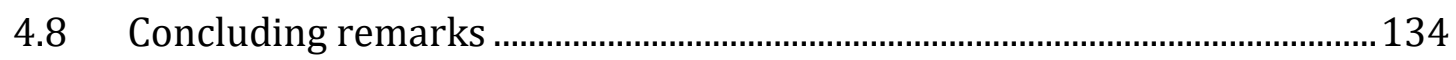

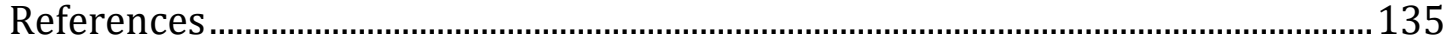

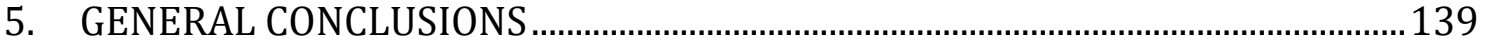

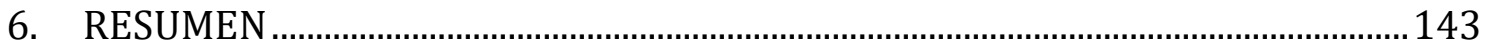

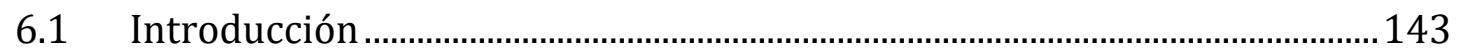

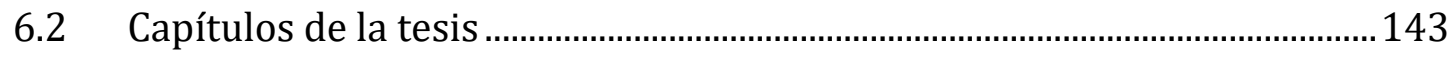

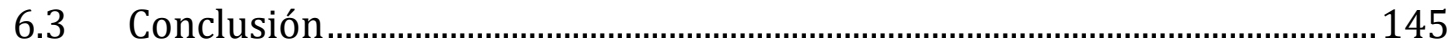

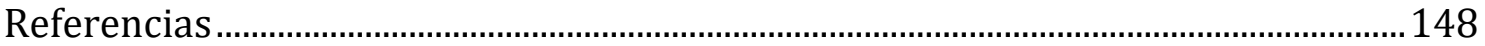




\section{List of Tables}

\section{CHAPTER A}

TABLE 1: Statistics results . .38

TABLE 2: Parameter estimates of the linear VECM ...................................................45

TABLE 3: Parameter estimates of the MS-VECM .....................................................49

\section{CHAPTER B}

TABLE 1: Summary statistics results for raw and standardized returns .70

TABLE 2: Parameter estimates of the bivariate Vector Autoregressive model (VAR)

TABLE 3: Summary statistics results for net pairwise volatility spillover . .92 CHAPTER C

TABLE 1: List of the considered datasets 110

TABLE 2: Annualized Sharpe ratio before transaction costs 119

TABLE 3: Turnover for the asset allocation strategies 122

TABLE 4: Breakeven transaction costs for monthly rebalancing strategies .. 125

TABLE 5: Measurement estimation error 128

TABLE 6: Annualized Sharpe ratio before transaction costs (excluding Nikkei 225 and Kospi 200 stock market indexes).

TABLE 7: Breakeven transaction costs for monthly rebalancing strategies (excluding Nikkei 225 and Kospi 200 stock market indexes) 


\section{List of Plots}

\section{CHAPTER A}

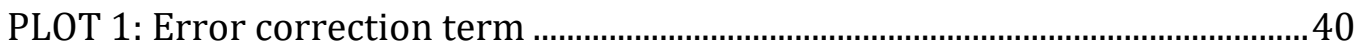

PLOT 2: Regimen Dependent Impulse Response Function ....................................51

\section{CHAPTER B}

PLOT 1: Mean absolute returns for CAC40, DAX30 and FTSE100 indexes ........72

PLOT 2: Autocorrelogram for raw and standardized five-minute intraday absolute returns

PLOT 3: Cross-correlations for raw and standardized five-minute intraday absolute returns . .76

PLOT 4: Impulse response function (IRF) for the CAC40 index .82

PLOT 5: Impulse response function (IRF) for the DAX30 index. .83

PLOT 6: Impulse response function (IRF) for the FTSE100 index. .84

PLOT 7: Net pairwise volatility spillover between the CAC40 index and CAC40 index future .88

PLOT 8: Net pairwise volatility spillover between the DAX30 index and DAX30 index future. .89

PLOT 9: Net pairwise volatility spillover between the FTSE100 index and FTSE100 index future 90 


\section{INTRODUCTION}

\section{ANALYSIS OF HIGH-FREQUENCY DATA ON INFORMATION TRANSMISSION AND OPTIMAL PORTFOLIO CHOICE}




\subsection{Motivation of this thesis}

The increased availability of high-frequency data has spurred a wide range of empirical investigations to comprehensively understand financial markets behavior. Certainly, the use of data on a high-frequency basis can disclose new facts that cannot be noticed at lower frequencies; however, they also pose a number of challenges for academics and researchers due to the intraday regularities present in intraday data (Goodhart and O'Hara, 1997).

Based on this approach, the general objective in this thesis is to discuss the main conclusions reached when high-frequency data are used in the following analysis: a) the analysis of the lead-lag relationship between spot and future stock indexes when regimes are present in the data, b) the influence of intraday seasonality in volatility transmission between spot and futures markets; and c) optimal portfolio choice. To do so, this dissertation is divided in three separate and publishable papers; in such a way that each one corresponds to a chapter. Thus, these three chapters (namely Chapter A, B and C) are the core of this thesis and are free standing (in the sense that each one can be read and understood independently) but they are on the related topic of high-frequency data. They are preceded by a short introduction to the overall topic with essential background information and are followed by a general conclusion.

Therefore, the common link between the three chapters in this dissertation is the use of high-frequency data.

\subsection{Methodology review}

The main objective of this subsection is to provide the reader a brief overview of the methodology used in this dissertation and explain in detail those empirical models which have not been described in each article.

The empirical models employed in Chapter A of this thesis are the Vector Error Correction Model (VECM), the Vector Error Correction Model Markov Switching (MS-VECM) and the Regime Dependent Impulse Response Function. This chapter gives a succinct overview of these methods, but do not give an in-depth examination of the Markovian regime shifts originally proposed by Hamilton (1988, 1989). Thus, section 1.2 .1 is devoted to the algorithm used for drawing probabilistic inference about whether and when shifts might occur. 
Chapter B uses as methodology to remove the intraday seasonality present in intraday data the Fourier Flexible Form (FFF) which is explained in detail throughout the chapter. Likewise, this chapter also implements and gives an overview of the Impulse Response Function. Additionally, one of the pillars of chapters B and C is the Realized Volatility theory based on high-frequency data which is revised in section 1.2.2.

As far as the chapter $\mathrm{C}$ is concerned, the methodology regarding the optimal portfolio strategies, the details of the estimation procedure as well as the measures to evaluate the performance are explained in sufficient detail. The reader can see this chapter to revise the aforementioned methods.

\subsubsection{Markov Switching Models}

In the last decades, the literature regarding the analysis of regime shits and nonlinear models has become an increasingly prominent field. The pioneer study applying regime shifts to financial series is the research of Hamilton (1989) who extended the Markov switching regression model of Goldfeld and Quandt (1973) to a time series framework and proposed an approach to model structural changes in which the parameters of an autoregressive model are viewed as the outcome of a discrete-state Markov process. These structural changes may not be observed directly, but it is possible to draw probabilistic inference about whether and when they may have occurred based on the observed behavior of the time series. In this article, an algorithm for drawing such probabilistic inference in the form of a nonlinear iterative filter is presented, which also allows estimating the population parameters by the method of maximum likelihood and provides the foundation for forecasting future values of the series.

Later, Krolzig (1997) extended the Markov Switching model in mean considering a multivariate framework with cointegration relationships among series (MS-VECM) According to Krolzig (1997), the main advantage of the MS-VECM is to provide a systematic approach to deliver statistical method for: a) extracting the information included in the data regarding regime shifts in the past, b) estimating consistently and efficiently the parameters of the model, c) detecting recent regime shifts, d) correcting the VECM at times when the regime alters, and e) incorporating the probability of future regimes shifts into forecasts.

As a first introduction to the Markov Switching models, we thereupon review the Regime Switching Autoregressive Systems. 
Let $r_{t}$ be a financial return series, Hamilton's (1989) two state Markov regime switching AR (1) ${ }^{1}$ model is defined as follows:

$$
r_{t}=c_{s_{t}}+\alpha_{1, s_{t}} r_{t-1}+e_{t}
$$

where we assume that the innovations $e_{t}$ follow a normal distribution $N\left(0, \sigma_{s_{t}}^{2}\right)$ and $s_{t}$ is an unobservable variable that determines if the process is in regime 1 at period $t\left(s_{t}=1\right)$ or in regime $2\left(s_{t}=2\right)$.

To construct the likelihood function a two-step procedure is implemented. First, joint density of returns $\left(r_{t}\right)$ and unobserved regime variable $\left(s_{t}\right)$ can be written as:

$$
f\left(r_{t}, s_{t} \mid \Psi_{t-1}\right)=f\left(r_{t} \mid s_{t}, \Psi_{t-1}\right) f\left(s_{t} \mid \Psi_{t-1}\right)
$$

where $\Psi_{t-1}$ is the all available information up to $t-1$ and $f\left(r_{t} \mid s_{t}, \Psi_{t-1}\right)$ is the state-dependent likelihood function defined as follows:

$$
f\left(r_{t} \mid s_{t}, \Psi_{t-1}\right)=\frac{1}{\sqrt{2 \pi \sigma_{s_{t}}^{2}}} \exp \left[-\frac{1}{2} \frac{\left(r_{t}-c_{s_{t}}-\alpha_{1, s_{t}} r_{t-1}\right)^{2}}{\sigma_{s_{t}}^{2}}\right]
$$

Then, the marginal density function of $r_{t}$ can be expressed as:

$$
f\left(r_{t} \mid \Psi_{t-1}\right)=\sum_{s_{t=1}}^{2} f\left(r_{t}, s_{t} \mid \Psi_{t-1}\right)=\sum_{s_{t}=1}^{2} f\left(r_{t} \mid s_{t}, \Psi_{t-1}\right) f\left(s_{t} \mid \Psi_{t-1}\right)
$$

where $f\left(r_{t} \mid s_{t}, \Psi_{t-1}\right)$ has been defined previously and $f\left(s_{t} \mid \Psi_{t-1}\right)=P_{r}\left(s_{t}=i \mid \Psi_{t-1}\right)$ for $i=1,2$ is the regime probability, that is to say, the probability that the process is in regime $i$ at time $t$ based on the all information up to time $t$.

Thus, the log-likelihood function can be defined as:

$$
L=\sum_{t=1}^{T} \ln \left(\sum_{s_{t=1}}^{2} f\left(r_{t} \mid s_{t}, \Psi_{t-1}\right) P_{r}\left(s_{t} \mid \Psi_{t-1}\right)\right)
$$

To estimate this log-likelihood function the regime probabilities must be computed, but to make inference about regime probabilities is necessary to do some assumptions on the unobserved variable. Therefore, we hypothesize that regime switching is directed by a first order Markov Chain process with constant

1 The procedure for the AR(p) case is analogous. 
transition probabilities, where the current regime $s_{t}$ only depends on the previous period, that is to say, only depends on $s_{t-1}$, thus

$$
P_{r}\left(s_{t} \mid s_{t-1}, s_{t-2 \ldots} s_{1}, \Psi_{t-1}\right)=P_{r}\left(s_{t} \mid s_{t-1}\right)
$$

Hence, considering two regimes with constant transition probabilities, the transition matrix which reflects the probability of switching from one regime to other regime is defined as follows:

$$
\hat{P}=\left[\begin{array}{cc}
P_{r}\left(s_{t}=1 \mid s_{t-1}=1\right)=p & P_{r}\left(s_{t}=1 \mid s_{t-1}=2\right)=(1-q) \\
P_{r}\left(s_{t}=2 \mid s_{t-1}=1\right)=(1-p) & P_{r}\left(s_{t}=2 \mid s_{t-1}=2\right)=q
\end{array}\right]
$$

An iterative technique designed for a general class of models is used to estimate the maximum-likelihood function, where the observed time series depends on some unobservable stochastic variables. Each iteration involves a pass through the filtering and smoothing iterations, followed by an update of the first order conditions and the parameter estimates guaranteeing an increase in the value of the likelihood function. In the filtering and smoothing steps the unobserved states are estimated by their smoothed probabilities where all probabilities are calculated with recursions by using the estimated parameter vector of the last maximization step. Using the regime probabilities, an estimation of the parameter vector is obtained as a solution and it can be employed to update the filter and smooth probabilities and so on. Hence, we have to apply the following steps:

Step 1: Given $P_{r}\left(s_{t-1}=j \mid \Psi_{t-1}\right)$ for $j=1,2$ at the end of the period $t-1$, the regime probability $P_{r}\left(s_{t}=i \mid \Psi_{t-1}\right)$ for $i=1,2$ is calculated as follows:

$$
P_{r}\left(s_{t}=i \mid \Psi_{t-1}\right)=\sum_{j=1}^{2} P_{r}\left(s_{t}=i, s_{t-1}=j \mid \Psi_{t-1}\right)
$$

We assume that current regime $s_{t}$ only depends on the regime one period before $\left(s_{t-1}\right)$, then: 


$$
\begin{aligned}
& P_{r}\left(s_{t}=i \mid \Psi_{t-1}\right) \\
& =\sum_{j=1}^{2} P_{r}\left(s_{t}=i, s_{t-1}=j \mid \Psi_{t-1}\right) \\
& =\sum_{j=1}^{2} P_{r}\left(s_{t}=i \mid s_{t-1}=j\right) P_{r}\left(s_{t-1}=j \mid \Psi_{t-1}\right)
\end{aligned}
$$

Step 2: At the end of time $t$, using Bayesian arguments the $P_{r}\left(s_{t-1}=j \mid \Psi_{t-1}\right)$ is computed as:

$$
\begin{aligned}
& P_{r}\left(s_{t}=i \mid \Psi_{t}\right)=P_{r}\left(s_{t}=i \mid r_{t}, \Psi_{t-1}\right) \\
& =\frac{f\left(s_{t}=i, \mathrm{r}_{t} \mid \Psi_{t-1}\right)}{f\left(r_{t} \mid \Psi_{t-1}\right)} \\
& =\frac{f\left(r_{t} \mid s_{t}=1, \Psi_{t-1}\right) P_{r}\left(s_{t}=i \mid \Psi_{t-1}\right)}{\sum_{i=1}^{2} f\left(r_{t} \mid s_{t}=1, \Psi_{t-1}\right) P_{r}\left(s_{t}=i \mid \Psi_{t-1}\right)}
\end{aligned}
$$

Then, the regime probabilities for all periods can be calculated by iterating these two steps that are determined by the likelihood function itself.

Step 3: An estimation of the parameter vector is obtained as a solution of the first order conditions of the likelihood function when the regime probabilities used are those obtained in the previous two steps. With the new parameter vector, the filtered and smoothed probabilities are updated and the algorithm starts again until the optimum is reached.

Thus, in the MS-VECM used in this study, we hypothesize that deviations from the long run equilibrium are characterized by different rates of adjustment depending on the unobservable regime $s_{t}$, which represent the probability of being in a different state. As the state variable $s_{t}$ cannot be directly observed, its realization is governed by a Markov Chain. Then, the MS-VECM is specified as follows:

$$
\begin{gathered}
\Delta S_{t}=a_{s}+\sum_{i=1}^{k} b_{s i} \Delta S_{t-i}+\sum_{i=1}^{k} c_{s i} \Delta F_{t-i}+\alpha_{s, s_{t}} Z_{t-1}+\varepsilon_{s, t, s_{t}} \\
\Delta F_{t}=a_{f}+\sum_{i=1}^{k} b_{f i} \Delta S_{t-i}+\sum_{i=1}^{k} c_{f i} \Delta F_{t-i}+\alpha_{f, s_{t}} Z_{t-1}+\varepsilon_{f, t, s_{t}} \\
\varepsilon_{s, t, s_{t}} \mid \psi_{t-1} \sim B N\left(0, H_{t, s_{t}}\right) \\
\varepsilon_{f, t, s_{t}} \sim \\
H_{t, s_{t}}=\left[\begin{array}{ll}
h_{s, s, s_{t}} & h_{s, f, s_{t}} \\
h_{f, s, s_{t}} & h_{f, f, s_{t}}
\end{array}\right]
\end{gathered}
$$


where the short run relationship is captured by coefficients $b_{s i}, c_{s i}, b_{f i}, c_{f i}$; the long run relationship is represented by the error correction term $Z_{t-1}=S_{t-1}-\beta-$ $\gamma F_{t-1}$, where $S_{t-i}$ and $F_{t-i}$ are log lagged spot and futures prices, respectively; $a_{s}$ and $a_{f}$ represent the unconditional return; $s_{t}$ is an unobservable state variable that can take the value 1 and $2 ; \varepsilon_{s, t, s_{t}}$ and $\varepsilon_{f, t, s_{t}}$ are the residuals in the spot and futures equations depending on the regime $s_{t}=\{1$ (state 1$)$, or 2 (state 2$\left.)\right\}$ respectively; $\psi_{t-1}$ refers to the information available at time t-1; $H_{t, s_{t}}$ is the regime dependent variance-covariance matrix and the parameters $\alpha_{s, s_{t}}, \alpha_{f, s_{t}}$ accompanying the ECT depend on the regime $s_{t}=\{1$ (state 1$)$, or 2 (state 2$\left.)\right\}^{2}$.

The MS-VECM is estimated using a two-step maximum likelihood procedure. The error correction term $Z_{t-1}$ is determined in the first step ${ }^{3}$ and is the same variable computed in the linear VECM, also implemented in this research. The second step consists of the implementation of an expectation-maximization algorithm using maximum likelihood to estimate equations (11) to (14).

\subsubsection{Realized Volatility theory}

It is widely known that volatility of financial assets is difficult to estimate because the conditional variance is latent and is not directly observable; therefore it has to be estimated by using parametric or nonparametric procedures. Whereas the parametric models rely on explicit functional form assumptions regarding the expected and/or instantaneous volatility, the nonparametric models do not make such functional form assumptions and therefore enable estimates of notional volatility that are flexible, as well as consistent, as the sampling frequency of the asset returns increases (Andersen et al., 2002).

The parametric models include the AutoRegressive Conditional Heteroskedastic (ARCH), which were first introduced in the seminal paper by Engle (1982). Since their inception, the ARCH models have enjoyed remarkable empirical success and the related literature has undergone unprecedented growth. These models allow the conditional variance to change over time as a function of past errors leaving the unconditional variance constant. Then, as an extension of these models, Bollerslev (1986) introduced the so-called Generalized Autoregressive Conditional Heteroskedasticity (GARCH) models which also allow the past conditional variances to be added in the current conditional variance equation.

\footnotetext{
2 These states will be identified as $1=$ Low State and $2=$ High State.

${ }^{3}$ In the first step the error correction term $Z_{t-1}$, is computed as follows: $Z_{t-1}=S_{t-1}-\beta-\gamma F_{t-1}$, where $S_{t-i}$ and $F_{t-i}$ are log lagged spot and futures prices, respectively.
} 
Although these models have been proven to be useful in modeling several different economic phenomena, the new technological era and the increasing availability of financial market data at intraday frequencies has produced an explosive growth in the financial econometrics of volatility dynamics, so that recent literature has focused on nonparametric approaches such as the Realized Volatility to fully exploit the benefits of high-frequency data as an information source to estimate return volatility.

Given that return volatility is a key element for the theory and practice of asset allocation, asset pricing, and risk management, much effort has been done to provide accurate estimates and forecast of current and future volatility. In this regard, it was Merton (1980) who first introduced the idea of estimating return volatility over shorter time intervals. As this author highlights, provided that data are available at a sufficiently high sampling frequency, "the variance over a fixed interval can be estimated arbitrarily, although accurately, as the sum of squared realizations". Moreover, high-frequency data is "one measure of progress in empirical econometrics" (Engle, 2000) that allows us to estimate realized measures by using all available information with the added advantage of not having to estimate parametrical models commonly used, such as the aforementioned ARCH and GARCH models. Later on, Andersen and Bollerslev (1998) and Andersen et al. (2001, 2003) paved the way for the use of models that employ Realized Volatility (RV) measures.

Below, we review in this subsection the RV theory (a more extensive theoretical explanation can be found in Andersen and Bollerslev, 1998; Andersen et al. 2001, 2003; Barndorff-Nielsen and Shephard, 2002; McAleer and Medeiros2008).

Thus, consider a simple discrete time model in which the daily returns of a given asset are typically characterized as follows,

$$
r_{t}=h_{t}^{1 / 2} \eta_{t}
$$

Where $\left\{\eta_{t}\right\}_{t=1}^{T}$ is a sequence of independently and normally distributed random variables with zero mean and unit variance, $\eta_{t} \sim \operatorname{NID}(0,1)$.

Assume that, in a given trading day $t$, the logarithmic prices are observed tick-bytick.

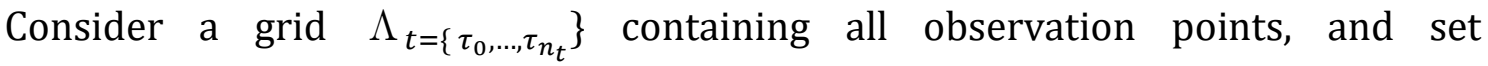
$p_{t, i}, i=1, \ldots, n_{t}$ to be the $i t h$ price observation during day $t$, where $n_{t}$ is the total number of observations at day $t$. 
Moreover, hypothesize that

$$
r_{t, i}=h_{t, i}^{1 / 2} \eta_{t, i}
$$

where $\eta_{t, i} \sim \operatorname{NID}\left(0, n_{t}^{-1}\right), r_{t, i}=p_{t, i}-p_{t, i-1}$ is the $i t h$ intraperiod return of day $t$ so that

$$
r_{t}=\sum_{i=0}^{n_{t}} r_{t, i}
$$

and

$$
h_{t}=\frac{1}{n_{t}} \sum_{i=1}^{n_{t}} h_{t, i}
$$

Describe the information set $\widetilde{S_{t, l}} \equiv \tilde{S}\left\{p_{a, b}\right\}_{a=-\infty, b=0}^{a=t, b=i}{ }_{a}^{4}$ as the $\sigma$-algebra generated by all the information to the ith tick in day $t$. Therefore, $\widetilde{S_{t, 0}}$ is the information set available before the start of day $t$. Then, it follows that $E\left(r_{t}^{2} \mid \widetilde{S_{t, 0}}\right)=h_{t}$ and $\mathrm{V}\left(r_{t}^{2} \mid \widetilde{S_{t, 0}}\right)=2 h_{t}^{2}$.

The realized variance, defined as the sum of all available intraday high-frequency squared returns given by

$$
R V_{t}^{(a l l)}=\sum_{i=0}^{n_{t}} r_{t, i}^{2}
$$

is a consistent estimator of the integrated variance when there is no microstructure noise (Andersen et al., 2003).

Andersen and Bollerslev (1998) showed that one can gain a better understanding of the ex post daily foreign exchange volatility by aggregating 288 squared five minute returns. Moreover, as stated in McAleer and Medeiros (2008), "the fiveminute frequency is a trade-off between accuracy, which is theoretically optimized using the highest possible frequency, and microstructure noise that can arise through the bid-ask bounce, asynchronous trading, infrequent trading, and price discreteness, among other factors". Likewise, notice, that in practice, as Cartea and Karyampas

\footnotetext{
${ }^{4} p_{a, b}$ is the tick price. For more details see McAleer and Medeiros (2008).
} 
(2011) suggest, employing the whole dataset at high-frequency data (HFD) is not the usual option to estimate the realized variance-covariance matrix; and it is usual to employ observations on a five-minute interval basis. Thus, based on this previous research, we rely on intraday returns data on a five-minute interval basis to estimate the RV.

\subsection{Thesis structure}

This thesis is divided in 3 chapters, besides the introduction and the last chapter devoted to the general conclusions.

Chapter A entitled Lead-lag relationship between spot and futures stock indexes: Intraday data and Regime Switching Models, investigates the lead-lag relationship between the DAX30 stock index and DAX30 index futures. This research contributes to the existing literature by using high-frequency data and nonlinear models based on an extension of Markovian regime shifts (named Regime Switching Models) to overcome the weakness of linear assumptions in the dynamic relationship between spot and futures prices widely used in previous literature. The findings highlight the importance of considering the different regimes detected in the error correction term to provide a more suitable empirical model and a better understanding of the information transmission so that market participants can define more efficient trading strategies. Moreover, the results suggest that linear models might be misspecified when structural changes are present in the data and they are neglected.

The title of chapter B is: The influence of intraday seasonality on volatility transmission pattern and it analyses the effects of the well-documented intraday seasonality on volatility transmission between the spot and futures markets of the CAC40, DAX30 and FTSE100. It uses high-frequency data and the realized variance to compare the results obtained using models in which the seasonal component has been neglected versus results reached by models in which the seasonal component has been considered. The major contribution of this investigation to the volatility spillovers literature is to become aware of the impact that the intraday seasonality has on the results and the conclusions reached in the studies about volatility transmission. The results suggest that high-frequency data can shed new light on issues concerning the volatility transmission between markets, and underscore how important it is to be conscious of the importance of removing the seasonal component to reduce the risk of spurious causality when employing high-frequency data in volatility modeling. 
Finally, chapter $\mathrm{C}$ entitled An application of high-frequency data to optimal portfolio choice studies the benefits of using intraday data to estimate the variance-covariance matrix for asset allocation purposes, considering a comprehensive listing of major stock market indexes to build a diversified portfolio. Recently, a prominent strand of literature related to portfolio allocation shows evidence that common portfolio optimization strategies do not beat the equally-weighted strategy (DeMiguel et al., 2009b); raising a serious doubt on the usefulness of the investment theory .To challenge these findings we evaluate in this investigation whether, by using high-frequency data in optimal portfolio choice, instead of data at lower frequencies, we can improve the performance and beat the naïve rule. Thus, we suggest the construction of diversified portfolios considering monthly and high-frequency data in the modelling of the second moments, and compare the performance of these portfolios in terms of several outof-sample metrics, namely the Sharpe ratio, the certainty equivalent rate of return and the turnover. The outcome of this research suggests that the positive performance of switching from data at lower frequencies to intraday data in the context of optimal asset allocation pays off; and moreover, by using high-frequency data, dynamic strategies beat the equally-weighted portfolio even in presence of transaction costs. 


\section{References}

Andersen, T. G., \& Bollerslev, T. (1998). Answering the skeptics: Yes, standard volatility models do provide accurate forecasts. International economic review, 885-905.

Andersen, T. G., Bollerslev, T., Diebold, F. X., \& Labys, P. (2001). The distribution of realized exchange rate volatility. Journal of the American statistical association, 96(453), 42-55.

Andersen, T. G., T. Bollerslev, \& F. X. Diebold (2002): "Parametric and Nonparametric Volatility Measurement," in Handbook of Financial Econometrics, ed. by L. P. Hansen and Y. A-Sahalia. Amsterdam: North-Holland, forthcoming.

Andersen, T. G., Bollerslev, T., Diebold, F. X., \& Labys, P. (2003). Modeling and forecasting realized volatility. Econometrica, 71(2), 579-625.

Barndorff-Nielsen, O. E., \& Shephard, N. (2002). Econometric analysis of realized volatility and its use in estimating stochastic volatility models. Journal of the Royal Statistical Society: Series B (Statistical Methodology), 64(2), 253-280.

Bollerslev, T. (1986). Generalized autoregressive conditional heteroskedasticity. Journal of econometrics, 31(3), 307-327.

Cartea, Á., \& Karyampas, D. (2011). Volatility and covariation of financial assets: A high-frequency analysis. Journal of Banking \& Finance, 35(12), 3319-3334.

DeMiguel, V., Garlappi, L., \& Uppal, R. (2009b). Optimal versus naive diversification: How inefficient is the $1 / \mathrm{N}$ portfolio strategy? The Review of Financial Studies, 22(5), 1915-1953.

Engle, R. F. (1982). Autoregressive conditional heteroscedasticity with estimates of the variance of United Kingdom inflation. Econometrica, 50(4), 987-1007.

Engle,R.F.(2000).The econometrics of ultra-high-frequency data. Econometrica, 68(1), 1-22.

Goldfeld, S., M. and Quandt, R., E., (1973), 'The estimation of structural shifts by switching regressions', Annals of Economic and Social Measurement 2, 475485. 
Goodhart, C. A., \& O'Hara, M. (1997). High-frequency data in financial markets: Issues and applications. Journal of Empirical Finance, 4(2), 73-114.

Hamilton, J. D. (1988). Rational-expectations econometric analysis of changes in regime: An investigation of the term structure of interest rates. Journal of Economic Dynamics and Control, 12(2-3), 385-423.

Hamilton, J. D. (1989). A new approach to the economic analysis of nonstationary time series and the business cycle. Econometrica, 57(2), 357-384.

Krolzig, H. M. (1997). Markov-Switching Vector Autoregressions: Modelling, Statistical Inference, and Application to Business Cycle Analysis. Springer, New York.

McAleer, M., \& Medeiros, M. C. (2008). Realized volatility: A review. Econometric Reviews, 27(1-3), 10-45.

Merton, R. C. (1980). On estimating the expected return on the market: An exploratory investigation. Journal of Financial Economics, 8(4), 323-361. 


\section{CHAPTER A:}

\section{LEAD-LAG RELATIONSHIP BETWEEN SPOT AND FUTURES STOCK INDEXES: INTRADAY DATA AND REGIME SWITCHING MODELS}

Abstract

This paper analyses the lead-lag relationship and the effect of arbitrage opportunity changes in the price discovery process between the futures and spot markets of the DAX30. The following two aspects will be considered: high-frequency data and nonlinearities in the cointegrating vector. The results reveal the importance of considering structural changes present in the error correction term using Regime Switching Models and the peril of assuming strong linear models. Additionally, the regime dependent impulse response function shows that the dynamic causal effect is remarkably different across regimes, so as the arbitrage opportunities increase, the impact of unexpected shocks on prices increases. 


\subsection{Introduction}

A key question in finance is the lead-lag relationship between spot and futures markets. Understanding information flow across markets, in addition to being of academic interest, is important for asset valuation, hedging, investment strategies and economic policy. A better comprehension of the information transmission provides investors with more efficient trading strategies (Kawaller et al., 1987). Although in past decades, a significant strand of both theoretical and empirical research has focused on the study of the dynamic relationship between futures and spot prices, the conclusions obtained remain ambiguous because the empirical evidence diverges across articles.

According to the efficient market theory, the price of an asset reflects all relevant information available about its intrinsic value. Numerous articles have focused on the study of deviations from the Cost of Carry model and have investigated the linkages between futures and spot prices (Kawaller et al., 1987; Ng, 1987; Stoll and Whaley, 1990 and Chan, 1992, among others). In an efficient market, there will be a simultaneously perfect relationship between spot index and index future contract price changes. Therefore, innovations would be synchronously reflected both in spot and futures prices, and there should be no lead-lag relationship between prices in the two markets. Notwithstanding, due to market imperfections, such as asymmetric information, transaction costs, liquidity and other market restrictions, one market may reflect information faster than the other one, and as a result of that, a lead-lag relationship exists. Hence, price discovery may be considered an indicator of the market efficiency (Tse, 1999).

The main goal and major contribution of this investigation is analyzing the lead-lag relationship between the futures and spot markets of the DAX30 considering three aspects, given that, as will be explained below, they are considered essential. These aspects include a) high-frequency data (on a five-minute interval basis); b) regime switching, which will allow us to consider arbitrage opportunities changes, linking these opportunities of arbitrage to the magnitude of long run disequilibrium between spot and futures prices given by the error correction term (ECT); and c) regime dependent impulse response analysis, which has been implemented to deepen the understanding of how markets react to shocks in high ECT regimes (more arbitrage opportunities) and low ECT regimes (less arbitrage opportunities).

The connection between the ECT and arbitrage is not recent. In fact, arbitrage has been described as an attempt to benefit from the long run trading opportunities involved in the cointegration relationship (Bondarenko, 2003; Hogan et al., 2004) ${ }^{5}$.

5 The ECT may be interpreted as an opportunity of arbitrage. When the futures price is higher than the spot price, arbitragers will buy in the spot market and sell in the futures market. If the futures price is lower, they 
Moreover, as Kawaller et al. (1987) highlight, "the lead-lag relationship during periods when arbitrage activity is present might reasonably be expected to differ from the lead-lag relationships present when no arbitrage activity occurs". Considering this approach, this study intends to determine whether there exists an asymmetric adjustment process between spot and futures prices depending on the magnitude of the deviation from the long run equilibrium and which market (spot or future) has more predictive capability. Previous research has documented that the presence of arbitrage opportunities has a noteworthy effect on the dynamics of the price discovery process and faster adjustment is expected when deviations are large enough to make arbitrage advantageous, that is to say, arbitrage is associated with more rapid convergence of the basis to the cost of carry (Dwyer et al., 1996 and Theissen, 2012). Consistent with the above outcome, this study finds that the nature of the price discovery process depends on the presence of regimes in the ECT and that in the German market the leading role of the futures market in the price discovery process is noticeably pronounced when arbitrage opportunities are greater.

The traditional Vector Error Correction Model (VECM) implies that the speed of adjustment of prices towards long-run equilibrium does not depend on the size of the deviation. To overcome this restraint, a state-dependent error correction model is estimated. Not considering that disequilibrium of different magnitudes in the ECT and hence that arbitrage opportunities provokes asymmetric responses in these markets might lead us to misspecified models and misleading conclusions regarding the market leadership or even conclude that these markets are not cointegrated.

A relevant issue that should be considered when studying empirically the lead-lag relationship between two markets or assets, and thus, the presence of arbitrage opportunities, is the frequency of the analysed data. Numerous empirical studies suggest that the lead-lag relationship is an important stylized fact at highfrequency data; nevertheless, it vanishes when the frequency of observations decreases (Huth and Abergel, 2014). Harris et al. (1995) show evidence that frequency is crucial to testing pricing dynamics between markets that are cointegrated due to the following two reasons: 1 ) if the time interval is too wide, it might provoke the error correction to occur inside an interval that had not been considered, so higher frequency trading strategies might not be detected considering daily prices; and 2) cointegration models allow establishing long-term relationships between temporal series that may diverge in very short periods but readjust to the long run equilibrium. Therefore, the use of data on a high-frequency basis can disclose new facts that cannot be detected at lower frequencies; for this reason, it is considered to be the most convenient way to approach this

will do the reverse. This trading forces prices back towards equilibrium in such a way that at the time of futures contract expiration, the ECT becomes zero. 
investigation. In this paper, data on a five-minute interval basis of transaction prices from January 2, 2014 to September 30, 2015 for the DAX30 index for both the stock index and index futures are used. ${ }^{6}$

Moreover, an increasing empirical strand of the literature suggests that the dynamic relationship between futures and spot prices may be characterized by a nonlinear specification, and failing to consider this might lead to biased results (Brooks, 1996; Hiesh, 1991). Regime Switching Models (RSM hereafter) have the ability to adequately characterize and capture unusual movements that appear in the relationship between spot and futures markets. These models can capture these changes of behaviour and the fact that the new dynamics of prices and fundamentals persist for several periods (Sarno and Valente, 20007). Ang and Timmermann (2012) determined three reasons why RSM have become popular in financial modelling, as follows. 1) The idea of regime shifts is natural and intuitive. When this methodology is implemented in financial series, regimes determined by econometric methods are often identified with different periods in regulation, policy, and other secular changes (Hamilton, 1989). 2) RSM can capture the stylized behaviour of many financial return series. Finally, 3) they can exhibit nonlinear dynamics of asset returns in a framework based on linear specifications. Furthermore, to achieve more complete comprehension of differences between states, the regime dependent impulse response function is implemented in this study. The authors perform this analysis in periods of low and high ECT and examine whether a shock of the same magnitude has similar responses in states with different arbitrage opportunities.

Although high-frequency data has been used in many previous studies, to the best of the authors' knowledge, there is no study that has analysed the contribution of spot and futures markets to the price discovery process on a high-frequency interval basis while using a) the nonlinear equilibrium correction model based on an extension of Markovian regime shifts in time series proposed by Hamilton $(1988,1989)$ to relax the restrictive linear assumption in the deviation from the long run equilibrium, and $\mathrm{b}$ ) the regime dependent impulse response function to trace out how a shock affects prices when arbitrage opportunities differ.

The main results of our paper related to linear models (traditional VECM) might be summarized as follows: a) in the short run, the relationship is unidirectional from the futures to the spot; and b) the ECT is not significant, so consequently it may be concluded that both markets are not cointegrated and do not respond to deviations

\footnotetext{
${ }^{6}$ As Andersen (2000) highlights, "the 5-minute frequency is about the highest at which properties of the return series are not seriously distorted by irregular quoting, the discreteness of prices, and the tendency of foreignexchange dealers to position their quotes with a view toward inventory control".

${ }^{7}$ They find strong evidence against the hypothesis of linear dynamics and in favor of the capability of regimeswitching-vector-equilibrium models (nonlinear models) to capture properly the time-series properties of the data.
} 
from the equilibrium relationship or the existence of arbitrage opportunities, and therefore, there would be no long run relationship binding the markets together. Likewise, nonlinear models (MS-VECM) indicate the following. a) The relationship is bidirectional in the short run, so that there is a two-way feedback relationship between both markets, although the futures market leads the spot market. b) The ECT becomes significant for both markets and regimes. c) In the long run, the futures market also leads the stock market, and moreover, the greater the ECT is, the faster the speed of adjustment is. Finally, d) the regime dependent impulse response function reveals the noticeable asymmetries across regimes when a shock hits the system, so the impact of unexpected shocks on prices is more pronounced when there are more arbitrage opportunities. In this regard, we can state that the results obtained and the conclusions that can be drawn certainly underpin the importance of considering nonlinear models MS-VECM vs. the linear traditional VECM.

The remainder of this paper is organized as follows: section 2.2 contains a review of the literature; section 2.3 describes the data used, including some summary statistics; section 2.4 explains the methodology employed; section 2.5 presents the empirical results from the traditional VECM and MS-VECM; section 2.6 addresses the regime dependent impulse response function; and finally, section 2.7 summarizes the results and concludes.

\subsection{Review of the literature}

The lead-lag relationship between price movements of stock index futures and the underlying cash market describes how fast one market reflects innovation relative to the other one as well as the linkage between them. When one market responds faster to new information and the other market reacts later, a lead-lag relationship is observed (Chan, 1992). A significant body of the literature has attempted to determine whether price discovery occurs primarily in the spot or futures market. Some empirical studies support the leading role of the spot market. Frino, Walter and West (2000) note that traders with stock specific information will benefit more by trading in the spot market than in the futures market; therefore, the spot market might reflect innovation better. There are other articles that conclude that both markets contribute to price discovery, but the conclusion drawn from previous research has mostly been supportive of the price discovery role of the futures prices. The reason why the futures market is the main source of marketwide information is generally explained by its inherent low transaction costs 8 , higher leverage effect and lack of short sales restrictions (Tse, 1999).

${ }^{8}$ Storage costs (if storability is possible) are only associated with commodities. 
Kawaller et al. (1987) examine the intraday price relationship between the S\&P 500 Index and S\&P 500 Futures Index using minute-to-minute data for all trading days during 1984 and 1985 and conclude that the equity futures market leads the stock market by over twenty to forty-five minutes; however, movements in the spot market rarely affect futures by more than one minute.

Ng (1987) used the S\&P 500 Index and S\&P 500 Futures Index daily data for approximately 5 years and concludes that futures prices lead spot prices by one day, although the magnitude of the lead coefficients is rather weak. It has not been detected as the lead for spot prices.

Stoll and Whaley (1990) examine the time series properties of 5-minute intraday returns for approximately 5 years of stock index and stock index futures contracts and conclude that on the one hand, S\&P500 Index and MM index futures returns tend to lead stock market returns over five minutes, on average, but sometimes 10 minutes or more. On the other hand, lagged stock index returns have a moderate predictive impact on futures returns, so the effect is bidirectional, but futures market has more predictive capability.

Chan, Chan and Karolyi (1991) studied, simultaneously, the intraday relationship between returns and returns volatility (utilizing the GARCH models) in the S\&P 500 stock index and stock index futures market from 1984 to 1989 . Each day, trading hours are partitioned into five-minute intervals. Their evidence is consistent with the hypothesis that both markets contribute to price discovery.

Chan (1992) studies the lead-lag relationship between intraday futures and cash index prices on a five-minute interval basis for two sample periods, August 1984June 1985 and January 1987-September 1987. The article analyses data on the MMI and an index comprising 20 actively traded stocks. The author finds strong evidence that there is an asymmetric lead-lag relationship between the two markets with strong evidence that the futures index leads the cash index and weak evidence that the cash index leads the futures.

Engle and Granger (1987) demonstrate that cointegrated series have an error correction term ${ }^{9}$ representation (also named speed of adjustment coefficient) that allows correcting in one period the disequilibrium detected in the previous one. Not only does the error correction term indicate the percentage of disequilibrium from one period that is corrected in the next period, but it also shows the relative magnitude of adjustments in both markets towards equilibrium. The rationale behind the concept of cointegration is that two variables may deviate in the short

${ }^{9}$ One interpretation of the error correction term is that it reflects the effect of arbitrage. If the futures price is too low compared to the index value, arbitragers will sell the stocks underlying the index and buy the futures contract. On the contrary, if the futures price is too high, they will sell the futures contract and buy the stocks underlying the index. 
run from each other, but market forces will bring them back together, and therefore, there exists a long run equilibrium relationship between these two variables. If the error correction term is not considered, then the model could be misspecified. Roughly, spot and futures prices are cointegrated with an order of one, and the linear VECM has been traditionally used to investigate the error correction process between spot and futures prices.

Wahab and Lashgari (1993) extend the study of the lead-lag relationship by applying the cointegration approach to investigate the robustness of previous studies including an alternative model parameterization, the error correction model. They use daily closing spot and futures prices for both the S\&P 500 Index and the Financial Times Index from January 4, 1988 to May 30, 1992. The authors find evidence that a two-way relationship exists between the cash and futures markets, which is consistent with the important price discovery role served by both the stock and index futures markets and confirm the hypothesis that both markets contribute to price discovery. Furthermore, they find that the price leadership of the spot market is stronger.

Tse (1999) examines the intraday price discovery process and volatility spillovers between the DJIA futures and index using minute-by-minute data for the six-month period of November 1997 to April 1998. The author uses the VECM to analyse the price discovery process and concludes that the informational contribution attributable to the futures market is $88,3 \%$ implying that DJIA futures dominate the cash market in price discovery. It is the spot price that makes the greater adjustment to re-establish the equilibrium, or, to put it another way, the futures price leads the cash price in price discovery.

Pardo and Climent (2000) and Blanco (2003) study the temporal relationship between the IBEX 35 Index and IBEX 35 Futures Contracts applying a cointegration parameterization and using minute-by-minute data for the entire year 1996 and five minute data from January 11, 1995 to October 27, 1995, respectively. They conclude that both markets contribute to price discovery, but there exists strong evidence that the predictive capability of the futures market is greater.

Several publications have appeared in the past decades documenting a new approach to answer the longstanding question in the research field regarding the lead-lag relationship between spot and futures prices. Plenty of articles, such as Sarno and Valente (2000), Li (2009) and Theissen (2012), among others suggest the presence of different regimes in financial markets and employ nonlinear models to account for the dynamic of the relationship between spot and futures prices.

Sarno and Valente (2000) examine the dynamic relationship between spot and futures prices in stock index futures markets using weekly data for the S\&P 500 
and the FTSE 100 indices from January 1, 1988 to December 26, 1997 and using nonlinear Markov-switching vector equilibrium correction models that allow for three regimes in the mean of the equilibrium correction model as well as in the variance-covariance matrix. They find strong evidence against the hypothesis of linear dynamics and in favour of the capability of regime-switching-vectorequilibrium models to capture the stylized behaviour of the financial series.

Li (2009) studied the dynamics of the relationship between spot and futures markets of three mature markets (S\&P500, FTSE100, DAX) and two emerging markets (BOVESPA, BSI) from the period April 3, 1995 to December 12, 2005 using daily data. The author uses a traditional VECM and a Markov-switching vector error correction model (MS-VECM), in which the parameter of the deviation of spot-futures prices changes according to the stage of the volatility regime, and compares the results. When a conventional VECM is used to examine the spotfutures price discovery process, the conclusions among markets are inconsistent. However, when a MS-VECM is considered, the findings show the following. 1) During a high variance state, the spot-futures disequilibrium adjustment process depends mainly on the futures market and on the spot market in the low variance state; that is to say, the futures price leads the spot price in price discovery during stable periods; on the contrary, during volatile periods, the price discovery occurs in the spot market. This finding is robust for all markets. 2) The scale of price adjustment in the futures market during a high variance state is greater than that in the spot markets during a low variance state. 3) The correlation between the spot and futures markets for the high variance state is lower than that for the low variance state in all cases. The study also provides evidence that the price adjustment process between spot and futures markets occurs very quickly in mature markets; additionally, for emerging markets, the disequilibrium between spot and futures prices takes longer to diminish. This fact denotes why the deviation in the spot and futures prices in the two emerging markets analysed is remarkably greater in absolute value than that in the three mature markets, particularly in the high variance state.

Theissen (2012) examines the intraday price discovery process of the following two data sets: 1) DAX index values from the spot equity market and DAX index futures data from the first quarter of 1999 at a frequency of 15 seconds and 2) DAX EX (the most liquid DAX ETF) and DAX index futures data from the last quarter of 2010 at a frequency of 1 minute. The datasets contain transaction prices, bid and ask quotes for 61 trading days. The author estimates a threshold error correction model to allow for arbitrage opportunities to have an impact on the return dynamics including two dummy variables to identify the arbitrage opportunities that require selling in both the spot and futures market. Bidirectional Granger causality is found, and the evidence shows that the spot market depends on the futures market much more than the converse. Consequently, the futures market leads in the process of price discovery, and furthermore, the presence of arbitrage 
opportunities has a strong impact on the dynamics of the price discovery process. Therefore, the results suggest that the leading role of the futures market in the price discovery process is noteworthy when arbitrage signals are present.

The novelty of this research lies in the use of high-frequency data on a five-minute interval basis, while using the nonlinear equilibrium correction model based on an extension of Markovian regime shifts in time series proposed by Hamilton (1988, 1989), and the regime dependent impulse response function. Thus, to shed more light on the lead-lag relationship between spot and futures markets, we begin in the next section by explaining the data used in this study.

\subsection{Data and preliminary analysis}

This study uses high-frequency observations on a five-minute interval basis of transaction prices from DAX30 for both the stock index and index futures. The sample period extends from January 2, 2014 to September 30, 2015, and only data for the period of simultaneous operation of both markets are used in our analysis.

Additionally, it is frequent in the literature to exclude some observations at the beginning of each trading day. When the negotiation in the spot markets begins, volatility reaches its highest level; therefore, in this study, the first return of the trading day, 09:05 hour, which generally reflects the adjustment to information accumulated overnight and displays the highest average return variability, is deleted to avoid deleterious effects on the econometric analysis (see Andersen et al., 2000 and Lee and Mathur, 1999).

After cleaning the data ${ }^{10}$, we obtain the continuously compounded returns at each 5-minute interval by taking the logarithms and subtracting the previous value. Returns at the $n$ interval at day $t$, for $n=1,2 \ldots N$ and $t=1,2, \ldots T$ can then be calculated as follows:

$$
R_{n, t}=100 \times \log \left(P_{n, t} \div P_{n, t-1}\right)
$$

where, $P_{n, t}$ represents the spot $\left(S_{n, t}\right)$ and futures $\left(F_{n, t}\right)$ price level on interval $n$, at day $t$.

Table 1 presents some statistical tests on a five-minute interval basis for the prices and the returns series used. Some results are remarkable. As can be appreciated in panel A, returns are clearly not normally distributed due to the asymmetric and

${ }^{10}$ This leave us with a sample of 438 days with 103 intraday five-minute returns per day. 
leptokurtic patterns of the series, and mean returns are close to zero. Leptokurtosis may be considered to be a measure of the fatness of the tails of distribution with more extreme movements than would be predicted by a normal distribution. Panel B shows the Ljung-Box test statistic that detects autocorrelation for both prices and returns.

Panels C and D exhibit stationary and cointegration tests. Spot and futures prices are nonstationary; however, returns series are found to be stationary. Thus, the study reveals that both series contain a unit root and are integrated of order one. Additionally, when analysing cointegration, contradictory results are encountered. Residuals $Z_{t}$ from the regression $S_{t}=\beta+\gamma F_{t}+Z_{t}$ are tested for the presence of unit root using Augmented Dickey Fuller (ADF) and Kwiatkowski-Phillips-SchmidtShin (KPPS) tests. According to ADF test, the residuals from this regression (ECT) are stationary, that is to say, the ECT is I (0), and as a consequence of that, the spot and futures markets are cointegrated; nevertheless, the result of the KPPS test is just the opposite; it reveals that the ECT is not stationary, and therefore, these markets are not cointegrated.

The cointegration analysis computes the long run equilibrium relationship between two series; thus, a large dataset is needed to test for cointegration. Nonetheless, the main disadvantage is that the longer is the dataset analysed, the more likely the series include structural changes. 
TABLE 1: Statistics results

\begin{tabular}{|c|c|c|c|c|}
\hline & \multicolumn{2}{|c|}{ Levels } & \multicolumn{2}{|c|}{ Returns } \\
\hline & Spot & Futures & Spot & Futures \\
\hline \multicolumn{5}{|c|}{ Panel A: Summary Statistics } \\
\hline Mean & $10,195.49$ & $10,201.05$ & -0.00034 & -0.00031 \\
\hline Standard Deviation & 927.45 & 930.61 & 0.099 & 0.100 \\
\hline Skewness & 0.66 & 0.67 & -0.389 & -0.367 \\
\hline Kurtosis & 2.12 & 2.15 & 16.78 & 17.021 \\
\hline Minimum & $8,363.08$ & $8,367.00$ & -2.100 & -2.205 \\
\hline Maximum & 12,385 & 12,422 & 1.245 & 1.292 \\
\hline Jarque Bera & 4,741 & 4,746 & 358,054 & 370,532 \\
\hline Observations & 45,115 & 45,115 & 45,114 & 45,114 \\
\hline \multicolumn{5}{|c|}{ Panel B: Autocorrelation test } \\
\hline $\mathrm{LB}-Q(20)$ & $900,772.62$ & $900,775.64$ & 98.41 & 114.15 \\
\hline $\mathrm{LB}-Q^{2}(20)$ & $896,284.85$ & $896,409.88$ & $15,126.42$ & $14,631.81$ \\
\hline \multicolumn{5}{|c|}{ Panel C: Stationary test } \\
\hline ADF(H0:Not stationary) & -0.0365 & -0.0494 & $-215.4262^{*}$ & $-216.9964^{*}$ \\
\hline KPSS(H0:stationary) & $347.51^{*}$ & $348.13^{*}$ & 0.1434 & 0.1336 \\
\hline \multicolumn{5}{|c|}{ Panel D: Cointegration test } \\
\hline ADF(H0:Not stationary) & \multicolumn{4}{|c|}{$-38.537^{*}$} \\
\hline KPSS (H0:stationary) & \multicolumn{4}{|c|}{$103.654^{*}$} \\
\hline
\end{tabular}

The * denotes the significance at 0.05 .

Table 1 shows some statistical tests for DAX30 index prices and returns on a five-minute interval basis for both the spot and futures market from January 2, 2014, to September 30, 2015. Returns at the $n$ interval at day $t$ have been calculated as follows: $R_{n . t}=$ $100 \times\left(\log P_{n, t} \div \log P_{n, t-1}\right)$, where $P_{n, t}$ represents the price level on interval $n$, at day $t$. Panel A presents the main summary statistics and the Jarque-Bera test for normality. Panel B displays the results of the serial autocorrelation test Ljung-Box using 20 lags. Panel C performs the Augmented-Dickey Fuller and Kwiatkowski-Phillips-Schmidt-Shin stationary tests, and panel D shows the results of the cointegration tests (checking whether the error correction term is stationary). 
Perron $(1989,1990)$ found that failure to allow for these structural changes in the data series leads to biased results in the ADF test. Additionally, Lee et al. (1997) showed that the stationarity test KPSS proposed by Kwiatkowski et al. (1992) is biased towards rejecting null hypothesis of stationarity repeatedly when the data generating process is stationary with a structural break. In other words, the power of unit root tests is sensitive to structural breaks in the data, and neglecting the presence of different regimes may lead to distorted values in the stationarity and cointegration tests (Bartley et al., 2001).

To gain more insight into this issue, the ECT for the German market is depicted in Plot 1. 


\section{PLOT 1: Error correction term}

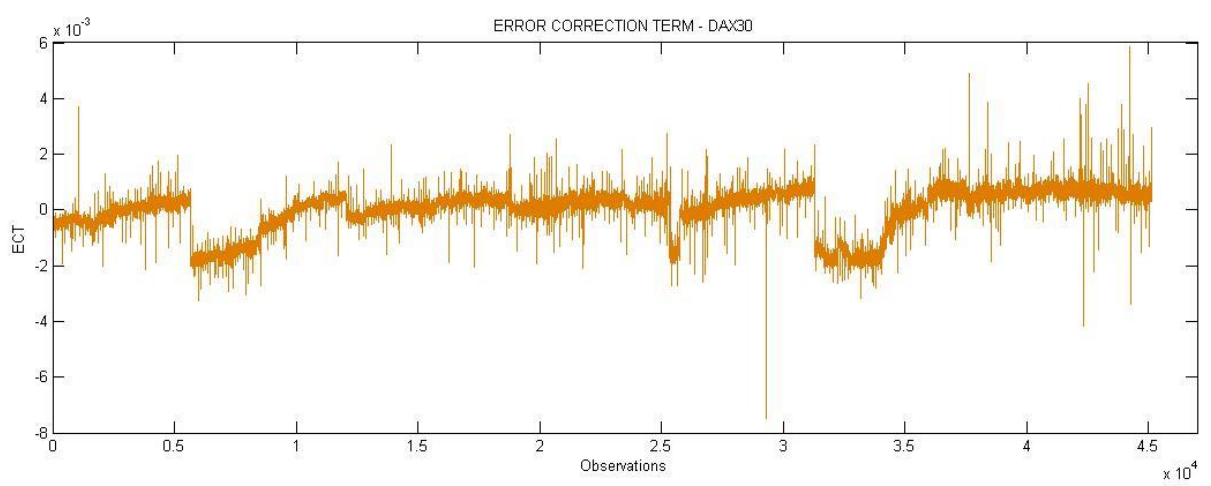

Plot 1 shows the error correction term for the DAX30 from January 2, 2014, to September 30,2015 . The horizontal axis represents the observations on a five interval basis, and the vertical axis measures the ECT. 
As can be appreciated in Plot 1, different regimes seem to be detected in the ECT. On the basis of this evidence, a state-dependent error correction model will be considered in our empirical study when comparing with the traditional VECM.

\subsection{Methodology}

This section explains the empirical models used in this study. First we describe the linear model, and then, we consider a nonlinear dynamic in the ECT. If two variables are cointegrated, they can be represented by a VECM that incorporates the last period error term as well as lagged returns of each variable. Thus, temporal causality may be evaluated by analysing the statistical significance and relative magnitude of lagged variables coefficients and ECT coefficients.

\subsubsection{Traditional VECM}

The first approach to analyse the price discovery process is the traditional Vector Error Correction Model (VECM), which assumes a permanent causal relationship between the spot and futures prices over the sample period.

$$
\begin{aligned}
& \Delta S_{t}=a_{s}+\sum_{i=1}^{k} b_{s i} \Delta S_{t-i}+\sum_{i=1}^{k} c_{s i} \Delta F_{t-i}+\alpha_{s} Z_{t-1}+\varepsilon_{s, t} \\
& \Delta F_{t}=a_{f}+\sum_{i=1}^{k} b_{f i} \Delta S_{t-i}+\sum_{i=1}^{k} c_{f i} \Delta F_{t-i}+\alpha_{f} Z_{t-1}+\varepsilon_{f, t}
\end{aligned}
$$

In the study of the price discovery process, both the short run and the long run causality will be analysed. The short run relationship is captured by coefficients $b_{s i}, c_{s i}, b_{f i}, c_{f i}$. When these coefficients are significant, it implies that a lead-lag relationship exists, and therefore, lagged returns in one market might be used to predict futures returns in the other market. Additionally, the long run relationship is represented by the error correction term $Z_{t-1}=S_{t-1}-\beta-\gamma F_{t-1}$, where $S_{t-i}$ and $F_{t-i}$ are log lagged spot and futures prices, respectively. 
The error correction coefficients $\alpha_{s}, \alpha_{f}$ collect information regarding the direction of the casual relationship between two series and show the speed with which the departures from equilibrium are corrected in the short run. Cointegrating variables may deviate from their relationship in the short run, but in the long run, their association will return. If a departure from equilibrium arises, prices in one or both markets should adjust to correct the deviation; otherwise, the series would wander apart without bound.

Additionally, $a_{s}$ and $a_{f}$ represent the unconditional return, and $\varepsilon_{s, t}$ and $\varepsilon_{f, t}$ are the residuals in the spot and futures equations, respectively. The optimal lag length will be determined using the Akaike information criteria (AIC) and the Bayesian information criteria (BIC).

\subsubsection{MS-VECM}

Recent years have witnessed a remarkable increase in the popularity of nonlinear modelling (Sarno and Valente, 2000 and Ang and Timmermann 2012, among others). Most of the previous studies have usually neglected nonlinearities in their empirical models employing linear specifications. In this section, to account for the dynamic of the ECT, we use a Vector Error Correction Model Markov Switching (MS-VECM) in which the parameter of the long run deviation of spot-futures prices is dependent on 2 regimes ${ }^{11}$.The nonlinear dynamic approach presented here implies that the degree and speed of adjustment towards long run equilibrium depends on the size of the deviation. Moreover, the main advantage of the Markov Switching methodology is that it endogenously determines the changes in the dynamic relationship without postulating exogenous structural changes. Thus, instead of conjecturing a known regime in a certain period, its probability in each point of time is estimated based on the information extracted from the sample.

The methodology is basically the result of extending the Markovian regime shifts to time series analysis originally proposed by Hamilton $(1988,1989)$, considering changes in causality as random events governed by an exogenous Markov process. In the MS-VECM used in this study, we parameterize that the ECT comes from a particular causality regime with a certain probability, and it is specified as follows:

$$
\Delta S_{t}=a_{s}+\sum_{i=1}^{k} b_{s i} \Delta S_{t-i}+\sum_{i=1}^{k} c_{s i} \Delta F_{t-i}+\alpha_{s, s t} Z_{t-1}+\varepsilon_{s, t, s t}
$$

11 To keep the number of parameters tractable, this investigation considers two regimes in the ECT. 


$$
\begin{gathered}
\Delta F_{t}=a_{f}+\sum_{i=1}^{k} b_{f i} \Delta S_{t-i}+\sum_{i=1}^{k} c_{f i} \Delta F_{t-i}+\alpha_{f, s t} Z_{t-1} \\
+\varepsilon_{f, t, s t} \quad(4) \\
\varepsilon_{s, t, s t} \mid \psi_{t-1} \sim B N\left(0, H_{t, s t}\right) \\
\varepsilon_{f, t, s t} \\
H_{t, s t}=\left[\begin{array}{ll}
h_{s, s, s t} & h_{s, f, s t} \\
h_{f, s, s t} & h_{f, f, s t}
\end{array}\right]
\end{gathered}
$$

where $\psi_{t-1}$ refers to the information available at time $\mathrm{t}-1, H_{t, s t}$ is the regime dependent variance-covariance matrix, and st is an unobservable state variable that can take the value 1 and 2; the parameters $\alpha_{s, s t}, \alpha_{f, s t}$ accompanying the ECT depend on the regime $s t=\{1(\text { state } 1) \text {, or } 2(\text { state } 2)\}^{12}$.

The MS-VECM is estimated using a two-step maximum likelihood procedure ${ }^{13}$. The error correction term $Z_{t-1}$ is determined in the first step and is the same variable computed in the traditional VECM. The second step consists of the implementation of an expectation-maximization algorithm using maximum likelihood to estimate equations (3) to (6). ${ }^{14}$

Moreover, one interpretation of the ECT is that it reflects the effect of arbitrage opportunities. When the futures price is too high relative to the index value, arbitragers will buy the stocks underlying the index and sell the futures contract. When the futures price is too low, they will do the reverse. As a consequence of these transactions, prices back towards equilibrium, that is to say, the ECT reverts to zero. We analyse in the next section, the extent to which the dynamic of the adjustment is affected by the presence of different regimes in the ECT.

\subsection{Empirical findings}

This section displays the main empirical results using the models described in the previous section. First, we will estimate the traditional VECM and then the MSVECM, discussing the main differences afterwards.

\footnotetext{
12 These states will be identified as $1=$ Low State and 2=High State.

13 See Perlin, M. (2010) MS Regress - The MATLAB Package for Markov Regime Switching Models. Available at SSRN: http://ssrn.com/abstract=1714016.

${ }^{14}$ For more details about the algorithm used for drawing probabilistic inference about whether and when shifts might occur, see Hamilton, 1989.
} 


\subsubsection{Estimations for linear models}

The use of the error correction models enables differentiation between short run and long run deviations from the equilibrium relationship. We initially investigate the short run and long run casual links between stock index futures returns and stock index returns using the model presented in section 2.4.1 (Traditional VECM). According to AIC/BIC criteria, the optimal lag length is set at 5.15

Table 2 represents the main results obtained for the traditional bivariate VECM.

15 The same lag length is used in the VECM-MS 
TABLE 2: Parameter estimates of the linear VECM

\begin{tabular}{|c|c|c|c|}
\hline & & $\begin{array}{l}\text { SPOT RETURN } \\
\text { EQUATION }\end{array}$ & $\begin{array}{c}\text { FUTURES } \\
\text { RETURN } \\
\text { EQUATION }\end{array}$ \\
\hline Intercept $a_{s}, a_{f}$ & & -0.00037 & -0.00033 \\
\hline ECT $\alpha_{s}, \alpha_{f}$ & & -0.011786 & 0.00222 \\
\hline \multirow[t]{5}{*}{ Lagged Spot Return Coefficient } & 1 & $-0.551384^{*}$ & 0.00559 \\
\hline & 2 & $-0.300798^{*}$ & 0.02479 \\
\hline & 3 & $-0.182988^{*}$ & 0.00462 \\
\hline & 4 & $-0.13084^{*}$ & -0.03498 \\
\hline & 5 & $-0.06758^{*}$ & -0.02765 \\
\hline Lagged Futures Return Coefficient & 1 & $0.54140^{*}$ & -0.02712 \\
\hline$c_{s i}, c_{f i}$ & 2 & $0.28443^{*}$ & -0.04650 \\
\hline & 3 & $0.20317^{*}$ & 0.01171 \\
\hline & 4 & $0.14388^{*}$ & 0.04631 \\
\hline & 5 & $0.07046^{*}$ & 0.02782 \\
\hline
\end{tabular}

The * denotes significance at 0.05 .

Table 2 presents the results of the linear VECM
$\Delta S_{t}=a_{s}+\sum_{i=1}^{k} b_{s i} \Delta S_{t-i}+\sum_{i=1}^{k} c_{s i} \Delta F_{t-i}+\alpha_{s} Z_{t-1}+\varepsilon_{s, t}$ Spot return equation $\Delta F_{t}=a_{f}+\sum_{i=1}^{k} b_{f i} \Delta S_{t-i}+\sum_{i=1}^{k} c_{f i} \Delta F_{t-i}+\alpha_{f} Z_{t-1}+\varepsilon_{f, t}$ Futures return equation

where $\boldsymbol{S}_{\boldsymbol{t}-\boldsymbol{i}}$ and $\boldsymbol{F}_{\boldsymbol{t}-\boldsymbol{i}}$ are log lagged spot and futures prices, respectively; $\Delta$ is the firstdifference lag operator, $\boldsymbol{a}_{\boldsymbol{s}}$ and $\boldsymbol{a}_{\boldsymbol{f}}$ represent the unconditional return; coefficients $b_{s i}, c_{s i}, b_{f i}, c_{f i}$ capture the short-run relationship; $\boldsymbol{Z}_{\boldsymbol{t}-\mathbf{1}}$, computed as $\boldsymbol{Z}_{\boldsymbol{t}-\mathbf{1}}=\boldsymbol{S}_{\boldsymbol{t}-\mathbf{1}}-\boldsymbol{\beta}-$ $\boldsymbol{\gamma} \boldsymbol{F}_{\boldsymbol{t}-\mathbf{1}}$, is the error correction term (ECT); $\alpha_{s}, \alpha_{f}$ are the error correction coefficients that collect information regarding the long-run relationship; and $\boldsymbol{\varepsilon}_{\boldsymbol{s}, \boldsymbol{t}}$ and $\boldsymbol{\varepsilon}_{\boldsymbol{f}, \boldsymbol{t}}$ are the residuals in the spot and futures returns equations, respectively. The optimal lag length has been determined using the Akaike information criteria (AIC) and the Bayesian information criteria (BIC) and has been set in five lags. 
It is worth noting that short run causality is unidirectional from the futures to the spot market. Note in Table 2 that lagged spot return coefficients $\left(\boldsymbol{b}_{f i}\right)$ are not significant in the futures equation. Therefore, the short run adjustments underscore the importance of futures prices in the price discovery process for the German market. Additionally, contemporaneous spot returns are affected negatively by lagged spot returns $\left(b_{s i}\right)$ and positively by lagged futures returns $\left(c_{s i}\right)$ (the same evidence is found by Theissen, 2012). In the futures market, this pattern is not observed.

As far as the long run relationship is concerned, it is found to be not significant (see significance of alfa parameters $\alpha_{s}, \alpha_{f}$ accompanying the ECT in Table 2). None of them is significant; hence, this means that both series are not cointegrated, and they deviate without a bound in the long run. Contradictory results in the unit root test ADF vs. KPPS are hereby confirmed. Because spot and futures prices concerning the same index react to the same information, short run deviations might be possible, but in the long run, spot and futures prices are expected to strike a balance. In this regard, and according to the MS-VECM results, which will be further explained, neglecting structural changes apparently present in the ECT (see Plot 1), may be leading us to inefficient estimations. This finding reinforces the idea that ECT regime switching should be considered; thus, in the next subsection, we postulate the existence of two regimes in the ECT (high and low regimes).

\subsubsection{Estimations for nonlinear models (MS-VECM)}

Table 3 presents the parameter estimates of MS-VECM ${ }^{16}$. As can be appreciated, in the spot equation, similar results to the linear estimation are obtained; lagged spot returns $\left(b_{s i}\right)$ have a negative impact while the impact of lagged futures returns is positive $\left(c_{s i}\right)$.

However, in the futures equation, the results differ from those in the linear estimation, considering that both lagged spot returns $\left(b_{f i}\right)$ and lagged futures returns $\left(c_{f i}\right)$ are significant. Thus, after considering regimes in the ECT, a two-way causality is detected in the German market, which means that price innovations in either the cash or futures markets might be able to predict the arrival of new information in the other market and both markets play important price discovery roles. However, note that there is an asymmetric lead-lag relationship between the two markets with strong evidence that the futures index leads the cash index and

\footnotetext{
16 For the estimation of the VECM-MS, we use the specification-robust estimator of the variance-covariance matrix suggested by Bollerslev and Wooldridge (1992) to prevent the effect of heteroskedasticity and autocorrelation in the residuals.
} 
weak evidence in the opposite direction (see in Table 3 that the magnitude of $c_{s i}$ coefficients accompanying lagged futures returns in the spot equation is much greater, in absolute terms, than the lagged spot returns parameters $b_{f i}$ in the futures equation, for instance, $c_{s 1}=0,70512$, whereas $b_{f 1}=0,00213$ ). Therefore, in the short run, the effect is bidirectional, but the futures market has more predictive capability. As one might expect, these findings are consistent with previous empirical studies that reinforce the idea of the leading role of the futures market (Kawaller et al., 1987; Ng, 1987; Stoll and Whaley, 1990; Chan, Chan and Karolyi, 1991; and Chan, 1992, among others).

The main difference between the estimations in the traditional VECM and the MSVECM is encountered in the analysis of the long run relationship. Contrary to results found in the linear estimation, parameters accompanying the ECT $\left(\alpha_{s, s t}\right.$ and $\alpha_{f, s t}$ ) have become statistically significant, suggesting that spot and futures prices may diverge temporarily but then readjust to the cointegrated pattern, and any mispricing is driven back to the equilibrium by arbitrage forces; in other words, there exists a long run equilibrium relationship between spot and futures markets. The leading role of the futures market is also corroborated in the long run in both the high and low states. Note that the $\alpha$ parameters measure the speed of disequilibrium correction and the greater is the value of this coefficient (in absolute terms), the more informationally efficient the market is. Hence, it is inferred from Table 3 that the spot price makes the greater adjustment to reestablish the equilibrium, and moreover, this speed of convergence to equilibrium is faster in states with higher ECT than in states with lower ECT. That is to say, the futures market leads the cash market in price discovery, but the dynamic of the adjustment differs when there exist arbitrage opportunities, and arbitrage can be related to faster convergence of the basis to the cost of carry. Note that in Table 3, in the spot return equation parameter accompanying the ECT in the high state $\left(\alpha_{s, 2}=0,020933\right)$ is more than four times the magnitude of the parameter accompanying the ECT in the low state $\left(\alpha_{s, 1}=0,004472\right)$. These results are, therefore, consistent with those found by Theissen (2012) ${ }^{17}$, who documents that the futures market leads in the process of price discovery and highlights that the leading role of the futures market in the price discovery process is especially pronounced when arbitrage opportunities arise.

As far as the expected duration of each regime is concerned, during states with lower ECT, the expected duration of the regime is approximately two hours, whereas it decreases to 25 minutes in states with more arbitrage opportunities (see in Table 3, state duration of 25,52 and 4,9 intervals of 5 minutes for the high

\footnotetext{
17 This author analyses 2 datasets with frequencies of 15 seconds and 1 minute (each dataset comprises 61 trading days for the German stock market) and uses a threshold error correction model (TECM) to account for different magnitudes of the ECT. To do this, arbitrage signals are defined exogenously.
} 
and low states). This implies that regime with lower ECT is more persistent than the other one, and it takes a longer time to reach the new equilibrium.

To sum up, our findings reveal the importance of considering the magnitude of the deviation from the long run equilibrium; otherwise, estimations may be biased. Linear models might be misspecified if there are structural changes in the sample analysed and they are not considered. 
TABLE 3: Parameter estimates of the MS-VECM

\begin{tabular}{|c|c|c|c|}
\hline \multicolumn{4}{|c|}{ Non-switching parameters } \\
\hline Intercept $a_{s}, a_{f}$ & & $\begin{array}{c}\text { SPOT RETURN } \\
\text { EQUATION } \\
-0.00004^{*}\end{array}$ & $\begin{array}{c}\text { FUTURES RETURN } \\
\text { EQUATION } \\
-0.00026^{*}\end{array}$ \\
\hline \multirow{5}{*}{$\begin{array}{l}\text { Lagged Spot Return Coefficients } \\
b_{s i}, b_{f i}\end{array}$} & 1 & $-0.73230^{*}$ & 0.00213 \\
\hline & 2 & $-0.53412^{*}$ & $0.02000^{*}$ \\
\hline & 3 & $-0.39150 *$ & $0.00601^{*}$ \\
\hline & 4 & $-0.26318^{*}$ & $-0.00686^{*}$ \\
\hline & 5 & $-0.12683^{*}$ & $0.00244^{*}$ \\
\hline \multirow{5}{*}{$\begin{array}{l}\text { Lagged Futures Return Coefficients } \\
c_{s i}, c_{f i}\end{array}$} & 1 & $0.70512^{*}$ & $-0.03853^{*}$ \\
\hline & 2 & $0.48213^{*}$ & $-0.07588 *$ \\
\hline & 3 & $0.00500^{*}$ & $0.35822^{*}$ \\
\hline & 4 & $0.29444^{*}$ & $0.03645^{*}$ \\
\hline & 5 & $0.14066^{*}$ & $0.00860 *$ \\
\hline \multicolumn{4}{|c|}{ Switching parameters } \\
\hline State with higher ECT $\alpha_{s, s t}, \alpha_{f, s t}$ & & 0.020933* & $-0.000317^{*}$ \\
\hline State with lower ECT $\alpha_{s, s t}, \alpha_{f, s t}$ & & $0.004472^{*}$ & $0.000403^{*}$ \\
\hline \multicolumn{4}{|c|}{ Variance - covariance matrix $H_{t, s t}$} \\
\hline \multirow[t]{2}{*}{ State with higher ECT } & & 0.025739 & 0.024996 \\
\hline & & 0.024996 & 0.026798 \\
\hline \multirow[t]{2}{*}{ State with lower ECT } & & 0.005084 & 0.005085 \\
\hline & & 0.005085 & 0.005219 \\
\hline \multicolumn{4}{|c|}{ State duration } \\
\hline State with higher ECT & & & \\
\hline State with lower ECT & & 52 & \\
\hline
\end{tabular}

The ${ }^{*}$ denotes significance at 0.05 .

Table 3 presents the results of the VECM - MS

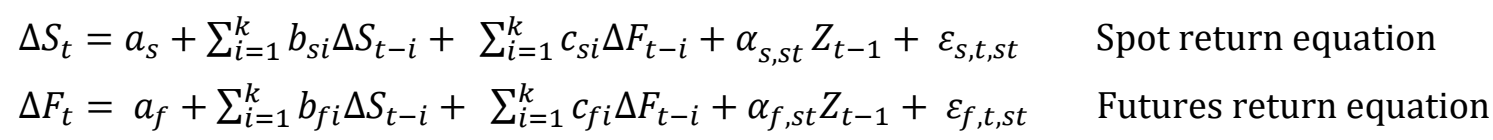

$\varepsilon_{s, t, s t} \mid \psi_{t-1, s t} \sim B N\left(0, H_{t, s t}\right)$

$H_{t, s t}=\left[\begin{array}{ll}h_{s, s, s t} & h_{s, f, s t} \\ h_{f, s, s t} & h_{f, f, s t}\end{array}\right]$

where $\boldsymbol{S}_{\boldsymbol{t}-\boldsymbol{i}}$ and $\boldsymbol{F}_{\boldsymbol{t}-\boldsymbol{i}}$ are log lagged spot and futures prices, respectively; $\Delta$ is the firstdifference lag operator; $\boldsymbol{a}_{\boldsymbol{s}}$ and $\boldsymbol{a}_{\boldsymbol{f}}$ represent the unconditional return; coefficients $b_{s i}, c_{s i}, b_{f i}, c_{f i}$ capture the short-run relationship; $\boldsymbol{Z}_{\boldsymbol{t}-\mathbf{1}}$, computed as $\boldsymbol{Z}_{\boldsymbol{t}-\mathbf{1}}=\boldsymbol{S}_{\boldsymbol{t}-\mathbf{1}}-\boldsymbol{\beta}-$ $\boldsymbol{\gamma} \boldsymbol{F}_{\boldsymbol{t}-\mathbf{1}}$, is the error correction term; $\alpha_{s, s t}, \alpha_{f, s t}$ are the parameters accompanying the ECT that depend on the regime $s t=\{1=$ Low State, $2=$ High State $\}$, which collect information regarding the long run relationship; $H_{t, s t}$ is the variance-covariance matrix (s=spot market, $\mathrm{f}=$ futures market); and $\varepsilon_{s, t, s t}$ and $\varepsilon_{f, t, s t}$ are the residuals in the spot and futures returns equations, respectively. The same lag length set in the VECM is used in the MS-VECM (five lags). 


\subsection{Regime dependent impulse response function}

Since the valuable contribution of Sims (1980), the dynamic interaction between the variables and the disturbances in vector autoregressive models (VARs) has been widely explained by the impulse response or "error shock" methodology. Impulse response functions (IRFs) are considered to be useful tools to study the effect of a shock on the variables in the model throughout time.

The analysis of IRFs in linear models has been extensively implemented; however, the study of nonlinear cases has been less covered. As Gallant et al. (1993) highlight, it is crucial to expand research of time series to nonlinear models. In this regard, these authors extend the analysis of IRFs to the nonlinear case and emphasize the importance of using these models to capture dynamics. Considering that characteristics of nonlinear models are different across regimes, the IRF will depend on the magnitude of the shock and the time that it occurs (Koop, 1996; Koop et al., 1996). Therefore, to gain more insight into the idiosyncrasy of each regime in the MS-VECM, we determine how the system will respond following a shock ${ }^{18}$ when arbitrage opportunities differ.

To obtain the regime dependent impulse response function, we follow a two-stage procedure. First, we convert the MS-VECM back to a VAR ${ }^{19}$ model, and then, the resulting VAR model is used to perform the regime dependent IRF (RDIRF) ${ }^{20}$.

The RDIRF may be defined as follows:

$$
\begin{aligned}
& \theta_{k, s t, h}=\frac{\partial \mathrm{E}_{t} P_{t+h}}{\partial u_{k, t}} \mid \text { st } \quad \text { for } h \geq 0 \\
& s t=\{1=\text { low regime, } 2=\text { high regime }\}
\end{aligned}
$$

where $u_{k, t}$ is the structural shock to the k-th variable, $P_{t+h}$ are the spot $\left(S_{t+h}\right)$ or futures $\left(F_{t+h}\right)$ prices at time $\mathrm{t}+\mathrm{h}^{21}$ and $\theta_{k, s t, h}$ is a $\mathrm{k}$-dimensional response vector dependent on the regime st.

Given that two regimes are present in the ECT, our general model contains 4 regime dependent impulse response functions, which include spot and futures market IRFs in low and high regimes.

\footnotetext{
${ }^{18}$ For each variable, a shock of one standard deviation magnitude is applied to the residuals.

19 The VECM(5) is converted into a VAR(6); then, we can express the VAR(6) as an infinite moving average model.

20 The Generalized impulse response function by Pesaran and Shin (1998) is used.

21 The dynamic response for each variable is traced out over a period of 30 intervals of five minutes (two and one half hours).
} 
PLOT 2: Regimen Dependent Impulse Response Function

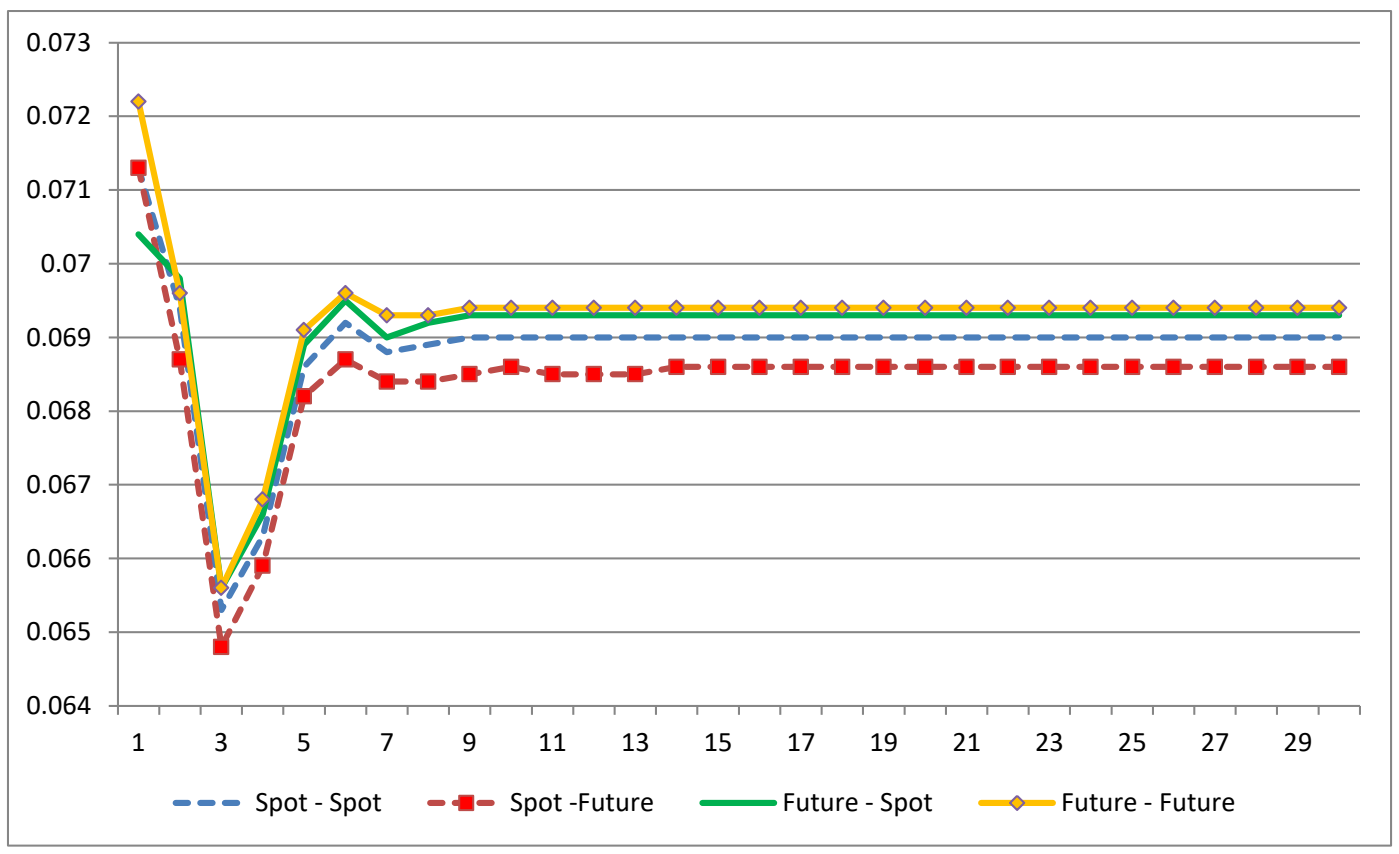

Response in states with lower ECT (subplot 2.1)

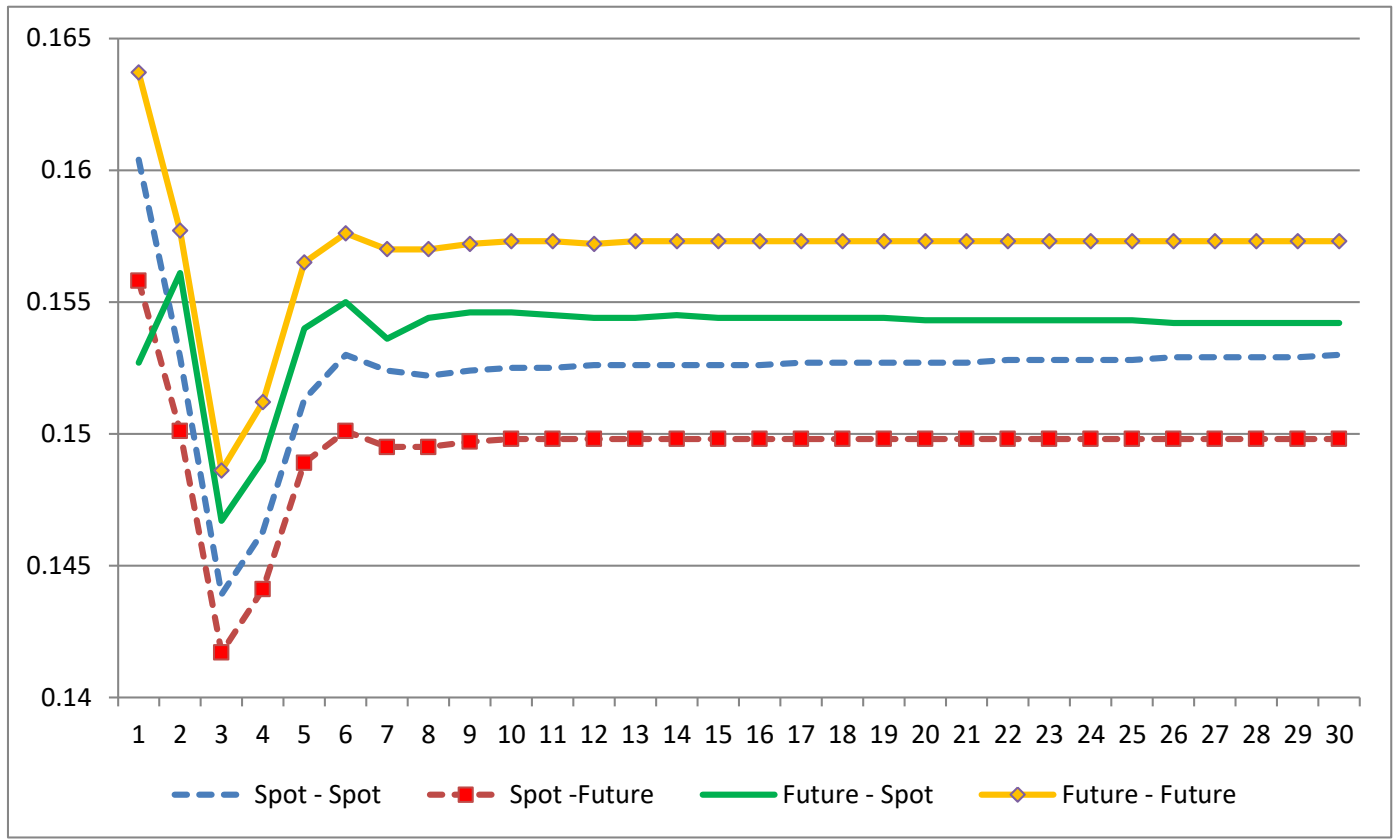

\section{Response in states with higher ECT (subplot 2.2)}

Plot 2 gives the impulse responses to a one standard deviation shock in states with lower (subplot 2.1) and higher ECT (subplot 2.2). The horizontal axis represents the period in intervals of five minutes. The vertical axis represents the magnitude of the shock expressed as a percentage of the price increase. The solid line and the solid line with markers denote the impulse response of the spot and futures markets to a shock in the futures market, respectively. In addition, the dashed line and the dashed line with markers represent the impulse response of the spot and futures markets to a shock in the spot market, respectively. All impulses are based on the Generalized Impulse Response Function by Pesaran and Shin (1998). 
Plot 2 illustrates the RDIRF for an unexpected shock in states with lower (subplot 2.1) and higher ECT (subplot 2.2). A noteworthy result is that the shock implies a temporary and permanent effect on prices, but note that the impact of a shock of one standard deviation magnitude has a greater reaction on regimes with higher ECT. As can be appreciated in subplot 2.1, after the shock hits the system in states with lower ECT, prices increase approximately 0,07\%, whereas in regimes with more arbitrage opportunities (see subplot 2.2), prices increase between 0,15 and 0,16\%. Moreover, the effect of the shock stabilizes after 40-45 minutes (8-9 periods), inducing a permanent increase in prices on both regimes, which rise to reach their new long run equilibrium level. Moreover, when a shock is applied to the futures prices, the market responses are more pronounced than when a shock is introduced into the spot market. The findings thus obtained in the impulse response analysis are coherent with the results of MS-VECM. As is illustrated in Plot 2, both futures and spot prices react to unexpected shocks in the spot and futures markets, which suggests that there exists bidirectional interaction between the DAX30 index and the DAX30 index futures; however, note that the response to a shock in futures prices is relatively larger than the response to a shock in spot prices (see that solid lines are above the dashed lines), indicating that the futures market leads the spot market and reinforcing the idea of the leading role of the futures markets in the price discovery process.

Therefore, summing up, the most interesting results of the RDIRF analysis are as follows: a) the response to a shock in futures prices is relatively larger than the response to a shock in spot prices; b) shocks induce a permanent increase ${ }^{22}$ in prices, which rise to reach their new long run equilibrium level; and c) the dynamic causal effect is remarkably different in low/high regimes, so as the arbitrage opportunities increase, the impact of unexpected shocks on prices increases.

These findings, therefore, support the importance of the RDIRFs to confirm causal relationships between spot and futures prices from MS-VECM and capture asymmetries in both regimes.

\subsection{Conclusions}

In this paper, we investigate the lead-lag relationship between the DAX30 stock index and DAX30 index futures. The development of high-frequency databases has boosted interest in empirical market microstructure and provides great potential to improve our understanding of financial markets (Goodhart and O'Hara, 1997).

22 Prices are not stationary. If prices contain a unit root, the shocks have permanent effects, while if they are stationary, then the effects of shocks eventually die out. 
In addition, increasingly growing empirical research has stressed the existence of relevant nonlinearities in both spot and futures returns (Sarno and Valente, 2000; Li, 2009 and Theissen, 2012 among others). This study contributes to the existing literature by using high-frequency data and nonlinear models based on an extension of Markovian regime shifts to overcome the weakness of linear assumptions in the dynamic relationship between spot and futures prices widely used in previous studies. These nonlinear models allow us to consider the presence of different regimes in the deviation from the long run equilibrium.

From the outcome of our investigation, it is possible to conclude that linear models might be misspecified when structural changes are present in the data and they are neglected. Therefore, it is important to capture the different regimes detected in the ECT to provide a more suitable empirical model and a better understanding of the information transmission so that market participants can define more efficient trading strategies.

In the short run, the results support the hypothesis that innovations propagate in the futures market before that in the spot market; however, pronounced two-way causality is detected in the estimation of the MS-VECM suggesting bilateral interaction in the price discovery process. These results are in good agreement with previous empirical studies that reinforce the idea of the leading role of the futures market (Kawaller et al., 1987; Ng, 1987; Stoll and Whaley, 1990; Chan, Chan and Karolyi, 1991; and Chan, 1992, among others). However, when analysing the cointegration relationship, the results are completely different depending on the model used to make the estimations.

In the long run analysis, according to the estimations of the traditional VECM, spot and futures prices do not follow a common long term trend. Nevertheless, in the MS-VECM, parameters accompanying the time varying ECT suggest that spot and futures prices may diverge temporarily but both readjust to the cointegrated pattern, although it is the spot price that makes the greater adjustment to reestablish the equilibrium. Moreover, spot price adjustment accelerates in states with higher ECT, revealing faster convergence of the basis when arbitrage opportunities arise.

Finally, results from the impulse response analysis reinforce the idea that the dynamic causal effect is remarkably different in regimes with different arbitrage opportunities in such a way that as the arbitrage opportunities increase, the impact of unexpected shocks on prices increases.

Overall, these results underpin the importance of considering regimes present in the error correction term and the perils of strong linear assumptions when analysing the lead-lag relationship. 


\section{References}

Andersen, T. G. (2000). Some reflections on analysis of high-frequency data. Journal of Business \& Economic Statistics, 18(2), 146-153.

Andersen, T. G., Bollerslev, T., \& Cai, J. (2000). Intraday and interday volatility in the Japanese stock market. Journal of International Financial Markets, Institutions and Money, 10(2), 107-130.

Ang, A., \& Timmermann, A. (2012). Regime changes and financial markets . Annual Review of Financial Economics, 4(1), 313-37

Bartley, W. A., Lee, J., \& Strazicich, M. C. (2001). Testing the null of cointegration in the presence of a structural break. Economics Letters, 73(3), 315-323.

Blanco, R. (2003). Transmisión de información entre el mercado de futuros sobre el Ibex 35 y el contado. Revista de Economía Aplicada, 11(31), 81-101.

Bollerslev, T., \& Wooldridge, J. M. (1992). Quasi-maximum likelihood estimation and inference in dynamic models with time-varying covariances. Econometric Reviews, 11(2), 143-172.

Bondarenko, 0. (2003). Statistical arbitrage and securities prices. The Review of Financial Studies, 16(3), 875-919.

Brooks, C. (1996). Testing for non-linearity in daily sterling exchange rates. Applied Financial Economics, 6(4), 307-317.

Chan, K. (1992). A further analysis of the lead-lag relationship between the cash market and stock index futures market. The Review of Financial Studies, 5(1), 123152.

Chan, K., Chan, K. C. \& Karolyi, G. A. (1991). Intraday volatility in the stock index and stock index futures markets. The Review of Financial Studies 4(4), 657-684.

Dwyer, G. P., Locke, P., \& Yu, W. (1996). Index arbitrage and nonlinear dynamics between the S\&P 500 futures and cash. The Review of Financial Studies, 9(1), 301332.

Engle, R. F., \& Granger, C. W. (1987). Co-integration and error correction: representation, estimation, and testing. Econometrica, 55(2), 251-276. 
Frino, A., Walter, T., \& West, A. (2000). The lead-lag relationship between equities and stock index futures markets around information releases. The Journal of Futures Markets, 20(5), 467-487.

Gallant, A. R., Rossi, P. E., \& Tauchen, G. (1993). Nonlinear dynamic structures. Econometrica, 61(4), 871-907.

Goodhart, C. A., \& O'Hara, M. (1997). High-frequency data in financial markets: Issues and applications. Journal of Empirical Finance, 4(2-3), 73-114.

Hamilton, J. D. (1988). Rational-expectations econometric analysis of changes in regime: An investigation of the term structure of interest rates. Journal of Economic Dynamics and Control, 12(2-3), 385-423.

Hamilton, J. D. (1989). A new approach to the economic analysis of nonstationary time series and the business cycle. Econometrica, 57(2), 357-384.

Harris, F.H. de B, McInish, T. H., Shoesmith, G. L., \& Wood, R. A. (1995). Cointegration, error correction, and price discovery on informationally linked security markets. Journal of Financial and Quantitative Analysis, 30(4), 563-579.

Hogan, S., Jarrow, R., Teo, M., \& Warachka, M. (2004). Testing market efficiency using statistical arbitrage with applications to momentum and value strategies. Journal of Financial Economics, 73(3), 525-565.

Hsieh, D. A. (1991). Chaos and nonlinear dynamics: application to financial markets. The Journal of Finance, 46(5), 1839-1877.

Huth, N., \& Abergel, F. (2014). High-frequency lead/lag relationships-Empirical facts. Journal of Empirical Finance, 26, 41-58.

Kawaller, I. G., Kock, P. D., \& Koch, T. W. (1987). The temporal relationship between S\&P 500 futures prices and the S\&P 500 index. The Journal of Finance, 42(5), 13091329.

Koop, G. (1996). Parameter uncertainty and impulse response analysis. Journal of Econometrics, 72(1-2), 135-149.

Koop, G., Pesaran, M. H., \& Potter, S. M. (1996). Impulse response analysis in nonlinear multivariate models. Journal of Econometrics, 74(1), 119-147.

Kwiatkowski, D., Phillips, P. C., Schmidt, P., \& Shin, Y. (1992). Testing the null hypothesis of stationarity against the alternative of a unit root: How sure are we 
that economic time series have a unit root?. Journal of Econometrics, 54(1-3), 159178.

Lee, J., Huang, C. J., \& Shin, Y. (1997). On stationary tests in the presence of structural breaks. Economics Letters, 55(2), 165-172.

Lee, C.I., \& Mathur, I., (1999). The influence of information arrival on market microstructure: evidence from three related markets. Financial Review, 34(1), 126.

Li, M. Y. L. (2009). The dynamics of the relationship between spot and futures markets under high and low variance regimes. Applied Stochastic Models in Business and Industry, 25(6), 696-718.

$\mathrm{Ng}$, N. (1987). Detecting spot prices forecasts in futures prices using causality tests. Review of Futures Markets, 6(2), 250-267.

Pardo, Á., \& Climent, F. (2000). Relaciones Temporales entre el Contrato de Futuro sobre Ibex35 y su Activo Subyacente. Investigaciones Económicas, 24(1), 219-236.

Perlin, M. (2010). MS Regress - The MATLAB Package for Markov Regime Switching Models. Accessed 04.12.2015.

Perron, P. (1989). The Great Crash, the Oil Price Shock and the unit root hypothesis. Econometrica, 57(6), 1361-1401.

Perron, P. (1990). Testing for a unit root in time series with a changing mean. Journal of Business and Economic Statistics, 8(2), 153-162.

Pesaran, H. H., \& Shin, Y. (1998). Generalized impulse response analysis in linear multivariate models. Economics Letters, 58(1), 17-29.

Sarno, L., \& Valente G. (2000). The cost of carry model and regime shifts in stock index futures markets: An empirical investigation. The Journal of Futures Markets, 20(7), 603-624.

Sims, C. A. (1980). Macroeconomics and reality. Econometrica, 48(1), 1-48.

Stoll, H. R., \& Whaley, R.E. (1990). The dynamics of stock index and stock index futures returns. The Journal of Financial and Quantitative Analysis, 25(4), 441-468.

Theissen, E. (2012). Price discovery in spot and futures markets: a reconsideration. The European Journal of Finance, 18(10), 969-987. 
Tse, Y. (1999). Price discovery and volatility spillovers in the DJIA index and futures markets. The Journal of Futures Markets, 19(8), 911-930.

Wahab, M., \& Lashgari, M. (1993). Price dynamics and error correction in stock index and stock index futures markets: A cointegration approach. The Journal of Futures Markets, 13(7), 711-742. 


\section{CHAPTER B:}

\section{THE INFLUENCE OF INTRADAY SEASONALITY ON VOLATILITY TRANSMISSION PATTERN}

Abstract

Using data on a five-minute interval basis, this article analyses the effects of the well-documented intraday seasonality on volatility transmission between the spot and futures markets of the CAC40, DAX30 and FTSE100. Remarkable differences in the impulse response analysis and in the dynamic and directional measurement of volatility spillovers are encountered depending on whether the intraday periodic component is considered. Thus, the importance of removing intraday seasonality seems to be critical to reduce the risk of spurious causality when employing high-frequency data in volatility transmission. 


\subsection{Introduction}

Volatility modelling is one of the key developments in empirical finance. As stated by Andersen et al. (2000) "financial market volatility is central to the theory and practice of asset pricing, asset allocation, and risk management". The importance of understanding volatility transmission comes from its crucial role in the pricing of many financial assets, which is paramount in the overall decision making process of researchers, market participants, regulators and policy makers. Most of the empirical literature analysing the dynamic of volatility spillover has focused on transmission across international stock indexes; however, the literature related to volatility transmission between the stock market index future and its underlying market is less extensive. ${ }^{23}$

Studies regarding the volatility transmission between spot and futures stock indexes might be organized into two major groups depending on the frequency of the data: a) The first category of studies employs data on a daily basis (Koutmos and Tucker, 1996 and Meneu and Torró, 2003 among others), and b) the second group of studies are based on high-frequency data (Kawaller et al., 1990; Tse, 1999; Chan et al 1991; Fung, et al., 2005 among others). Although the empirical evidence about volatility spillovers between spot and futures markets diverges across articles, and there are some studies that document unilateral volatility spillover from the futures market to the stock market or the other way round, the conclusions drawn from previous research have mostly been supportive of the presence of bidirectional volatility transmission. Thereby, studies such as Koutmos and Tucker (1996) conclude that volatility transmission is unidirectional from the futures market to its underlying market; Kawaller et al. (1990) and Abhyankar (1995) conclude that this relationship depends on the time interval considered and that the intraday volatility transmission runs from one direction to another, in both directions, or in neither direction, concluding that there is not a systematic pattern of futures volatility leading the index volatility or vice versa; Meneu and Torró (2003), Chan et al. (1991), Tse (1999) and Fung et al. (2005) find evidence that there exists a two-way volatility transmission between the cash and futures markets. Additionally, it should be noted that Meneu and Torró (2003) and Chan et al. (1991) extend the analysis of volatility transmission by using the impulse response function and find evidence that shocks take a very long time to vanish (concretely, Meneu and Torró, 2003 document that the effect of the shock vanishes in about 100 days) ${ }^{24}$.

\footnotetext{
${ }^{23}$ Soriano and Climent (2006) review the literature on volatility transmission and provide a broad vision of the state of the art on this topic.

${ }^{24}$ Koutmos and Tucker (1996) examine the dynamic of volatility transmission between the S\&P 500 Index and S\&P 500 Futures Index using daily data from the period 1984 to 1993; Kawaller et al. (1990) study the intraday volatility transmission between the S\&P 500 Index and S\&P 500 Futures Index, employing minute-by-
} 
As has been discussed above, although conclusions drawn from most of the studies are not conclusive, the vast majority of research on volatility transmission finds evidence of a bidirectional volatility transmission, and moreover, historically, there has been a general consensus of the leading role of the futures market due to its trading cost advantage, greater liquidity and fewer restrictions.

Likewise, high-frequency data can shed new light on issues concerning the volatility spillover between markets that otherwise might be neglected when analysing data on a lower frequency basis. Certainly, the recent availability of highfrequency data has offered more efficient ways for a more detailed analysis and further comprehension of market microstructure activity. It enables us to estimate daily volatilities, particularly realized volatility (RV), with the added advantage of not having to estimate parametrical models commonly used, such as the ARCH and GARCH models. After the introduction of the ARCH models by Engle (1982), models employing realized volatility (RV) have been promoted by Andersen et al. $(2001,2003){ }^{25}$

As Goodhart and O'Hara (1997) highlight, the economic value of analysing highfrequency financial data is now undeniable and of direct practical relevance, both in the academic and financial world. Nevertheless, researchers should be cautious about the intraday statistical idiosyncrasies of many financial markets, particularly the so-called intraday periodic (or intraday seasonality) component, when dealing with intraday data in the volatility modelling process. Note that the studies mentioned above that use intraday data neglect the intraday periodic component.

It is a well-known stylized fact of the intraday statistical features of many financial markets that a strong intraday repetitive pattern is observed in the average absolute returns ${ }^{26}$. At market opening, absolute returns usually reach the highest values, and then around lunch hour, they decrease dramatically; finally, at the end of the trading day, they rise again. This suggests a U-shaped seasonal volatility pattern $^{27}$ (see, among others, Wood et al., 1985; Harris, 1986; Andersen and Bollerslev, 1997 and Tse, 1999). Due to this strong intraday periodicity generally

minute data from 1984 to 1986; Abhyankar (1995) uses FTSE100 Index and FTSE100 Futures Index hourly data from April, 1986 to March, 1990; Meneu and Torró (2003) use IBEX 35 Index and IBEX 35 Futures Index daily data from 1994 to 2001; Chan et al. (1991) study, simultaneously, the intraday relationship between returns and returns volatility in the S\&P 500 stock index and stock index futures market from 1984 to 1989 using five-minute data; Tse (1999) examines the intraday price discovery process and volatility spillovers between the DJIA futures and index using minute-by-minute data for the six-month period of November 1997 to April 1998; and Fung et al. (2005) examine the volatility transmission between the Hang Seng Index and Hang Seng Index future using intraday data on a one-minute interval basis from the period November, 1999 to December, 2000.

25 The concept of "realized volatility" dates back from Merton (1980). This author already mentioned that the sum of squared intraday returns can be used to estimate daily volatility.

${ }^{26}$ Intraday volatility is often proxied by the average absolute returns.

27 Some markets exhibit a double U-shape pattern, one in the morning and the other one in the afternoon (Andersen et al., 2000; Harju and Hussain, 2011). 
detected in the average absolute returns, standard volatility models, which usually involve a monotone geometric decay in the autocorrelation structure of the absolute returns (for instance, standard ARCH models), are not appropriate and might lead to spurious inference about the dynamic of the return volatility 28 (Andersen and Bollerslev, 1997). Therefore, any study that analyses asset return volatility should consider the strong intraday seasonality exhibited by the data. The Fourier Flexible Form (FFF), originally proposed by Gallant $(1981,1982)$, is particularly useful for this problem of seasonality detected in the intraday data and makes it possible to obtain deseasonalized or standardized data (Andersen and Bollerslev, 1997).

The main goal and major contribution of this investigation is to highlight the impact that the seasonal component of volatility has on the results and the conclusions reached in the studies about volatility transmission. In essence, this research attempts to address the following questions: Are the results obtained in this research field the same whether raw data or standardized data (data in which this seasonal component has been removed) are considered? Or, is the persistence of a shock on volatility return in a market and the net directional spillover effects among the spot and futures markets the same regardless of whether this seasonal component is considered?

In accordance with the approach of Andersen and Bollerslev, 1997 (A\&B97 hereafter), this investigation computes the deseasonalized volatility ${ }^{29}$, also called standardized volatility, and compares the results obtained through models in which raw data are considered (that is to say, those that do not remove the seasonal or periodic component) with results reached by models with standardized data. Overall, this study contributes to the existing literature by providing clear and overwhelming evidence of the effects on results of neglecting this aspect and the importance of removing the seasonal component to reduce the risk of spurious causality when employing high-frequency data in volatility modelling.

To complement and provide added value to the existing literature regarding volatility transmission, the futures and spot markets of the CAC40, DAX30 and FTSE100 will be studied considering the following issues: a) high-frequency data on a five-minute interval basis, b) the Fourier Flexible Form (FFF) as a methodology for standardized returns, c) realized volatility (RV) computed using standardized returns, d) an analysis of the volatility spillover and the Impulse Response (IR) effects on volatility models with raw and standardized data, and e) the methodology developed by Diebold and Yilmaz (2012) to provide information

28 Inference procedures implemented using high-frequency returns should consider, as noted by Andersen (2000), "the strong daily periodicity and the longer-run slow decay in the serial dependence".

29 The realized volatility from which the seasonal component has been removed, which will be explained further on. 
about how much the spot (futures) market contributes to volatility in the futures (spot) market in net terms. This novel approach is based on forecast error variance decompositions from vector autoregression models to measure which markets are the net contributors and the net receivers of volatility spillovers. In this study, we will show that the high persistence of a shock and the contribution of one market to the volatility in another market in net terms are directly related to the lack of consideration of the intraday seasonality in all markets studied.

From the outcome of our investigation, the following conclusions can be drawn: a) although there exists a seasonal structure in our intraday data and remarkable similarities are detected in the markets analysed, they do not illustrate a conventional intraday U-shape pattern but a distorted double U-shape; b) the FFF methodology used to remove the intraday periodic component considerably reduces intraday seasonality; c) cross-correlation analysis reveals significant cross-market volatility interactions between the spot and futures markets that have also been reduced noticeably after considering the seasonal pattern; d) volatility transmission differs significantly when considering raw and standardized absolute returns; that is to say, when intraday data are not standardized, the optimal number of lags in the VAR model determined by the selection criteria seems to be redundant, suggesting that if the seasonal pattern is neglected, it might have serious side effects in the spillover analysis due to the presence of spurious causality; f) the impulse response function shows that when a shock hits the system and the intraday periodic component has not been used to adjust the returns before conducting the spillover analysis, the response to that shock is highly persistent, reinforcing, once again, the importance of considering intraday seasonality; and g) the directional measurement of volatility spillover (Diebold and Yilmaz, 2012) also exhibits the fact that considering such a periodic component is paramount. In particular, it suggests that changes over time of either direction in volatility seem to occur less frequently, that the spot market is the largest net sender of volatility spillovers to the futures market throughout all the sample and that, in terms of magnitude, the net volatility spillovers are generally greater than those in models in which seasonality has not been removed.

The remainder of this chapter is organized into 5 sections: Section 3.2 explains the methodology employed; section 3.3 describes the data used, including summary statistics of them; section 3.4 presents the empirical results; and finally, section 3.5 concludes by summarizing the main results. 


\subsection{Flexible Fourier Form for deseasonalized volatility}

The intraday pattern in the volatility of financial market returns has an important impact on volatility modelling of high-frequency data. Two straightforward methods that consider the intraday pattern are as follows: a) a time-of-day volatility dummy is used for each return observation, or b) alternatively, the returns might be mean adjusted. Unfortunately, the first approach is generally over-parameterized and leads to inefficient estimations, and the second one is useless because the mean return is nearly zero (A\&B97; Andersen, 2000).

As A\&B97 highlight, the FFF is especially convenient to deal with this intraday seasonality. This approach involves polynomial methods that approximate the intraday periodic component by using linear polynomials regression and also Fourier methods, which consider sines and cosines to approximate the periodic intraday component.

The general framework for modelling high-frequency return volatility explicitly incorporates the effect of intraday periodicity. Concretely, the following decomposition for the intraday returns is considered:

$$
R_{t, n}=E\left(R_{t, n}\right)+\frac{\sigma_{t} S_{t, n} Z_{t, n}}{N^{1 / 2}}
$$

where $E\left(R_{t, n}\right)$ indicates the unconditional mean, $N$ indicates the number of return intervals per day, $S_{t, n}$ is the periodic component for the $n t h$ intraday interval, $\sigma_{t, n}$ is the conditional volatility factor for day $t$ and $Z_{t, n}$ is an i.i.d. mean zero, unit variance error term assumed to be independent of the daily volatility process. By taking squares on both sides and applying logarithmic transformations, it can be rewritten as

$$
\log \left(R_{t, n}^{2}\right)=\log \left(E\left[R_{t, n}\right]^{2}\right)+\log \left(\frac{\sigma_{t}^{2} s_{t, n}^{2} z_{t, n}^{2}}{N}\right)
$$

From equation (2), define

$$
X_{t, n} \equiv 2 \log \left[\operatorname{abs}\left(R_{t, n}-E\left(R_{t, n}\right)\right]-\log \sigma_{t}^{2}+\log N \equiv \log S_{t, n}^{2}+\right.
$$


The linear FFF regression modelling approach is then based on the ordinary least squares (OLS) regression of $X_{t, n} \equiv f\left(\theta ; \sigma_{t} ; n\right)+\varepsilon_{t, n}$, where the error term $\varepsilon_{t, n} \equiv \log \left(Z_{t, n}^{2}\right)-E\left(\log Z_{t, n}^{2}\right)$ is i.i.d mean zero, and $f\left(\theta_{t} ; \sigma_{t} ; n\right)$ takes the following parameterized form:

$$
\begin{gathered}
\log \left(S_{t, n}^{2}\right)=f\left(\theta ; \sigma_{t} ; n\right)=\sum_{j=0}^{J} \sigma_{t}^{j}\left[\mu_{0 j}+\mu_{1 j} \frac{n}{N_{1}}+\mu_{2 j} \frac{n^{2}}{N_{2}}+\sum_{i=1}^{D} \lambda_{i j} I_{n=d_{i}}+\right. \\
\left.\sum_{i=1}^{P}\left(\gamma_{p j} \cos \frac{p n 2 \pi}{N}+\delta_{p j} \sin \frac{p n 2 \pi}{N}\right)\right]
\end{gathered}
$$

where $N_{1}, N_{2}$ are normalizing constants defined as $N_{1}=(N+1) / 2 ; \quad N_{2}=$ $(N+1)(N+2) / 6$ and $I_{n=d_{i}}$ are dummy variables that capture irregularities in the seasonal pattern ${ }^{30}$. Additionally, if $\mathrm{J}>0$, the whole regression is multiplied by the daily volatility factor $\sigma_{t}^{j}$. In our empirical application, we follow A\&B97 and set $\mathrm{J}=1$, allowing the pattern to be a function of the daily volatility factor. The optimal value of the coefficient $\mathrm{P}$ is determined by means of Schwartz Information Criteria or Akaike information Criteria.

Additionally, according to Berument and Kiymaz (2001), knowing the volatility pattern of stock index returns by day of the week "may allow investors to adjust their portfolios by taking into account day of the week variations in volatility". Thus, to deepen the understanding of the seasonal volatility pattern and determine whether market volatility is the same or different for each day of the week, the intraday periodic component has been classified by weekday. Additionally, the expiration and maturity effects have also been studied ${ }^{32}$. To our knowledge, this is the first study to examine the day of the week (DOW) effect and the expiration and maturity effects on volatility by means of the intraday periodic component.

The DOW literature states that market participants behave in a different way depending on the day of the week. Consistent with the previous literature, results corroborate that there exists a DOW effect on market volatility for the three markets analysed for both the spot and the future stock index; moreover, the highest volatility is observed on Thursday and Friday, whereas the lowest volatility occurs on Monday (see, among others, Han et al., 1999; Kiymaz and Berument, 2003).

\footnotetext{
30Dummy variables have been considered for the 5 -interval minute in which volatility rises dramatically (three dummy variables for CAC40 and DAX30 at intervals 14:35, 14:40 and 16:05, and four dummy variables for FTSE100 at intervals 13:35, 13:40, 15:05 and 15:10).

31 We employ the widely used parametric $\operatorname{GARCH}(1,1)$ model to capture daily volatility. In most empirical applications, the GARCH $(1,1)$ is enough to reproduce the volatility dynamics of financial series, and thus the GARCH $(1,1)$ is the "workhorse" model for both academics and practitioners (Engle, 2001).

32 Dummy variables representing the day of the week and the expiration week have been introduced in the Fourier regression to identity the intraday periodic component for each day and for the expiration week.
} 
As far as the maturity effect ${ }^{33}$ is concerned, according to the Samuelson (1965) hypothesis, futures prices should increase as the futures contract approaches the expiration date. However, there is a wide range of literature that documents that the maturity effect in financial futures is weaker (Duong and Kalev, 2008). Related to the expiration effect, some studies suggest that stock market volatility tends to increase significantly when the expiration date of the futures contracts approach (see, among others, Stoll and Whaley, 1991); nevertheless, there are those that find the opposite results (Kan, 2001). Thus, the effect of the expiration of futures contracts on spot market volatility, the so-called expiration effect, is far from conclusive (Stoll and Whaley 1987, 1991; Hancock, 1993; Chow et al., 2003; Karolyi, 1996 among others). Our results suggest that there is a significant increase in the conditional variance of the stock index and the stock index future in the week of the expiration day for the three markets analysed ${ }^{34}$.

To consider these 3 effects (DOW, expiration and maturity), dummy variables representing these aspects have been included in the fourier regression as follows:

$$
\begin{gathered}
\log \left(S_{t, n}^{2}\right)=f\left(\theta ; \sigma_{t} ; n\right)=\sum_{j=0}^{J} \sigma_{t}^{j}\left[\mu_{0 j}+\mu_{1 j} \frac{n}{N_{1}}+\mu_{2 j} \frac{n^{2}}{N_{2}}+\sum_{i=1}^{D} \lambda_{i j} I_{n=d_{i}}+\right. \\
\left.\sum_{s} \gamma_{s} D_{s}+\sum_{x} \mu_{x} D_{x}+\sum_{i=1}^{P}\left(\gamma_{p j} \cos \frac{p n 2 \pi}{N}+\delta_{p j} \sin \frac{p n 2 \pi}{N}\right)\right]
\end{gathered}
$$

where variables $D_{s}$ represent dummy variables for each day of the week ${ }^{35}$, and variables $D_{x}$ are dummy variables for each expiration and maturity date ${ }^{36}$.

In order to implement the Fourier regression, a two-step procedure is applied: In the first stage, $\hat{X}_{t, n}$ is computed from equation (3). Then, $\hat{X}_{t, n}$ is considered as a dependent variable in the fourier regression (4.1), which is estimated by OLS.

Once $\widehat{f}\left(\hat{\theta} ; \sigma_{t} ; n\right)$ is calculated, the intraday periodic component $\widehat{S_{t, n}}$ for interval $n$ on day $t$, which provides a close approximation to the overall volatility patterns in each market, is retrieved as ${ }^{37}$ :

$$
\widehat{S_{t, n}}=\frac{T \cdot e\left(\widehat{f_{t, n}} / 2\right)}{\sum_{t=1}^{\left[\frac{T}{N}\right]} \sum_{n=1}^{N} e\left(\widehat{f_{t, n}} / 2\right)}
$$

\footnotetext{
33 The effect on the volatility of the future markets when the expiration date of futures contracts approaches.

${ }^{34}$ To keep this article to a reasonable length, results are not attached to this article, but they are available upon request.

35 Their role is to capture the daily effects by taking a value of 1 at each five-minute interval belonging to a trading day of the week (s=Monday, Tuesday, Wednesday, Thursday and Friday) and 0 otherwise.

36 These dummy variables capture the expiration and maturity effects by taking the value 1 at each five-minute interval belonging to a trading day of the expiration week and 0 otherwise. Additionally, the day before expiration and the week before expiration have also been considered in our analysis; the results are available upon request.

${ }^{37}$ For more details, see A\&B97.
} 
Finally, the standardized five-minute returns series are defined as follows:

$$
\widehat{R_{t, n}} \equiv R_{t, n} /\left(\widehat{\sigma_{t}} \widehat{S_{t}}\right)
$$

\subsection{Data: Descriptive statistic for raw and standardized data}

Our empirical data set comprises high-frequency observations on a five-minute interval basis of transaction prices from different markets, namely, CAC40, DAX30 and FTSE10038, for both the stock index and the index futures during the period from July 1, 2003 to September, $302015 .{ }^{39}$

Only data for the period of simultaneous operation of the spot market and future market are used in this study. Additionally, in order not to mislead the statistical inference, the first return of the trading day, 09:05 hour, which generally reflects the adjustment to overnight information and is regarded as the highest average return variability, is removed (Andersen et al., 2000).

Once data 40 have been cleaned, the continuously compounded returns are computed at each five-minute interval by taking the logarithms and subtracting the previous value. So, the five-minute raw returns $R_{t, n}$ at the $n-t h$ interval at day $t$ for $n=1,2 \ldots N$ and $t=1,2, \ldots T$ are computed as follows:

$$
R_{t, n}=100 \times \log \left(P_{t, n} \div P_{t-1, n}\right)
$$

where $P_{t, n}$ represents the spot $\left(S_{t, n}\right)$ and future $\left(F_{t, n}\right)$ price level on interval $n$ at day $t$.

Table 1 reports some summary statistics for raw $\left(R_{t, n}\right)$ and standardized returns $\left(\widehat{R_{t, n}}\right)$ on a five-minute interval basis. Note that returns are not normally

\footnotetext{
${ }^{38}$ Intraday data has been collected from Tick Data

39 The RV, computed as the sum of the squared intraday returns for the given trading day, would be an excellent estimate of the volatility in an ideal world in which prices were observed continuously and without measurement error (Merton, 1980). In this regard, the optimal intraday sampling frequency plays a critical role. The decision to use a five-minute frequency is based on the research of Andersen (2000), who highlights that "the five-minute frequency is about the highest at which properties of the return series are not seriously distorted by irregular quoting, the discreteness of prices, and the tendency of foreign-exchange dealers to position their quotes with a view toward inventory control".

${ }^{40}$ This leaves us with a sample of 3,055 trading days for CAC40, 3,070 trading days for DAX30 and 2,982 days for FTSE100. Each day consists of 101 intraday five-minute returns.
} 
distributed and mean returns for all markets are close to zero. Returns are characterized by statistically significant kurtosis, suggesting that the series are leptokurtic; that is to say, the series have fatter tails and higher peaks compared with a normal distribution; note that the Jarque-Bera test suggests that the returns are far from being normal.

As far as the first order autocorrelation coefficient AC (1) is concerned, it is small for returns for the three markets analysed; nonetheless, it increases considerably for absolute raw returns (which stand at approximately 0,3 as shown in Table 1), suggesting volatility persistence. Conversely, note that the AC (1) coefficient diminishes considerably for absolute standardized returns ${ }^{41}$.

${ }^{41}$ See previous section in which standardized returns are defined. Further on in this section the study of the absolute standardized returns will be addressed in depth. 
TABLE 1: Summary statistics results for raw and standardized returns

\begin{tabular}{|c|c|c|c|c|c|c|c|c|c|c|c|c|}
\hline & \multicolumn{4}{|c|}{ CAC40 } & \multicolumn{4}{|c|}{ DAX30 } & \multicolumn{4}{|c|}{ FTSE100 } \\
\hline & \multicolumn{2}{|c|}{ Spot } & \multicolumn{2}{|c|}{ Future } & \multicolumn{2}{|c|}{ Spot } & \multicolumn{2}{|c|}{ Future } & \multicolumn{2}{|c|}{ Spot } & \multicolumn{2}{|c|}{ Future } \\
\hline & $\begin{array}{l}\text { Raw } \\
\text { returns }\end{array}$ & $\begin{array}{l}\text { Standardized } \\
\text { returns }\end{array}$ & $\begin{array}{l}\text { Raw } \\
\text { returns }\end{array}$ & $\begin{array}{l}\text { Standardized } \\
\text { returns }\end{array}$ & $\begin{array}{l}\text { Raw } \\
\text { returns }\end{array}$ & $\begin{array}{l}\text { Standardized } \\
\text { returns }\end{array}$ & $\begin{array}{l}\text { Raw } \\
\text { returns }\end{array}$ & $\begin{array}{l}\text { Standardized } \\
\text { returns }\end{array}$ & $\begin{array}{l}\text { Raw } \\
\text { returns }\end{array}$ & $\begin{array}{l}\text { Standardized } \\
\text { returns }\end{array}$ & $\begin{array}{l}\text { Raw } \\
\text { returns }\end{array}$ & $\begin{array}{l}\text { Standardized } \\
\text { returns }\end{array}$ \\
\hline Mean $\left(10^{3}\right)$ & 0.1485 & -0.0494 & 0.0986 & 0.0005 & -0.1459 & -0.0169 & -0.1205 & 0.0140 & -0.2754 & 0.4296 & -0.2051 & -0.3425 \\
\hline $\begin{array}{l}\text { Standard } \\
\text { Deviation }\end{array}$ & 0.1069 & 0.0961 & 0.1078 & 0.9777 & 0.1106 & 0.0963 & 0.1100 & 0.0967 & 0.0917 & 0.0960 & 0.0921 & 0.0999 \\
\hline Skewness & -0.0820 & -0.1670 & -0.1250 & -0.1549 & -0.1416 & -0.3045 & -0.1027 & -0.3009 & -2.2980 & -0.1473 & 0.1502 & -0.1345 \\
\hline Kurtosis & 20.1962 & 14.0596 & 18.9137 & 15.9970 & 27.3136 & 17.2746 & 31.0580 & 21.6101 & 381.5737 & 14.0286 & 31.2606 & 13.4104 \\
\hline Minimum & -1.9756 & -2.6242 & -1.9309 & -2.7415 & -2.5480 & -3.1251 & -2.7321 & -3.5134 & -8.9585 & -2.5886 & -1.9973 & -2.7737 \\
\hline Maximum & 2.9889 & 2.1737 & 2.5160 & 2.6164 & 3.1769 & 2.0023 & 3.9045 & 2.5418 & 4.6610 & 2.2975 & 3.3360 & 2.0435 \\
\hline Jarque Bera & $3,802,141$ & $3,256,653$ & $1,573,980$ & $2,172,967$ & $7,638,433$ & $10,171,472$ & $2,637,329$ & $4,479,170$ & $1,798,799,271$ & $10,023,762$ & $1,527,450$ & $1,360,946$ \\
\hline $\mathrm{AC}(1)$ returns & -0.0052 & -0.0031 & -0.0191 & -0.0189 & -0.0151 & -0.0168 & -0.0154 & -0.0193 & 0.0080 & 0.0105 & -0.0144 & -0.0212 \\
\hline $\begin{array}{l}\operatorname{AC}(1) \text { absolute } \\
\text { returns }\end{array}$ & 0.3145 & 0.1716 & 0.3090 & 0.1721 & 0.3210 & 0.1707 & 0.3166 & 0.1740 & 0.3227 & 0.1638 & 0.3442 & 0.1697 \\
\hline
\end{tabular}

Table 1 shows the main summary statistics, the Jarque-Bera test for normality and the first-order autocorrelation coefficient (AC(1)) for the CAC40, DAX30 and FTSE100 index on a five-minute interval basis for both the spot and futures markets from July 1, 2003, to September 30, 2015. For each market, the statistical analysis has been implemented for raw returns $\left(R_{t, n}\right)$ and standardized returns $\left(\widehat{R_{t, n}}\right)$. Raw returns at the $n$ interval on day $t$ have been calculated as follows: $R_{t, n}=100 \times\left(\log P_{t, n} \div \log P_{t-1, n}\right)$, where, $P_{t, n}$ represents the spot $\left(S_{t, n}\right)$ and future $\left(F_{t, n}\right)$ price levels on interval $n$, at day $t$. Additionally, standardized returns have been computed as $\widehat{R_{t, n}} \equiv R_{t, n} /\left(\widehat{\sigma_{t}} \widehat{S_{t}}\right)$, where $\sigma_{t, n}$ is the conditional volatility factor for day $t$ and $S_{t, n}$ is the periodic component for the $n t h$ intraday interval. 
As has been underlined by A\&B97 an appropriate intraday dynamic analysis requires computing and extracting the intraday periodic component of return volatility. Thus, following these authors and in view of the AC (1) results, the next step is to evaluate whether there are intraday patterns in our data. To do so, the intraday average absolute returns for each five-minute interval are depicted in Plot 1. Whereas it is notable that the intraday average returns are centred on zero with little clear evidence for any systematic pattern ${ }^{42}$, Plot 1 reveals that the volatility dynamic of high-frequency spot and future returns, often estimated as the average of the absolute returns during a time interval, is characterized by remarkable intraday patterns.

42 To keep this article to a reasonable length the intraday average returns plot is not attached to this document. It is available upon request. 
PLOT 1: Mean absolute returns for CAC40, DAX30 and FTSE100 indexes

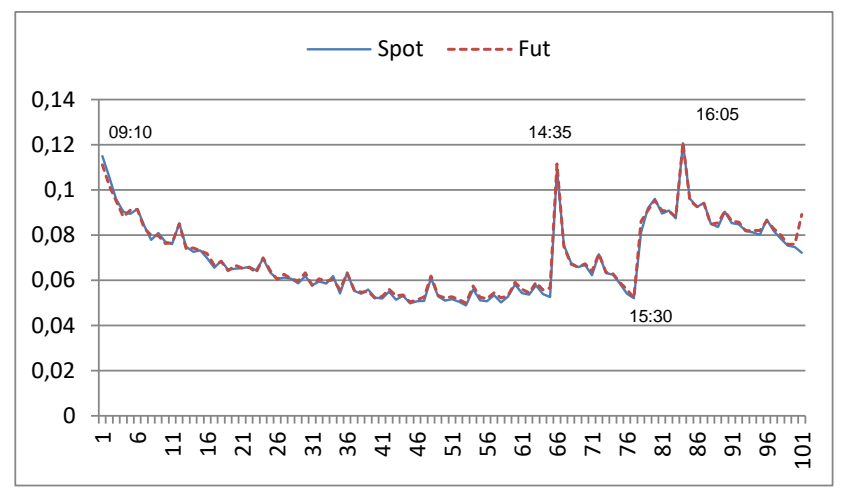

SUBPLOT 1.1: Mean absolute returns for CAC40

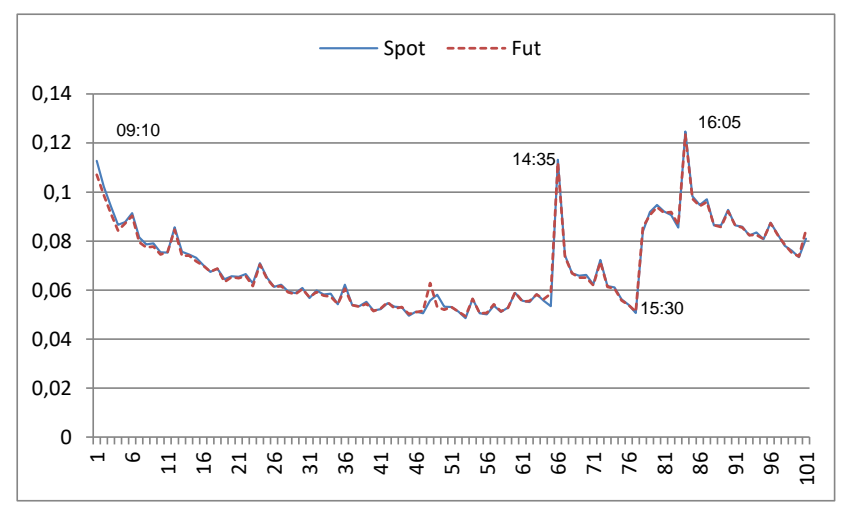

SUBPLOT 1.2: Mean absolute returns for DAX30

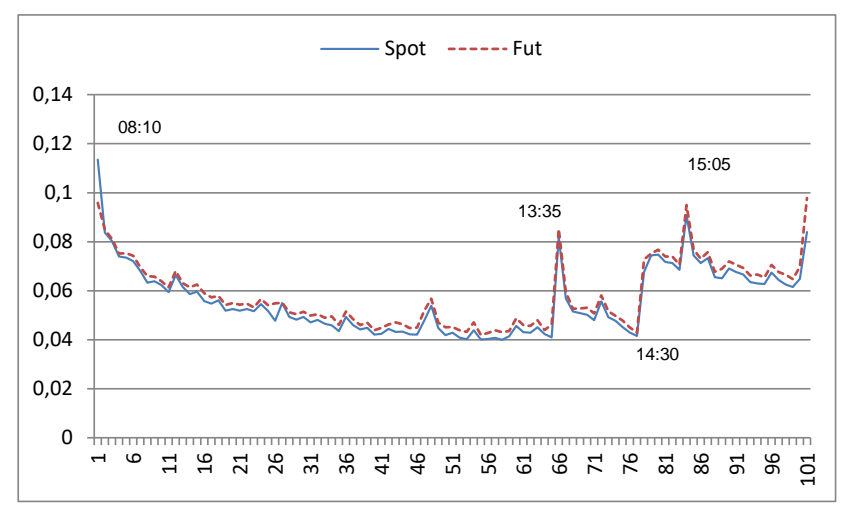

\section{SUBPLOT 1.3: Mean absolute returns for FTSE100}

Plot 1 reports the five-minute average absolute returns during a trading day for the stock index and the stock index futures of CAC40 (subplot 1.1), DAX30 (subplot 1.2) and FTSE100 (subplot 1.3) during the period from July 1, 2003, to September 30, 2015, for a total of 308,555, 310,070 and 301,182 observations for CAC40, DAX30 and FTSE100, respectively. The horizontal axis represents the number of five-minute intervals in a trading day. There are 101 intervals per day; thus, observation 1 corresponds to 09:10 for CAC40 and DAX30 indexes and 8:10 for FTSE100, and observation 101 corresponds to 17:30 for CAC40 and DAX30 indexes and 16:30 for FTSE100. The vertical axis represents the mean absolute returns. These plots provide evidence of the presence of seasonal structures in our intraday data. 
A widely known stylized fact about the intraday statistical features of many financial markets is that volatility is higher at the opening and closing of the trading day and lower in the middle (see, among others, Wood et al, 1985; Harris, 1986 and Tse, 1999). This strong intraday periodicity in the average absolute returns is hereby confirmed by Plot 1 . Note an observable repetitive pattern each day for all markets in which remarkable similarities can be appreciated. However, they do not present the conventional intraday U-pattern; instead, they suggest a distorted double U-shape pattern in the sample autocorrelations, which occupies precisely one day. All markets show a decaying pattern in intraday volatility until 14:30 (which corresponds to the interval 65 in plot 1). At 14:35 (interval 66), return volatility increases considerably and then declines until 15:30 (interval 77), a point at which a remarkable increment occurs again and remains relatively high until 17:30, reaching its maximum peak at 16:05 (interval 84) ${ }^{43}$. This pattern is similar to that found by Harju and Hussain (2011) for the major European equity markets, that is to say, CAC40, FTSE100, SMI and DAX 30 indexes, from 1 September 2000 to 31 March 2006. They identify a periodic pattern in the intraday volatilities that resembles a $\mathrm{W}$, and find evidence that US macroeconomic announcements $^{44}$ at 14:30 and 16:05, and the NYSE cash market opening time at 15:30 have cross border impacts on European equity volatilities.

After corroborating evidence of intraday periodicities in return volatility and the noticeable repetitive pattern in the 10-day autocorrelogram for the absolute returns, we implement the FFF and compute the intraday periodic component, $\widehat{S_{t, n}}$. Once the intraday periodic component has been estimated, standardized fiveminute returns are computed using equation (6).

${ }^{43}$ Notice that for the FTSE100 index this pattern occurs an hour earlier due to the different time zones.
${ }^{44}$ Such as, Producer Price Index, Retail Sales, Consumer Price Index, Consumer Confidence, etc. 


\section{PLOT 2: Autocorrelogram for raw and standardized five-minute intraday absolute returns}

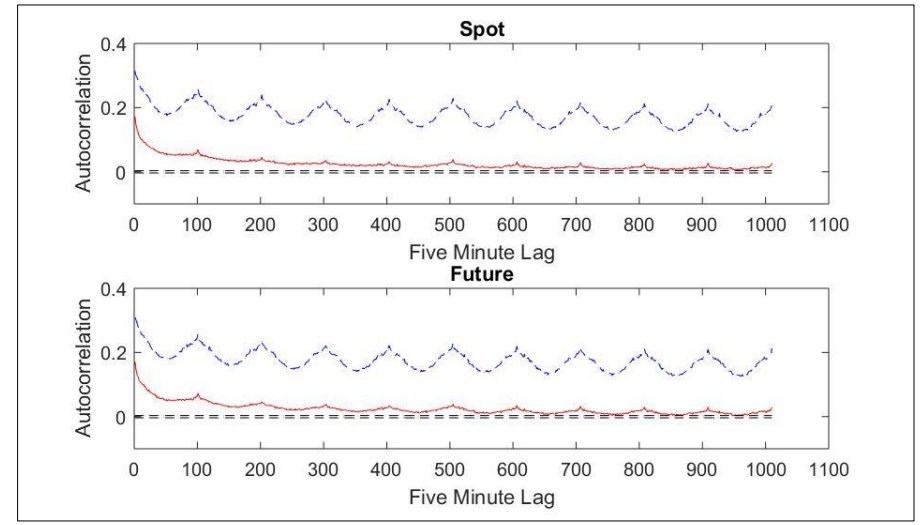

SUBPLOT 2.1: CAC40

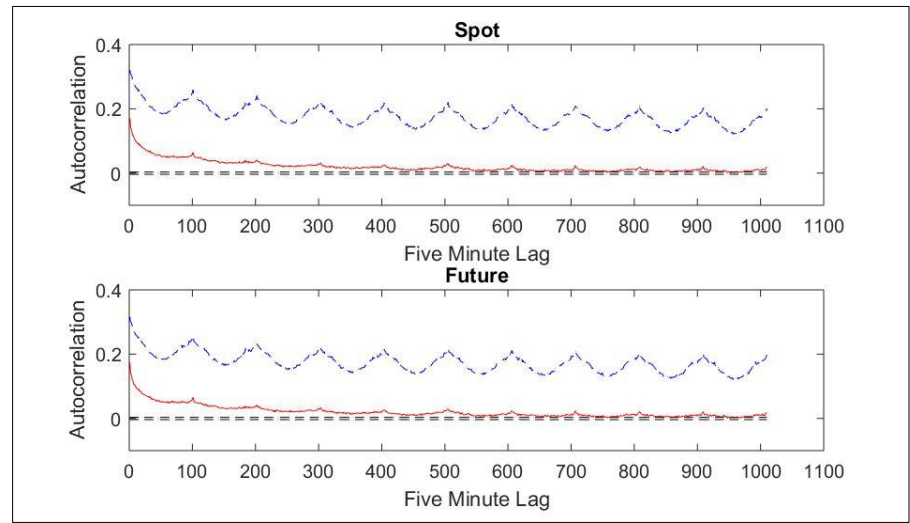

SUBPLOT 2.2: DAX30

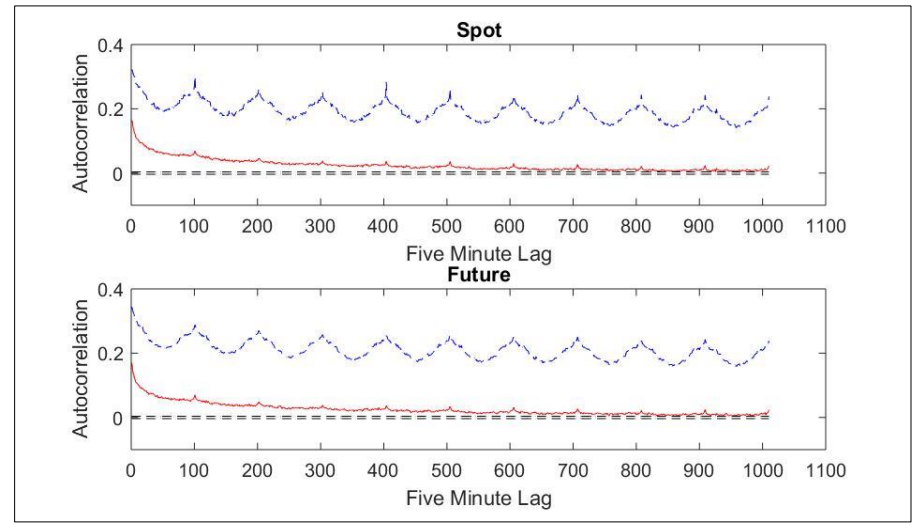

SUBPLOT 2.3: FTSE100

Plot 2 shows the autocorrelation pattern for the raw (dashed line) and standardized (solid line) five-minute absolute index returns up to a lag of 1,010 (10 days with 101 intervals of five minutes per day). In each subplot, the autocorrelogram for the index stock is depicted at the top, and the autocorrelogram for the index stock future is depicted at the bottom. The sample period extends from July 1,2003 , to September 30,2015 , for a total of $308,555,310,070$ and 301,182 observations for CAC40, DAX30 and FTSE100, respectively. The horizontal axis represents the lag length, and the vertical axis represents the magnitude of the autocorrelation coefficient. 
Plot 2 depicts the autocorrelogram for the absolute returns (the dashed line) and absolute standardized returns (the solid line) considering a maximum lag length of 10 trading days. The periodic volatility pattern across each trading day, whose origin is the intraday seasonality illustrated in Plot 1 , is clearly illustrated by the autocorrelation structure of absolute returns, and it reveals the importance of considering the intraday seasonal component of the volatility and the hazard of straightforward ARCH modelling of intraday return volatility (A\&B97). As can be appreciated in Plot 2, after standardizing the data, the periodic dependencies have been considerably reduced, and there is a significant decay in the serial autocorrelation. From observation 600-700 (approximately 1 week) onwards, autocorrelation is close to zero for the spot and futures market and for the three indexes surveyed (see the solid line in subplots 2.1, 2.2 and 2.3). Therefore, it can be inferred that the FFF significantly reduces the intraday seasonality. Furthermore, to comprehensively understand financial market performance and model volatility dynamics, the analysis of cross-correlations between assets is highly relevant. Previous research has documented significant cross-correlations between spot and futures market returns (see, among others, Kawaller et al., 1987; Herbst et al., 1987; Brooks et al., 1999). At this stage, it is important to analyse the differences in the degree of cross-correlation between spot and futures markets considering both raw and standardized returns in a similar way to the analysis implemented in plot 2. Thus, consider now the five-minute intraday absolute returns (dashed line) and the five-minute intraday absolute standardized returns (solid line) cross-correlations between the spot and futures markets up to ten days depicted in Plot 3. 
PLOT 3: Cross-correlations for raw and standardized five-minute intraday absolute returns

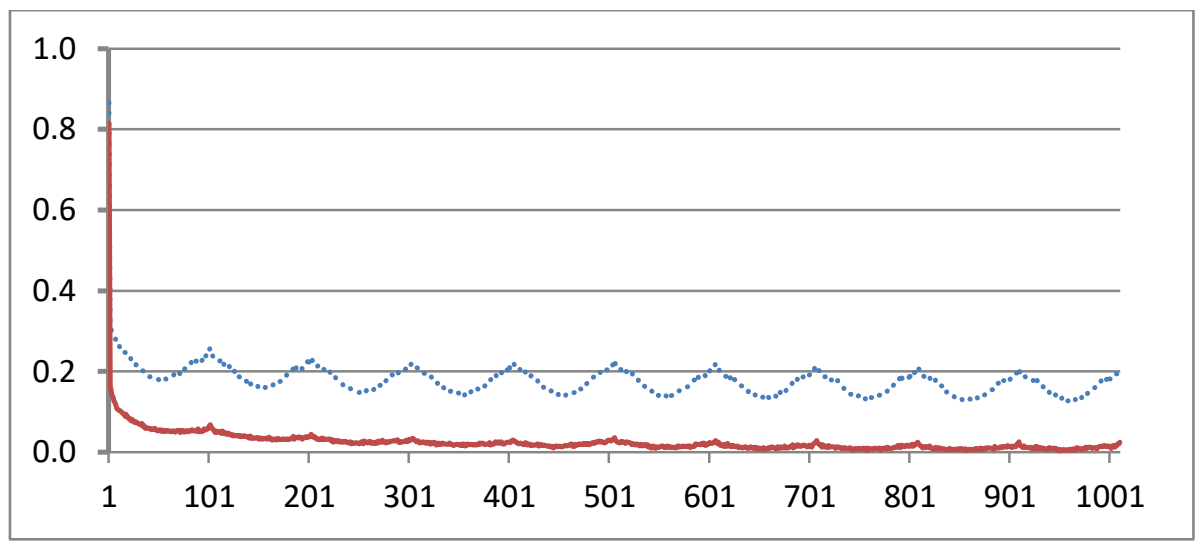

Subplot 3.1 Cross-correlations for raw and standardized absolute returns for CAC40 index

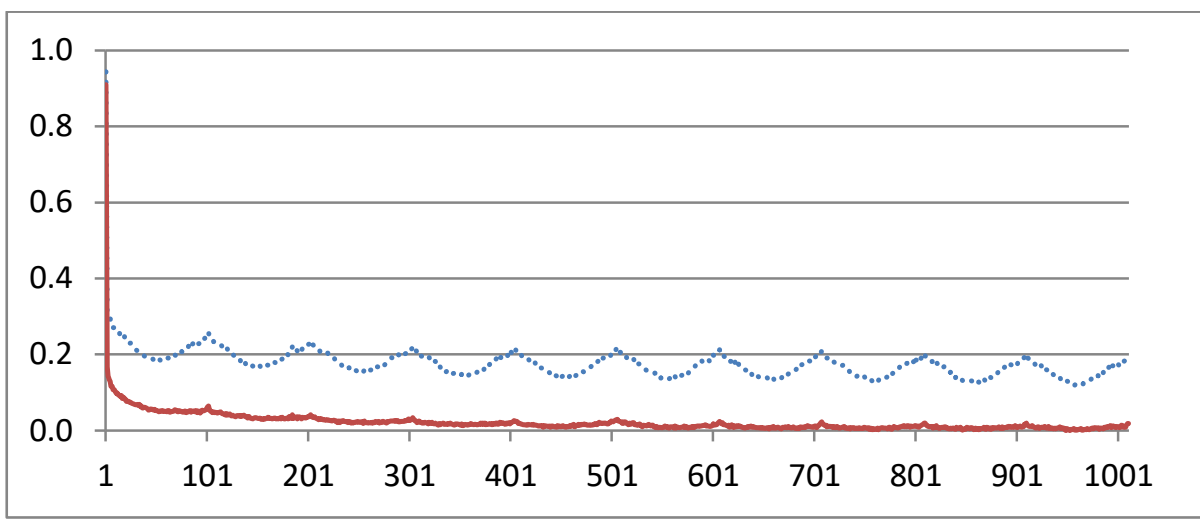

Subplot 3.2 Cross-correlations for raw and standardized absolute returns for DAX30 index

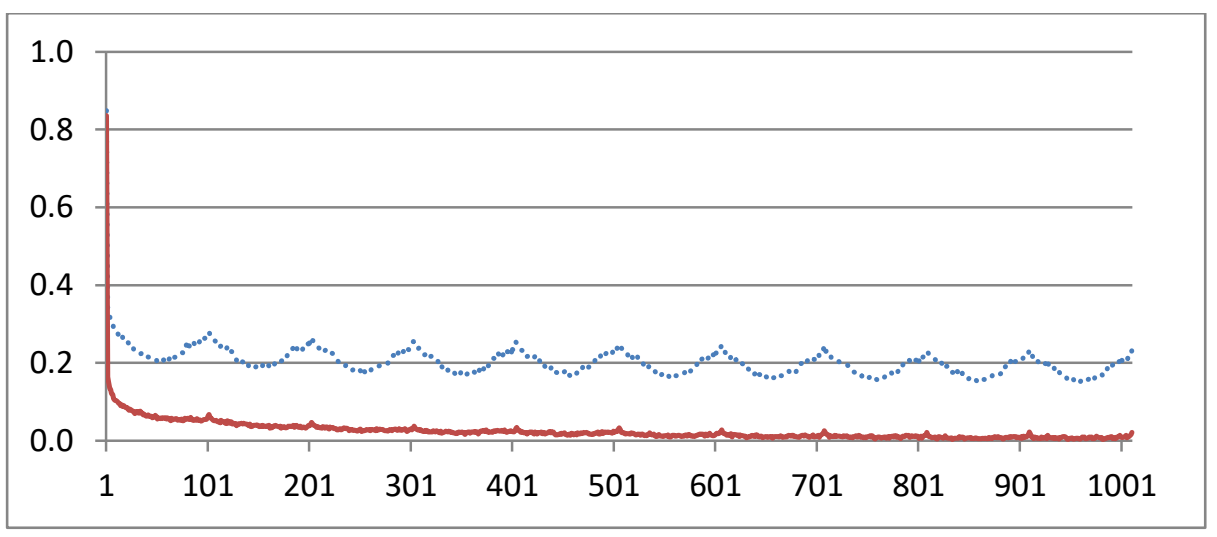

Subplot 3.3 Cross-correlations for raw and standardized absolute returns for FTSE100 index

Plot 3 depicts the cross-correlations for five-minute intraday absolute returns between the stock index and the stock index futures up to ten days for raw (dashed line) and standardized returns (solid line) for the CAC40, DAX30 and FTSE100 indexes, up to a lag length of 1,010 or 10 trading days (101 five-minute intervals per day). The sample period extends from July 1, 2003 to September, 302015 for a total of 308,555, 310,070 and 301,182 observations for CAC40, DAX30 and FTSE100 respectively. The horizontal axis represents the lag length, and the vertical axis the magnitude of the cross-correlation coefficient. 
Note that the dashed line reveals a similar pattern detected in the 10-day autocorrelogram for the absolute returns (see Plot 2), suggesting the presence of significant cross-market volatility interactions between the spot and futures market. All markets show a U-pattern correlogram each trading day. Crosscorrelations increase at the beginning of the day $(0.30$ for CAC40, 0.31 for DAX30 and 0.33 for FTSE100), then decline until 12:15 approximately $(0.12$ for CAC40, and DAX30 and 0.15 for FTSE100), the point at which an increment occurs again and remains relatively high until 17:30. As we expected after standardizing the returns, it can be appreciated in Plot 3 (solid line) that cross-correlations for standardized absolute returns have been steadily reduced and remain relatively constant during the trading day ( 0.02 for the three indexes). This finding is consistent with results obtained by Kofman and Martens (1997) and underscores, once more, the importance of considering seasonalities present in high-frequency data; otherwise, significant bias in the second moment causality analysis might be introduced.

The conclusions reached in this section highlight significant differences, particularly a noticeable reduction in correlation, either in the autocorrelation or in the cross-correlation when considering raw or standardized data. These findings lead us to conjecture that remarkable differences might be encountered in the results of studies regarding volatility spillover and certainly in the response to a shock on volatility through the Impulse Response Function.

\subsection{Empirical Results: Volatility transmission, Impulse Response Function and Directional Measurement of Volatility Spillovers.}

Based on the results reached so far, in section 3.4.1, we investigate the daily volatility transmission by using the widely known bivariate vector autoregressive model (VAR) and the consequences of the presence of seasonality in the volatility spillover analysis when using high-frequency data. Additionally, in section 3.4.2, an impulse response analysis is implemented to deepen the understanding of volatility transmission. Finally, in section 3.4.3 we use the spillover index approach proposed by Diebold and Yilmaz (2012) to measure the net pairwise volatility spillovers among the spot and futures markets of the CAC40, DAX30 and FTSE100 indexes. 


\subsubsection{Volatility transmission}

Ross (1989) suggests that the volatility of an asset is directly related to the rate of information flow in a market. Because information flow is the core of risk management and asset pricing, it is crucial to fully understand volatility dynamics and the way in which volatility is transmitted across markets. Sims (1980) first introduced the vector autoregressive (VAR); from then on, these models have become one of the most widely used methodologies in the fields of macroeconomics and financial economics to analyse the existence of volatility spillover effects between two markets.

In this section, we use the following bivariate model to examine the way in which spot and futures markets interact through their second moments.

$$
\begin{aligned}
& V_{s, t}=\alpha_{s}+\sum_{i=1}^{k} \beta_{s s, i} V_{s, t-i}+\sum_{i=1}^{k} \beta_{s f, i} V_{f, t-i}+\varepsilon_{s, t} \\
& V_{f, t}=\alpha_{f}+\sum_{i=1}^{k} \beta_{f s, i} V_{s, t-i}+\sum_{i=1}^{k} \beta_{f f, i} V_{f, t-i}+\varepsilon_{f, t}
\end{aligned}
$$

where $\boldsymbol{V}_{\boldsymbol{s}, \boldsymbol{t}}, \boldsymbol{V}_{\boldsymbol{f}, \boldsymbol{t}}$ and $\boldsymbol{V}_{\boldsymbol{s}, \boldsymbol{t}-\boldsymbol{i}}, \boldsymbol{V}_{\boldsymbol{f}, \boldsymbol{t}-\boldsymbol{i}}$ are the contemporaneous spot and futures daily volatilities and the lagged spot and futures daily volatilities, respectively; $\boldsymbol{\alpha}_{\boldsymbol{s}}$ and $\boldsymbol{\alpha}_{f}$ represent the unconditional spot and future market daily volatilities; coefficients $\beta_{s s, i}, \beta_{s f, i}, \beta_{f s, i}, \beta_{f f, i}$ are the parameters accompanying the lagged daily volatilities and $\varepsilon_{s t}$ and $\varepsilon_{f t}$ are the residuals in the spot and futures volatility equations. Our focus is on the consequences of ignoring or considering the periodic intraday component on the study of volatility transmission. First, we analyse the effects on volatility transmission when the intraday seasonality is neglected. To do so, we perform a VAR estimation employing the following input data: a) daily volatilities computed using raw returns and the GARCH $(1,1)$ model (namely, VAR A) ${ }^{45}$ and b) daily realized volatilities using raw returns (namely, VAR B) ${ }^{46}$. Then, the importance of removing the seasonal component to reduce the risk of spurious causality in the analysis of volatility spillovers is evaluated by c) estimating the VAR model using daily realized volatilities computed with standardized returns (namely, VAR C) ${ }^{47}$.

45 First, daily returns, $R_{t}$, have been computed by adding the five-minute returns $R_{t, n}$ in each day, that is to say, $R_{t}=\sum_{n=1}^{N} R_{t, n}$. Then, daily volatilities have been calculated using a GARCH $(1,1)$ model.

46 Realized volatility, $R V_{t}$, is computed as the sum of squared intraday returns; thus, $R V_{t}=\sum_{n=1}^{N} R_{t, n}^{2}$.

47 Realized volatility computed using the standardized returns $\left(\overline{V R_{t}}\right)$ is described as the sum of squared intraday standardized returns $\quad \widehat{V R_{t}}=\sum_{n=1}^{N} \widehat{R_{t, n}^{2}}$ 
TABLE 2: Parameter estimates of the bivariate Vector Autoregressive model (VAR)

\begin{tabular}{|c|c|c|c|c|c|c|c|c|c|c|}
\hline & & \multicolumn{3}{|c|}{ CAC40 } & \multicolumn{3}{|c|}{ DAX30 } & \multicolumn{3}{|c|}{ FTSE100 } \\
\hline & & VAR A & VAR B & VAR C & VAR A & VAR B & VAR C & VAR A & VAR B & VAR C \\
\hline & & $\begin{array}{c}\text { Raw } \\
\text { GARCH }\end{array}$ & $\begin{array}{c}\text { Raw } \\
\text { RV }\end{array}$ & $\begin{array}{c}\text { Standardized } \\
\text { RV }\end{array}$ & $\begin{array}{c}\text { Raw } \\
\text { GARCH }\end{array}$ & $\begin{array}{c}\text { Raw } \\
\text { RV }\end{array}$ & $\begin{array}{c}\text { Standardized } \\
\text { RV }\end{array}$ & $\begin{array}{c}\text { Raw } \\
\text { GARCH }\end{array}$ & $\begin{array}{c}\text { Raw } \\
\text { RV }\end{array}$ & $\begin{array}{c}\text { Standardized } \\
\text { RV }\end{array}$ \\
\hline Intercept & $\alpha_{s}$ & $0.0291^{*}$ & $0.1393^{*}$ & $0.6261^{*}$ & $0.0305^{\star}$ & $0.0678^{*}$ & $0.6136^{*}$ & $0.0207^{\star}$ & -0.0693 & $0.5041^{\star}$ \\
\hline Intercept & $\alpha_{f}$ & $0.0316^{*}$ & $0.1296^{\star}$ & $0.6589^{\star}$ & $0.0343^{*}$ & $0.1233^{\star}$ & $0.6190^{*}$ & $0.0237^{*}$ & $0.0750^{\circ}$ & $0.5449^{*}$ \\
\hline \multirow[t]{4}{*}{$A R(1)$} & $\beta_{\mathrm{ss}, 1}$ & $0.9168^{*}$ & $0.1030^{\star}$ & $0.4581^{*}$ & $0.2320^{*}$ & $0.1243^{\star}$ & $0.3531^{*}$ & $1.0720^{\star}$ & $0.2155^{\circ}$ & $0.5128^{\star}$ \\
\hline & $\beta_{\mathrm{sf}, 1}$ & 0.0345 & $0.3482^{*}$ & $-0.1948^{\star}$ & $0.6987^{\star}$ & $0.3651^{\star}$ & -0.0960 & $-0.1529^{*}$ & -0.0619 & $-0.2105^{\star}$ \\
\hline & $\beta_{\mathrm{fs}, 1}$ & 0.0538 & 0.0886 & $0.3478^{\star}$ & $-0.5232^{*}$ & $0.1036^{\star}$ & $0.3288^{*}$ & $-0.0372^{\star}$ & -0.0689 & $0.3211^{*}$ \\
\hline & $\beta_{\mathrm{ff}, 1}$ & $0.9015^{*}$ & $0.3768^{*}$ & -0.0873 & $1.452^{\star}$ & $0.3846^{*}$ & -0.0623 & $0.9789^{\star}$ & $0.4821^{\circ}$ & -0.0130 \\
\hline \multirow[t]{4}{*}{$A R(2)$} & $\beta_{\mathrm{ss}, 2}$ & $0.8747^{\star}$ & $0.2013^{\star}$ & 0.0017 & $0.4704^{\star}$ & -0.0147 & $0.2252^{*}$ & $-0.1387^{*}$ & -0.2336 & $-0.1918^{\star}$ \\
\hline & $\beta_{\mathrm{sf}, 2}$ & $-0.8738^{*}$ & -0.0851 & 0.0720 & $-0.3821^{*}$ & $0.4027^{*}$ & -0.1354 & $0.1983^{*}$ & $1.3680^{\circ}$ & $0.2898^{\star}$ \\
\hline & $\beta_{\mathrm{fs}, 2}$ & $0.5632^{\star}$ & 0.0664 & -0.1096 & $0.5502^{\star}$ & -0.0625 & 0.1789 & $0.1008^{\star}$ & $0.0463^{\circ}$ & $-0.1934^{*}$ \\
\hline & $\beta_{\mathrm{ft}, 2}$ & $-0.5797^{\star}$ & 0.0509 & $0.1747^{*}$ & $-0.4684^{*}$ & $0.3354^{*}$ & -0.9722 & $-0.1140^{*}$ & $0.2859^{\circ}$ & $0.2967^{\star}$ \\
\hline \multirow[t]{4}{*}{$A R(3)$} & $\beta_{\mathrm{ss}, 3}$ & $-0.7459^{*}$ & $0.2581^{*}$ & & $0.4027^{*}$ & -0.0490 & & $0.1558^{*}$ & -0.0166 & 0.0590 \\
\hline & $\beta_{\mathrm{st}, 3}$ & $0.7691^{*}$ & $-0.3257^{*}$ & & $-0.4469^{*}$ & $-0.1998^{*}$ & & $-0.1522^{*}$ & $-0.1510^{*}$ & -0.0574 \\
\hline & $\beta_{\mathrm{fs}, 3}$ & $-0.5108^{*}$ & $0.2416^{*}$ & & $0.2241^{*}$ & -0.0762 & & $0.0955^{\star}$ & -0.0770 & -0.0331 \\
\hline & $\beta_{\mathrm{ff}, 3}$ & $0.5449^{*}$ & $-0.3263^{*}$ & & $-0.2641^{*}$ & $-0.1345^{*}$ & & -0.0283 & 0.0235 & 0.0298 \\
\hline \multirow[t]{4}{*}{$\operatorname{AR}(4)$} & $\beta_{\mathrm{ss}, 4}$ & & $0.4011^{*}$ & & & -0.1836 & & 0.0235 & $0.3320^{\circ}$ & 0.0733 \\
\hline & $\beta_{\mathrm{sf}, 4}$ & & $-0.2431^{*}$ & & & $0.2173^{*}$ & & -0.0550 & -0.4478 & -0.0425 \\
\hline & $\beta_{\mathrm{fs}, 4}$ & & $0.3591^{*}$ & & & $-0.2218^{*}$ & & $-0.1624^{*}$ & 0.1726 & -0.0217 \\
\hline & $\beta_{\mathrm{ff}, 4}$ & & $-0.2435^{\star}$ & & & $0.2774^{\star}$ & & $0.0817^{\star}$ & -0.1878 & 0.0447 \\
\hline \multirow[t]{4}{*}{$A R(5)$} & $\beta_{\mathrm{ss}, 5}$ & & -0.0929 & & & $-0.1935^{\star}$ & & $-0.1005^{\star}$ & -0.0141 & $0.2953^{*}$ \\
\hline & $\beta_{\mathrm{st}, 5}$ & & $0.2551^{*}$ & & & $0.2653^{\star}$ & & $0.2499^{\star}$ & $0.1688^{\circ}$ & $-0.2553^{*}$ \\
\hline & $\beta_{\mathrm{ts}, 5}$ & & $-0.1508^{*}$ & & & $-0.1593^{*}$ & & 0.0201 & -0.0419 & $0.2241^{*}$ \\
\hline & $\beta_{\mathrm{ff}, 5}$ & & $0,3531^{*}$ & & & $0.2551^{\star}$ & & $0.1185^{\star}$ & $0.1688^{\circ}$ & $-0.1849^{*}$ \\
\hline \multirow[t]{4}{*}{$A R(6)$} & $\beta_{\mathrm{ss}, 6}$ & & $0.1937^{\star}$ & & & -0.0618 & & $-0.1050^{*}$ & $-0.1903^{*}$ & -0.1576 \\
\hline & $\beta_{\mathrm{st}, 6}$ & & $-0.2183^{*}$ & & & $0.1200^{\star}$ & & -0.0102 & $0.1229^{\circ}$ & 0.1495 \\
\hline & $\beta_{\mathrm{ts}, 6}$ & & $0.2522^{\star}$ & & & 0.0163 & & -0.0078 & -0.1134 & $-0.2521^{*}$ \\
\hline & $\beta_{\mathrm{ff}, 6}$ & & $-0.2473^{*}$ & & & 0.0808 & & -0.0302 & 0.1584 & $-0.2395^{\star}$ \\
\hline \multirow[t]{4}{*}{$\operatorname{AR}(7)$} & $\beta_{\mathrm{ss}, 7}$ & & -0.0852 & & & $0.1118^{*}$ & & $0.1760^{\star}$ & -0.0918 & 0.0375 \\
\hline & $\beta_{\mathrm{sf}, 7}$ & & 0.1105 & & & 0.0373 & & $-0.2607^{*}$ & 0.0712 & -0.0303 \\
\hline & $\beta_{\mathrm{ts}, 7}$ & & -0.0144 & & & $0.1322^{\star}$ & & $0.1713^{*}$ & -0.0485 & -0.0740 \\
\hline & $\beta_{\mathrm{ff}, 7}$ & & 0.0141 & & & -0.0312 & & $-0.2670^{*}$ & $0.1119^{\circ}$ & 0.0733 \\
\hline \multirow[t]{4}{*}{$A R(8)$} & $\beta_{\mathrm{ss}, 8}$ & & $-0.1840^{*}$ & & & 0.0662 & & $-0.2796^{*}$ & & \\
\hline & $\beta_{\mathrm{sf}, 8}$ & & $0.2420^{\star}$ & & & -0.0921 & & $0.3932^{\star}$ & & \\
\hline & $\beta_{\mathrm{ts}, 8}$ & & -0.1386 & & & 0.0067 & & $-0.2590^{*}$ & & \\
\hline & $\beta_{\mathrm{ft}, 8}$ & & $0.2203^{*}$ & & & $-0.0965^{\star}$ & & $0.3564^{*}$ & & \\
\hline \multirow[t]{4}{*}{ AR(9) } & $\beta_{\mathrm{ss}, 9}$ & & & & & $-0.1446^{*}$ & & $0.1872^{*}$ & & \\
\hline & $\beta_{\mathrm{st}, 9}$ & & & & & 0.0218 & & $-0.2260^{*}$ & & \\
\hline & $\beta_{\mathrm{ts}, 9}$ & & & & & $-0.1267^{*}$ & & $0.1198^{*}$ & & \\
\hline & $\beta_{\mathrm{ft}, 9}$ & & & & & 0.0482 & & $-0.1686^{\star}$ & & \\
\hline \multirow[t]{4}{*}{$\operatorname{AR}(10)$} & $\beta_{\mathrm{ss}, 10}$ & & & & & 0.0114 & & & & \\
\hline & $\beta_{\mathrm{st}, 10}$ & & & & & $0.1555^{\star}$ & & & & \\
\hline & $\beta_{\mathrm{fs}, 10}$ & & & & & 0.0279 & & & & \\
\hline & $\beta_{\mathrm{ff}, 10}$ & & & & & $0.1444^{*}$ & & & & \\
\hline BIC & & $-10,745$ & 11,1138 & 5,685 & $-8,541$ & 16,423 & 5,040 & $-2,478$ & 18,627 & 6,613 \\
\hline \multicolumn{2}{|c|}{ Number of lags } & 3 & 8 & 2 & 3 & 10 & 2 & 9 & 7 & 7 \\
\hline
\end{tabular}

The * denotes significance at 0.05 .

Table 2 presents the results of the bivariate VAR

$$
\begin{gathered}
V_{s, t}=\alpha_{s}+\sum_{i=1}^{k} \beta_{s s, i} V_{s, t-i}+\sum_{i=1}^{k} \beta_{s f, i} V_{f, t-i}+\varepsilon_{s, t} \text { Spot Equation } \\
V_{f, t}=\alpha_{f}+\sum_{i=1}^{k} \beta_{f s, i} V_{s, t-i}+\sum_{i=1}^{k} \beta_{f f, i} V_{f, t-i}+\varepsilon_{f, t} \quad \text { Future Equation }
\end{gathered}
$$

where $\boldsymbol{V}_{s, t}, \boldsymbol{V}_{\boldsymbol{f}, \boldsymbol{t}}$ and $\boldsymbol{V}_{\boldsymbol{s}, \boldsymbol{t}-\boldsymbol{i}}, \boldsymbol{V}_{\boldsymbol{f}, \boldsymbol{t}-\boldsymbol{i}}$ are the contemporaneous spot and futures daily volatility and the lagged spot and futures daily volatilities, respectively; $\boldsymbol{\alpha}_{\boldsymbol{s}}$ and $\boldsymbol{\alpha}_{f}$ represent the unconditional daily volatility; coefficients $\beta_{s s, i}, \beta_{s f, i}, \beta_{f s, i}, \beta_{f f, i}$ are the parameters accompanying the lagged daily volatilities; and $\varepsilon_{s t}$ and $\varepsilon_{f t}$ are the residuals in the spot and futures volatility equations, respectively. The lag length has been set by means of the AIC/BIC criteria. This VAR model has been implemented by employing the following data: 1) daily volatilities computed using raw returns and the GARCH [1, 1] model (named VAR A), 2) realized volatilities using raw returns (named VAR B); and 3) realized volatilities computed with standardized returns (named VAR C). The estimated coefficients are displayed in the first, second and third columns respectively for each index. 
Table 2 displays some remarkable results from the estimations of the VAR A, VAR $\mathrm{B}$ and the VAR C models ${ }^{48}$.

As far as the VAR A model is concerned, note in table 2 that parameters accompanying the lagged spot and future volatilities in the spot and future equation $\left(\beta_{s s, i}, \beta_{s f, i} \beta_{f s, i}, \beta_{f f, i}\right)$ are significant until lag 3 for the CAC40 and DAX30 index and until lag 9 for the FTSE100 index. The results show that contemporaneous volatility returns are affected by their own lagged return volatility and by the lagged return volatility of the other market. Therefore, there exists significant bidirectional volatility spillover for the three indexes studied; that is to say, the most recent innovations in one market are quickly transmitted and affect the volatility of the other market. These results are in good agreement with previous results (Chan et al., 1991; Abhyankar, 1995; Fung et al., 2004 among others).

Regarding the VAR B model, two fundamental aspects should be highlighted: a) It is the model that includes more significant lags on the whole: 8 lags for the CAC40 index, 10 lags for the DAX 30 and 7 lags for the FTSE100 index; and b) the dynamic interaction between the spot and futures markets through their second moments is also bilateral. Nevertheless, when dealing with high-frequency data, it should not be neglected that the intraday repetitive pattern in average absolute returns may induce bias in the estimation of volatility transmission. Any study that analyses assets return volatility using intraday data should consider the strong intraday seasonality exhibited by the data (A\&B97); therefore, we finally estimate in this section the VAR model using RV with standardized returns (VAR C model).

Note that in the VAR C model, there is bidirectional volatility transmission for the CAC40 and FTSE100 indexes, whereas volatility transmission runs from the spot to the futures market for the DAX3049. Additionally, as we expected, it is the VAR C model that has less significant lags: 2 lags for the CAC40 and DAX30 index and 6 lags ${ }^{50}$ for the FTSE100 index. Note that in all markets, the models with more lags are the VAR A or the VAR B, that is to say, those models that do not consider the intraday periodic component. ${ }^{51}$ The most likely explanation of this finding is that the repetitive pattern in the autocorrelogram for the absolute returns (dashed lines in Plot 2) makes some endogenous variables redundant in equation (8); therefore, this outcome may be indicative of the presence of spurious causality in the models VAR A and VAR B.

Certainly, one of the best ways to fully understand how volatility shocks in one market affect the volatility of the other market is to invert the system in order to

\footnotetext{
${ }^{48}$ The optimal lag length for each bivariate VAR model has been set by means of the AIC/BIC criteria.

49 Thus, although results from VAR A, B and C suggest that volatility transmission is mostly bidirectional, they are not conclusive. This finding is in line with Kawaller et al.,1990 and Abhyankar 1995.

${ }^{50}$ Note that lag 7 is statistically insignificant for the FTSE100 index.

${ }^{51}$ Although for the FTSE100 index the lag length of the VAR B and the VAR C model is the same, note that there are more significant parameters in the VAR B model.
} 
express volatilities as a function of all past shocks emanating from both markets, that is to say, by means of the Impulse response function that will be further explained in the next section.

\subsubsection{Impulse response function}

Since the seminal contribution by Sims (1980), the dynamic interaction between the variables and the disturbances in vector autoregressive models (VARs) has been widely analysed using the impulse response methodology 52 . The Impulse response function (IRF) is considered to be a useful mechanism to study the effect of a shock on the variables in the model throughout time and can be generalized to the study of shocks in volatility ${ }^{53}$.The IRF will therefore provide valuable information about the impact of a shock on volatility.

Plots, 4, 5 and 6 exhibit the IRFs for an unexpected shock for the CAC40, DAX30 and FTSE100 indexes, respectively ${ }^{54}$.

52 For more details on the methodology, see Sims (1980).

53 The Generalized impulse response function by Pesaran and Shin (1998) is applied.

${ }^{54}$ Each plot consists of three subplots. The first, the second and the third subplot represent the IRF for the VAR A, VAR B and VAR C models, respectively. In Plots 4, 5 and 6, subplot spot-spot represents the impact on the spot market of an unexpected shock in the spot market, subplot spot-future represents the impact on the futures market of an unexpected shock in the spot market, subplot future-spot represents the impact on the spot market of an unexpected shock in the futures market, and subplot future-future represents the impact on the futures market of an unexpected shock in the futures market. 
PLOT 4: Impulse response function (IRF) for the CAC40 index
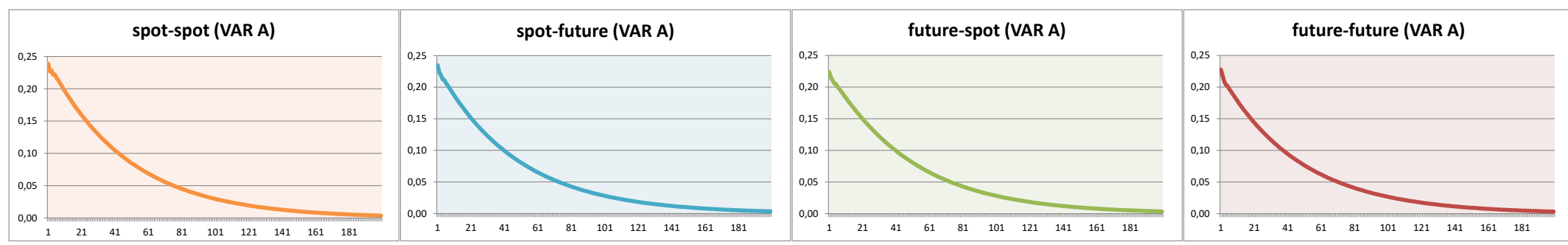

Subplot 4.1: IRF for the CAC40 considering daily volatilities computed by the means of the GARCH $(1,1)$ model (named the VAR A model)

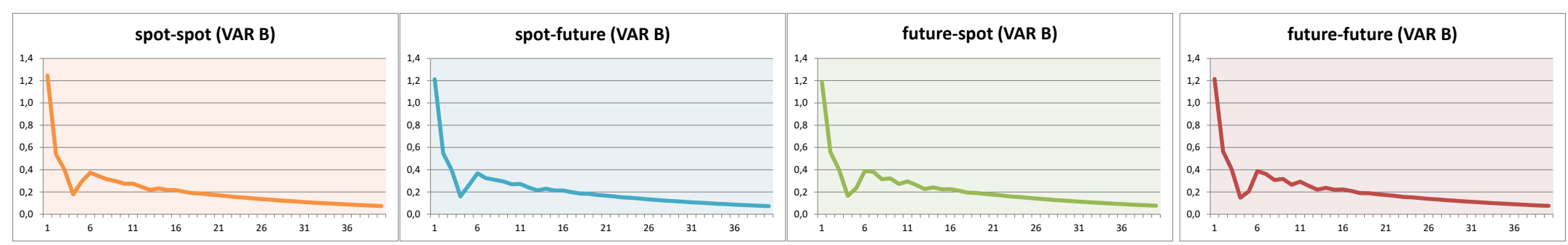

Subplot 4.2: IRF for the CAC40 considering daily volatilities computed by the means of the RV using raw returns (named the VAR B model)
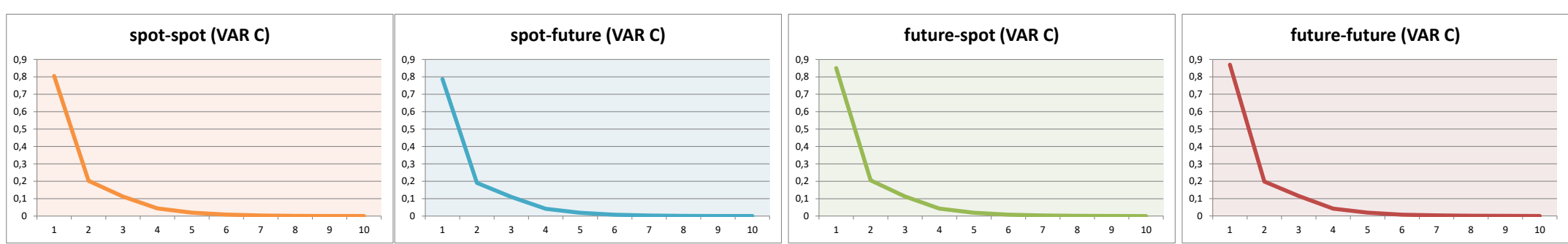

Subplot 4.3: IRF for the CAC40 considering daily volatilities computed by the means of the RV using standardized returns (named the VAR C model)

Plot 4 exhibits the impulse response to a one-standard-deviation shock for the CAC40 index considering the VAR A model (subplot 4.1), the VAR B model (subplot 4.2) and the VAR C model (subplot 4.3). The horizontal axis represents the number of days, and the vertical axis represents the magnitude of the shock expressed as a percentage of the volatility increase. Subplots spot-spot represent the impact on the spot market of an unexpected shock in the spot market, subplots spot-future represent the impact on the futures market of an unexpected shock in the spot market, subplots future-spot represent the impact on the spot market of an unexpected shock in the futures market, and subplots future-future represent the impact on the futures market of an unexpected shock in the futures market. 
PLOT 5: Impulse response function (IRF) for the DAX30 index
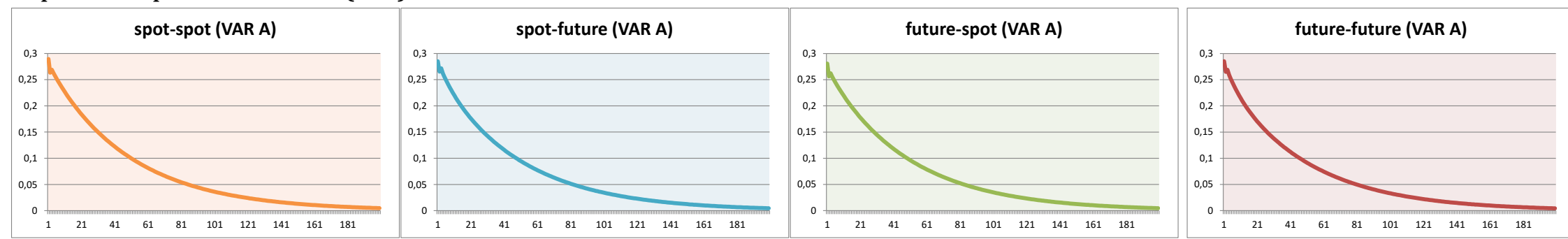

Subplot 5.1: IRF for the DAX30 considering daily volatilities computed by the means of the GARCH $(1,1)$ model (named the VAR A model)
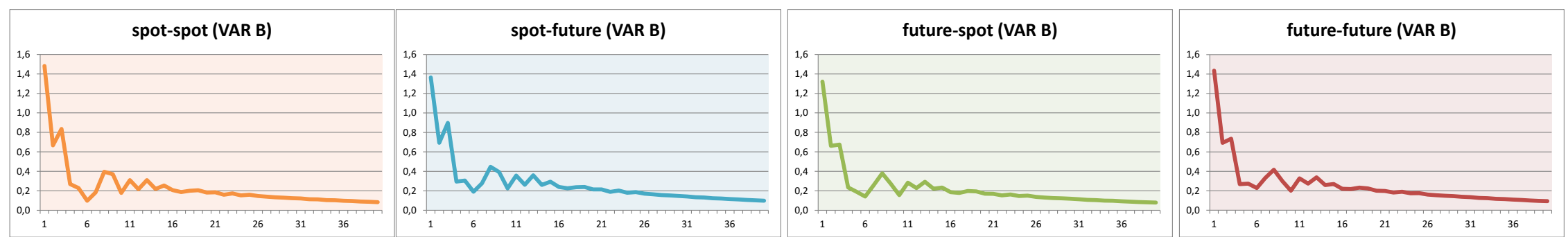

Subplot 5.2: IRF for the DAX30 considering daily volatilities computed by the means of the RV using raw returns (named the VAR B model)
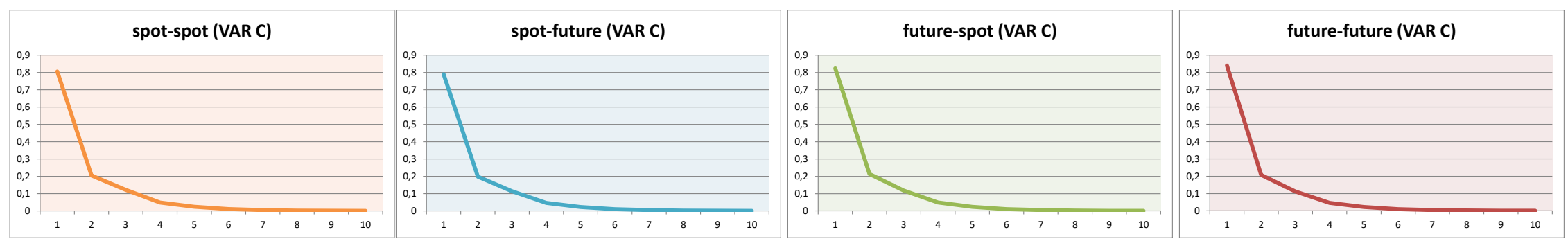

Subplot 5.3: IRF for the DAX30 considering daily volatilities computed by the means of the RV using standardized returns (named the VAR C model)

Plot 5 exhibits the impulse response to a one-standard-deviation shock for the DAX30 index considering the VAR A model (subplot 5.1), the VAR B model (subplot 5.2) and the VAR C model (subplot 5.3). The horizontal axis represents the number of days, and the vertical axis represents the magnitude of the shock expressed as a percentage of the volatility increase. Subplots spot-spot represent the impact on the spot market of an unexpected shock in the spot market, subplots spot-future represent the impact on the futures market of an unexpected shock in the spot market, subplots future-spot represent the impact on the spot market of an unexpected shock in the futures market, and subplots future-future represent the impact on the futures market of an unexpected shock in the futures market. 
PLOT 6: Impulse response function (IRF) for the FTSE100 index
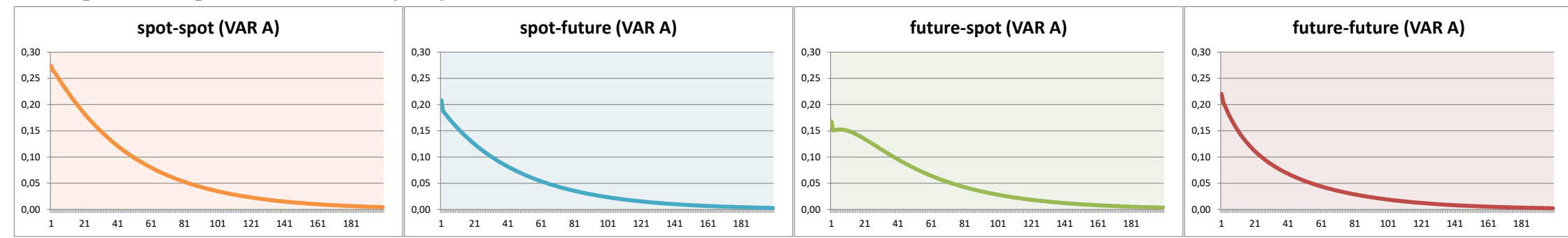

Subplot 6.1: IRF for the FTSE100 considering daily volatilities computed by the means of the GARCH $(1,1)$ model (named the VAR A model)
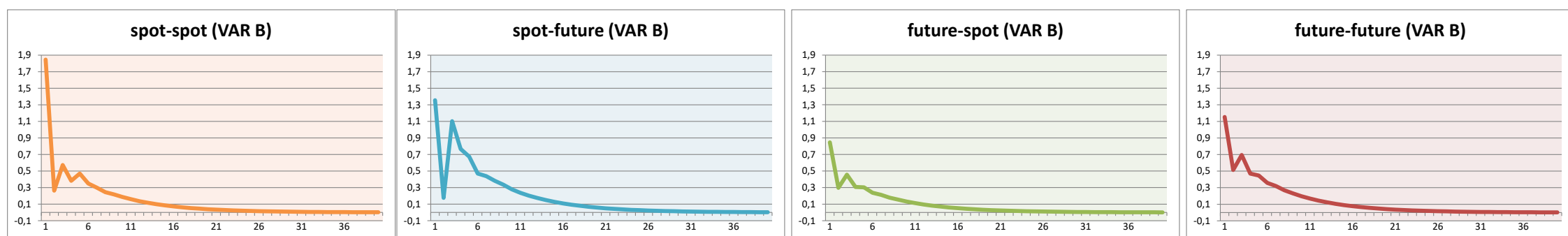

Subplot 6.2: IRF for the FTSE100 considering daily volatilities computed by the means of the RV using raw returns (named the VAR B model)
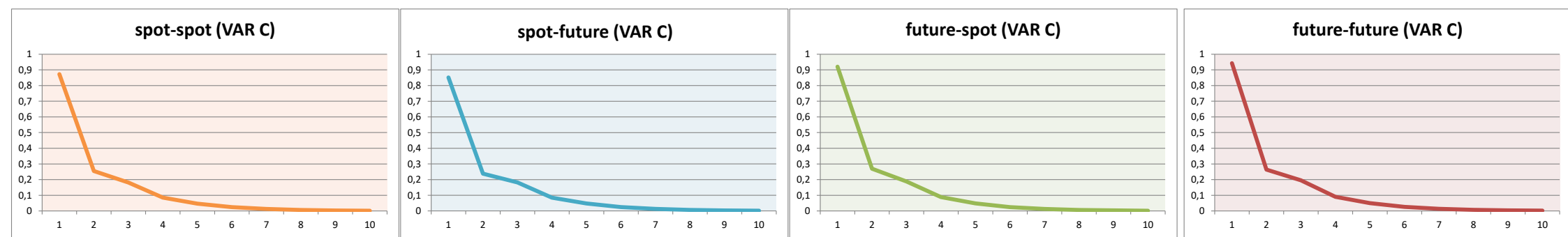

Subplot 6.3: IRF for the FTSE considering daily volatilities computed by the means of the RV using standardized returns (named the VAR C model)

Plot 6 exhibits the impulse response to a one-standard-deviation shock for the FTSE100 index considering the VAR A model (subplot 6.1), the VAR B model (subplot 6.2) and the VAR C model (subplot 6.3). The horizontal axis represents the number of days, and the vertical axis represents the magnitude of the shock expressed as a percentage of the volatility increase. Subplots spot-spot represent the impact on the spot market of an unexpected shock in the spot market, subplots spot-future represent the impact on the futures market of an unexpected shock in the spot market, subplots future-spot represent the impact on the spot market of an unexpected shock in the futures market, and subplots future-future represent the impact on the futures market of an unexpected shock in the futures mis 
As can be appreciated in subplot 4.1(CAC40), 5.1(DAX30) and 6.1(FTSE100), when daily volatilities are computed by means of the GARCH $(1,1)$ model (named VAR A), after the shock hits the system, volatility increases approximately $0.23 \%$ for the CAC40 index, $0.28 \%$ for the DAX30 index and $0.17 \%-0.27 \% 55$ for the FTSE100 index and then steadily diminishes until the shock stabilizes after approximately 200 days $^{56}$ in the three markets. Thus, the results show that the degree of volatility persistence is remarkably high when the intraday periodic component is not considered and the daily volatility is estimated through a GARCH model. Such a result is in good agreement with evidence provided by Lamoureux and Lastrapes (1990), who suggest that a common finding when GARCH models are employed with high-frequency data is that shocks on volatility are highly persistent ${ }^{57}$. This result highlights that standard volatility models, which usually involve a monotone geometric decay in the autocorrelation structure of the absolute returns, may not be appropriate and might lead to spurious inference about the dynamic of the return volatility when strong intraday periodicity is observed in the average absolute returns (A\&B97).

Likewise, note that in subplots 4.2 (CAC40), 5.2 (DAX30) and 6.2 (FTSE100), the magnitude of the shock when daily volatilities are computed using RV with raw returns (named VAR B) is significantly greater (approximately $1.20 \%$ for the CAC40 index, $1.40 \%$ for the DAX30, and $0.85 \%-1.84 \%$ for the FTSE $100^{58}$ ) and exhibits a rather erratic pattern during the first days after the shock. Furthermore, observe that the effect of the shock is less persistent and disappears in about 40 days for the CAC40 and DAX30 indexes and after 25 days for the FTSE100 index. Notice that, the presence of market seasonality in high-frequency data may hamper the estimation of volatility because it induces autocorrelation in the intraday returns; as a consequence of this, the results obtained through the VAR B model might be questionable.

Strikingly, as can be noted in subplots 4.3(CAC40), 5.3(DAX30) and 6.3(FTSE100), when the intraday periodic component has been removed before conducting volatility transmission analysis (the VAR C model), the effect of the shock vanishes after approximately a week in the three markets. In terms of magnitude, volatility increases by around $0.80 \%$ for the CAC40 and DAX30 indexes and approximately $0.90 \%$ for FTSE100 after the shock hits the system. Note that when a shock is

\footnotetext{
$550.27 \%$ when the shock is from the spot market to the spot market, $.0 .21 \%$ when the shock is from the spot market to the future market, $0.17 \%$ when the shock is from the future market to the spot market and $0.22 \%$ when the shock is from the future market to the future market.

56 Meneu and Torró (2003) study the volatility transmission between the IBEX 35 Index and IBEX 35 Futures Index using daily data and extend their analysis implementing an impulse response analysis. They find evidence that shocks take a very long time to vanish (about 100 days).

57 "The application of GARCH to long time series of stock returns data will yield a high measure of persistence because of the presence of deterministic shifts in the unconditional variance and the subsequent failure of the econometrician to model these shifts" (Lamoureux and Lastrapes, 1990)

$581.84 \%$ when the shock is from the spot market to the spot market, $1.35 \%$ when the shock is from the spot market to the future market, $0.85 \%$ when the shock is from the future market to the spot market and $1.15 \%$ when the shock is from the future market to the future market.
} 
applied to the futures market, the immediate market responses are slightly more pronounced than when a shock is introduced into the spot market, and then, the impact of the shock evolves in a similar pattern. Observe for instance that for the CAC40 index, after a shock on the spot market, volatility in the spot (spot-spot) and futures (spot-future) markets rises $0.80 \%$ and $0.78 \%$, respectively, whereas after a shock on the futures market, volatility in the spot (future-spot) and futures (future-future) markets rises $0.85 \%$ and $0.87 \%$, respectively; it then declines until the effect of the shock dies out after about a week ${ }^{59}$. Thus, the results obtained in the impulse response analysis are consistent with previous findings (Chan et al., 1991; Meneu and Torró, 2003) and suggest that there exists bidirectional interaction between the stock index and the stock index future, although we find evidence that shocks on volatility are far less persistent.

Consequently, the most remarkable results of this section may be summarised as follows: a) Volatility transmission differs significantly regardless of whether raw and standardized returns are considered or not, suggesting that if the seasonal pattern is neglected, it might have serious side effects in the spillover analysis; and b) when a shock hits the system and the intraday periodic component has not been used to adjust the returns before conducting the spillover analysis, the response to that shock is highly persistent.

Additionally, to further assess spillovers across spot and futures markets, the Diebold and Yilmaz (2012) Spillover Index is implemented in the following section.

\subsubsection{Directional measurement of volatility spillovers}

Diebold and Yilmaz (2012) show how it is possible to aggregate spillover effects across markets, capturing a great deal of information in a single spillover measure. This volatility spillover measure is based on forecast error variance decompositions from vector autoregressions and is useful for measuring the impact that shocks on a market have on the volatility of others markets. This method, which is an extension of the one proposed in Diebold and Yilmaz (2009), has two main advantages: a) The generalized variance decomposition makes spillover measures independent of the ordering of variables in the VAR model, and b) not only does it consider the total spillovers from one market to another, but it also considers the directional and the net spillovers ${ }^{60}$.

In this section, we study the net directional spillover effects among the spot and futures markets utilizing the novel Diebold and Yilmaz (2012) approach

${ }^{59}$ In the VAR C model, this pattern is observed in the three indexes.

${ }^{60}$ For more details about this methodology, see Diebold and Yilmaz 2009, 2012. 
mentioned above. Our main focus point is the net pairwise volatility spillover (NPVS) between the spot and futures markets of the CAC40, DAX30 and FTSE100 indexes for each VAR model defined in the previous sections. Thus, the originality of our research lies in the fact that in order to determine which market is net sender and which market is net recipient of volatility spillovers, we use three input data based on high-frequency data on a five-minute interval basis: a) The daily volatilities of returns obtained using raw returns and the GARCH $(1,1)$ model (VAR A), b) the daily realized volatilities using raw returns (VAR B) and, c) the daily realized volatilities using standardized returns (VAR C). This analysis will enable us to shed new light on the dynamic interdependence between spot and futures market volatilities by providing new empirical evidence about differences in the directional measurement of volatility transmission regardless of whether the seasonal component of volatility is considered. ${ }^{61}$

To quantify the contribution of the spot (futures) market to the volatility shocks in the futures (spot) market in net terms, we study the NPVS between these markets. In this respect, Plots 7, 8 and 9 depict the NPVS for the CAC40, DAX30 and FTSE100 indexes examined in this article. ${ }^{62}$ These graphics allow us to analyse the evolution of the net directional spillovers among the spot and futures markets and to identify which markets are the net transmitters and receivers of spillovers and the main contributors to total spillovers.

\footnotetext{
61 In this study, we follow Diebold and Yilmaz (2012), and we use generalized variance decompositions of 10day ahead volatility forecast errors and estimate the time-varying volatility spillovers using a 200-day rolling sample framework. Additionally, the optimal lag length for each bivariate VAR model has been set by means of the AIC/BIC criteria. Note that even though the Diebold and Yilmaz (2012) results are based on vector autorregressions of order 4, these authors report that the total spillover plot is sensitive neither to the lag order of the VAR nor the choice of forecast horizon.

62 The net spillover for the spot market is calculated as a positive value, indicating that the spot market transmits spillovers to the futures market. On the contrary, when the net spillover has a negative value, the spot market receives spillovers from the futures market.
} 
PLOT 7: Net pairwise volatility spillover between the CAC40 index and CAC40 index future

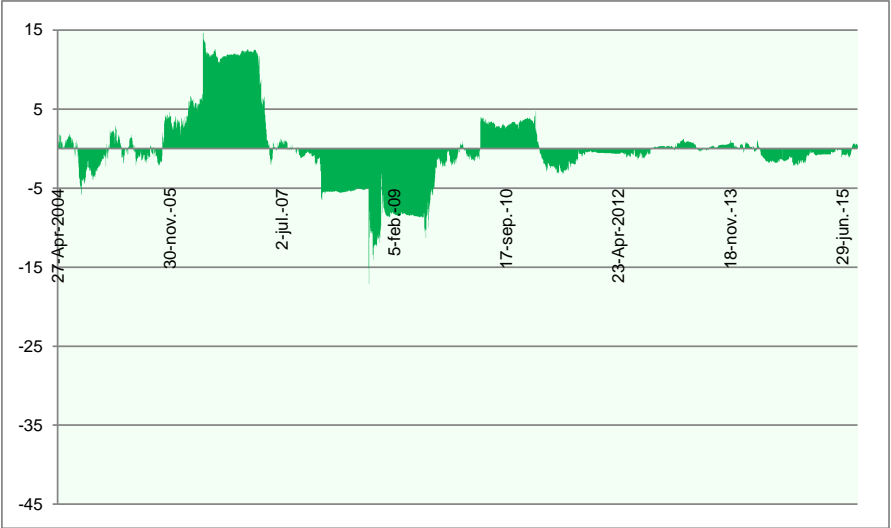

Subplot 7.1 VAR A model (GARCH)

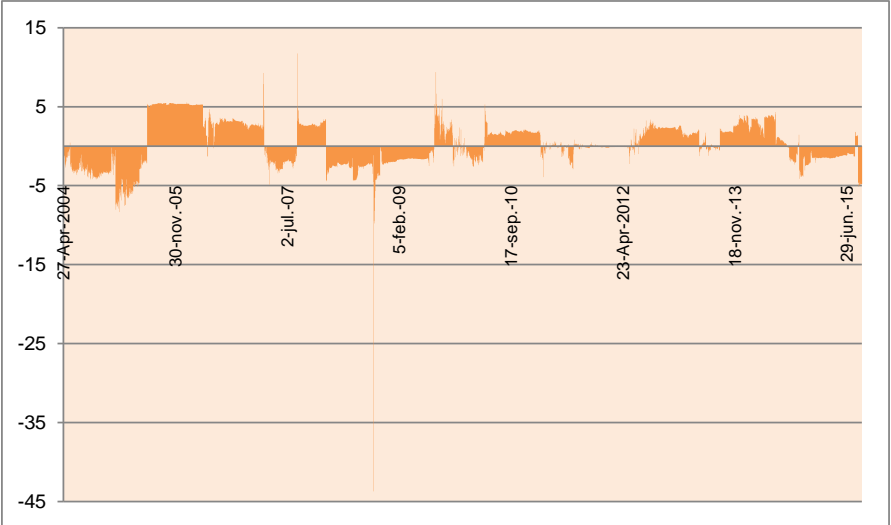

Subplot 7.2 VAR B model (RV raw returns)

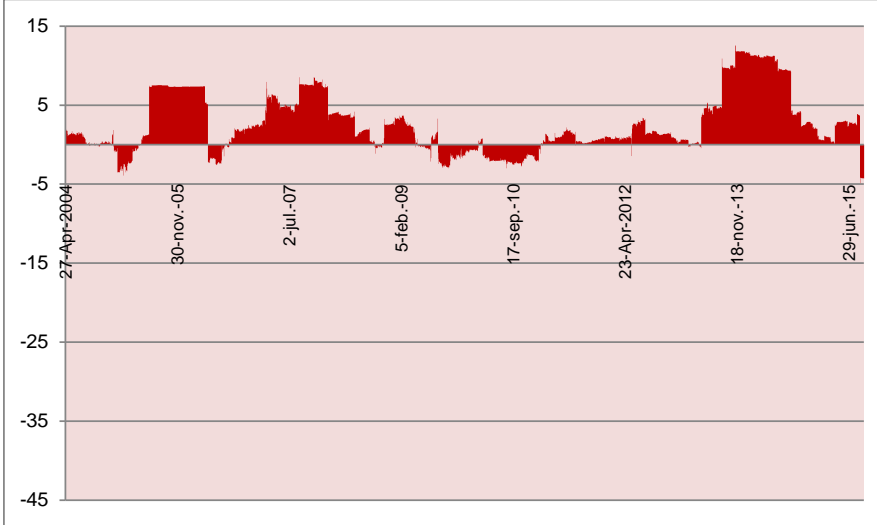

Subplot 7.3 VAR C model (RV standardized returns)

Subplots 7.1, 7.2 and 7.3 represent the net pairwise volatility spillover between the CAC40 index and CAC40 index future for the VAR A, VAR B and VAR C models, respectively. The horizontal axis represents the date (from April 2004 to September 2015), and the vertical axis represents the net spillover (expressed in terms of percentages). When the net spillover has a positive value, it indicates that the spot market transmits spillovers to the futures market. On the contrary, when the net spillover has a negative value, it means that the spot market receives spillovers from the futures market. 
PLOT 8: Net pairwise volatility spillover between the DAX30 index and DAX30 index future

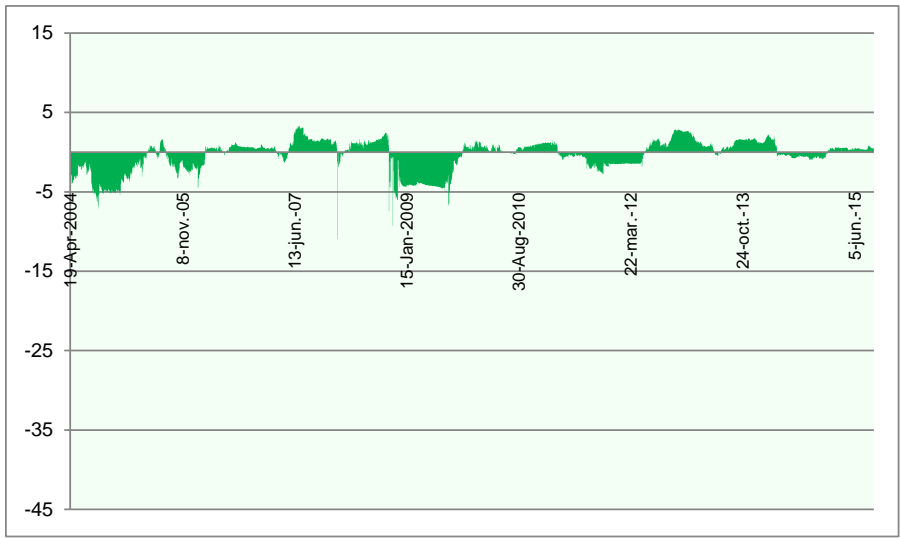

Subplot 8.1 VAR A model (GARCH)

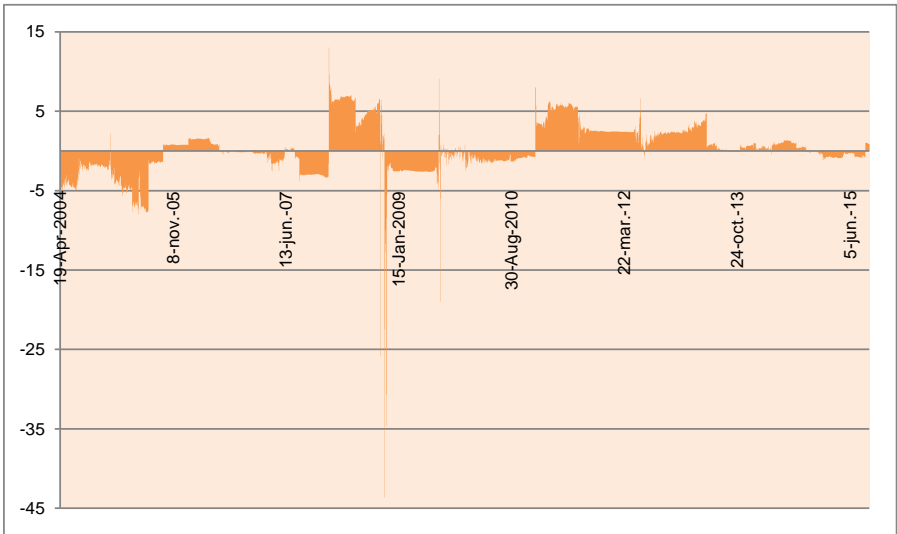

Subplot 8.2 VAR B model (RV raw returns)

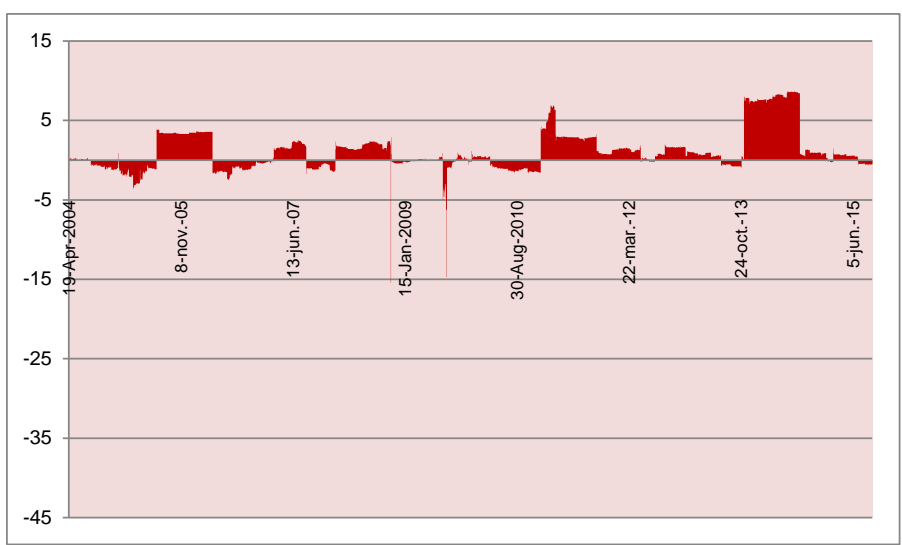

Subplot 8.3 VAR C model (RV standardized returns)

Subplots 8.1, 8.2 and 8.3 represent the net pairwise volatility spillover between the DAX30 index and DAX30 index future for the VAR A, VAR B and VAR C models, respectively. The horizontal axis represents the date (from April 2004 to September 2015), and the vertical axis represents the net spillover (expressed in terms of percentages). When the net spillover has a positive value, it indicates that the spot market transmits spillovers to the futures market. On the contrary, when the net spillover has a negative value, it means that the spot market receives spillovers from the futures market. 
PLOT 9: Net pairwise volatility spillover between the FTSE100 index and FTSE100 index future

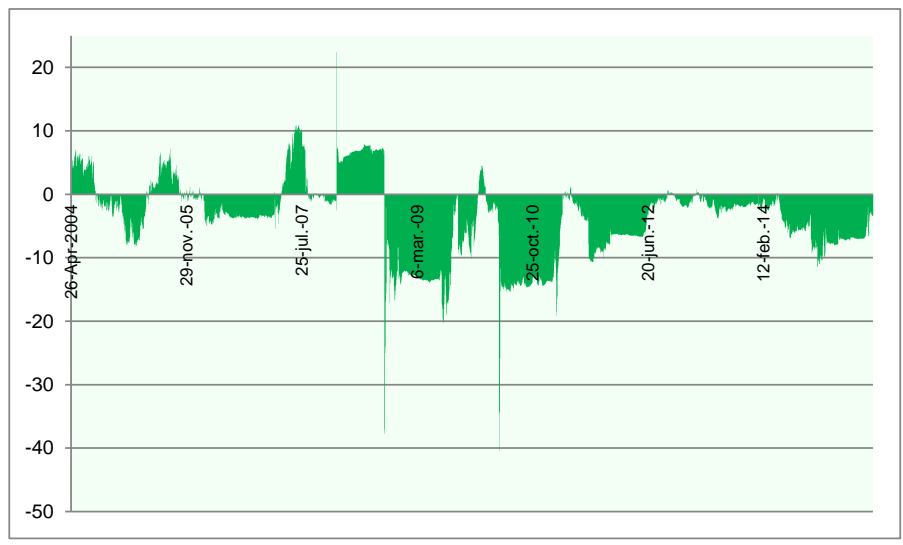

Subplot 9.1 VAR A model (GARCH)

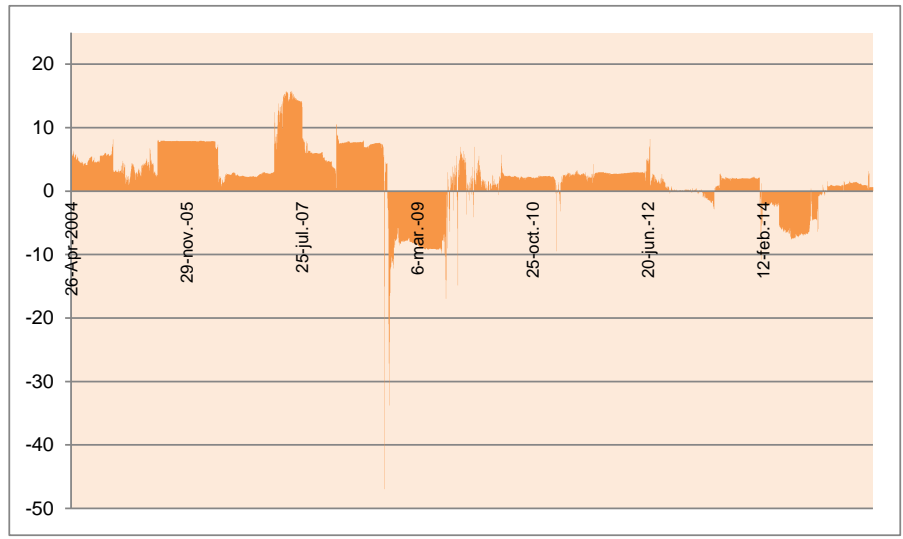

Subplot 9.2 VAR B model (raw returns)

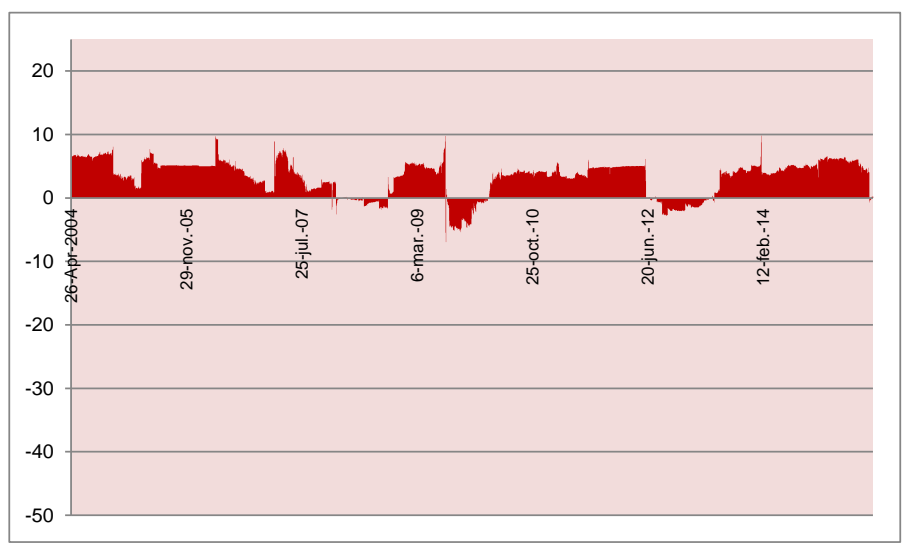

Subplot 9.3 VAR C model (standardized returns)

Subplots 9.1, 9.2 and 9.3 represent the net pairwise volatility spillover between the FTSE100 index and FTSE100 index future for the VAR A, VAR B and VAR C models, respectively. The horizontal axis represents the date (from April 2004 to September 2015), and the vertical axis represents the net spillover (expressed in terms of percentages). When the net spillover has a positive value, it indicates that the spot market transmits spillovers to the futures market. On the contrary, when the net spillover has a negative value, it means that the spot market receives spillovers from the futures market. 
Subplots 7.1(CAC40), 8.1(DAX 30) and 9.1(FTSE100) report the variation over time in the NPVS between the spot and futures market when daily volatilities have been calculated by means of the GARCH $(1,1)$ model (named VAR A). Note that net volatility tends to switch between positive and negative values in the three indexes during the period analysed; this occurs in such a way that positive values mean that the spot market is a net transmitter of volatility to the futures market, and conversely, when the net spillover has a negative value, the spot market is a net receiver. Likewise, it can be drawn from Table 3 that on average, the futures market is the greatest net contributor of volatility spillovers $(0.11 \%, 0.39 \%$ and $3.73 \%$ for the CAC40, DAX30 and FTSE100 indexes). These results are consistent with most of the previous studies related to volatility spillover that find evidence of a two-way volatility transmission and support the leading role of the futures market in information transmission. 
TABLE 3: Summary statistics results for net pairwise volatility spillover

\begin{tabular}{|c|c|c|c|c|c|c|c|c|c|c|c|c|}
\hline & \multicolumn{4}{|c|}{ VAR A (GARCH) } & \multicolumn{4}{|c|}{ VAR B (RV raw returns) } & \multicolumn{4}{|c|}{ VAR C (RV standardized returns) } \\
\hline & $\begin{array}{l}\text { Spot to } \\
\text { future }\end{array}$ & Future to spot & $\begin{array}{l}\text { Net spot to } \\
\text { future }\end{array}$ & $\begin{array}{l}\text { Net future to } \\
\text { spot }\end{array}$ & $\begin{array}{l}\text { Spot to } \\
\text { future }\end{array}$ & $\begin{array}{c}\text { Future to } \\
\text { spot }\end{array}$ & $\begin{array}{l}\text { Net spot } \\
\text { to future }\end{array}$ & $\begin{array}{l}\text { Net future } \\
\text { to spot }\end{array}$ & $\begin{array}{l}\text { Spot to } \\
\text { future }\end{array}$ & $\begin{array}{l}\text { Future to } \\
\text { spot }\end{array}$ & $\begin{array}{l}\text { Net spot } \\
\text { to future }\end{array}$ & $\begin{array}{c}\text { Net future } \\
\text { to spot }\end{array}$ \\
\hline \multicolumn{13}{|c|}{ CACO } \\
\hline Mean & 24.57 & 24.68 & -0.11 & 0.11 & 24.27 & 24.02 & 0.24 & -0.24 & 24.97 & 22.42 & 2.55 & -2.55 \\
\hline Standard deviation & 2.31 & 2.42 & 4.67 & 4.67 & 1.67 & 1.39 & 2.88 & 2.87 & 1.87 & 2.13 & 3.74 & 3.74 \\
\hline Skewness & -0.08 & -1.25 & 0.66 & -0.66 & -1.60 & 0.65 & -1.25 & 1.25 & 0.32 & -0.89 & 0.80 & -0.80 \\
\hline Kurtosis & 4.77 & 5.15 & 4.77 & 4.77 & 18.65 & 16.45 & 21.10 & 21.10 & 2.31 & 3.27 & 2.89 & 2.89 \\
\hline Min & 14.88 & 16.21 & -17.10 & -14.65 & 0.12 & 18.44 & -43.70 & -11.73 & 20.61 & 16.45 & -4.86 & -12.57 \\
\hline $\operatorname{Max}$ & 30.87 & 31.98 & 14.65 & 17.10 & 30.17 & 43.83 & 11.73 & 43.70 & 29.03 & 26.72 & 12.57 & 4.86 \\
\hline \multicolumn{13}{|c|}{ DAX30 } \\
\hline Mean & 24.63 & 25.02 & -0.39 & 0.39 & 24.07 & 23.87 & 0.20 & -0.20 & 24.64 & 23.56 & 1.08 & -1.08 \\
\hline Standard deviation & 1.10 & 0.91 & 1.97 & 1.97 & 2.19 & 2.32 & 3.16 & 3.16 & 1.38 & 1.80 & 2.52 & 2.52 \\
\hline Skewness & -1.08 & 0.82 & -0.97 & 0.97 & -1.91 & -1.56 & -1.95 & 1.95 & -0.77 & -1.86 & 1.12 & -1.12 \\
\hline Kurtosis & 3.64 & 3.57 & 3.55 & 3.55 & 11.62 & 12.86 & 26.73 & 26.73 & 9.49 & 6.92 & 5.76 & 5.76 \\
\hline $\operatorname{Min}$ & 19.24 & 23.17 & -10.96 & -3.34 & 2.00 & 14.24 & -43.67 & -13.01 & 9.46 & 14.94 & -15.43 & -8.65 \\
\hline $\operatorname{Max}$ & 26.51 & 30.23 & 3.34 & 10.96 & 30.31 & 45.66 & 13.01 & 43.67 & 27.69 & 31.60 & 8.65 & 15.43 \\
\hline \multicolumn{13}{|c|}{ FTSE100 } \\
\hline Mean & 21.11 & 24.85 & -3.73 & 3.73 & 24.07 & 21.95 & 2.12 & -2.12 & 24.79 & 21.52 & 3.27 & -3.27 \\
\hline Standard deviation & 5.81 & 3.40 & 6.21 & 6.21 & 4.39 & 2.49 & 5.13 & 5.13 & 1.96 & 2.73 & 2.81 & 2.81 \\
\hline 2.81 & -1.87 & -0.85 & -0.35 & 0.35 & -1.92 & -0.41 & -0.95 & 0.95 & -0.95 & -1.38 & -0.91 & 0.91 \\
\hline Kurtosis & 5.95 & 4.59 & 4.07 & 4.07 & 6.43 & 8.88 & 8.07 & 8.07 & 3.71 & 5.77 & 3.18 & 3.18 \\
\hline Min & 0.53 & 11.61 & -40.43 & -22.42 & 1.87 & 12.76 & -46.97 & -15.79 & 18.29 & 11.69 & -6.92 & -9.83 \\
\hline $\operatorname{Max}$ & 34.45 & 45.77 & 22.42 & 40.43 & 29.84 & 48.85 & 15.79 & 46.97 & 28.67 & 25.91 & 9.83 & 6.92 \\
\hline
\end{tabular}

Table 3 shows the main summary statistics for the net pairwise volatility spillover (NPVS) between the spot and futures markets of the CAC40, DAX30 and FTSE100 indexes for the VAR A, B and C models, respectively, for the period from July 1, 2003, to September 30, 2015. 
With regard to subplots 7.2 (CAC40), 8.2 (DAX 30) and 9.2 (FTSE100), in which the input data are the realized volatility computed with raw returns (VAR B model), it is important to highlight two main findings. First, net volatility also tends to shift between positive and negative values, and second, contrary to the previous findings, the results when considering the VAR B model show that the spot market is on average a net volatility transmitter for most of the sample period $0.24 \%$, $0.20 \%$ and $2.12 \%$ for CAC40, DAX30 and FTSE100, respectively, according to Table $3)$. Nevertheless, considering the perils of the presence of seasonality in highfrequency data when modelling the volatility dynamic and given the fact that neither the VAR A model nor the VAR B model consider the intraday periodic component before implementing the Diebold and Yilmaz (2012) approach, previous findings might be unreliable and should be interpreted with caution. We therefore remove intraday seasonality before estimating the NPVS.

Therefore, we finally depict subplots 7.3 (CAC40), 8.3 (DAX 30) and 9.3 (FTSE10), in which, as mentioned above, the intraday periodic component has been removed before conducting the directional measurement of volatility spillovers (VAR C model). Some interesting findings are remarkable. Note that, in general terms, changes over time with positive and negative values of the NPVS between the spot and futures markets are not so frequent, and since positive values in the graphic indicates that the spot market transmits spillovers to the futures market, it is visually observable that the spot market is the largest net sender of volatility spillovers to the futures market throughout all the sample. This finding is corroborated by the results reported in Table 3. Note that on average the magnitude in which the spot market contributes to the NPVS is about $2.55 \%$ for the CAC40, $1.08 \%$ for the DAX30, and 3.27\% for the FTSE100. That is to say, on average, considering for instance the CAC40, the volatility shocks transmitted from the spot market to the futures markets is about $2.55 \%$ in net terms ${ }^{63}$. On the whole, looking at the graphics, it is also worth emphasizing that in terms of magnitude, the NPVS are greater than those in models VAR A and VAR B ${ }^{64}$; this suggests, once more, that when the intraday periodic component is neglected (models VAR A and B), we might be losing some relevant information regarding the volatility transmission. Although at first sight one might think that the conclusions drawn from the IRF and the Diebold and Yilmaz (2012) approach are contradictory, note that they are two different measures used to assess spillovers across markets. The IRF provides information about the impact of a shock on volatility at a particular time and might be regarded as indicative of the effects of

63 See in Table 3 that, on average, the directional spillover from the spot market to the futures market is $24.98 \%$, while the directional spillover from the futures market to the spot market is $22.43 \%$; therefore, the spot market is a net volatility transmitter $(2.55 \%)$ for most of the sample period.

64 Except for the FTSE100, in which on average the net volatility transmission from the futures market to the spot market for the VAR A model is higher than the net volatility transmission from the spot market to the futures market for the VAR C model (although this difference is not significant). 
future shocks, whilst the Diebold and Yilmaz (2012) methodology captures an average of directional and net spillovers throughout a period.

Based on the above results, it is highly evident that there exist significant differences in the measurement of volatility transmission depending on whether the intraday seasonality has been considered. Overall, the results underscore the importance of removing the intraday periodic component to reduce the risk of spurious causality when employing high-frequency data in volatility modelling.

\subsection{Conclusions}

In the last decades, the upsurge in interest in studying the interaction between the financial markets has increased dramatically. Significant attention has been paid to examining the volatility transmission mechanism that exists in major financial equity markets. Needless to say, understanding volatility spillover is important by virtue of the critical repercussions for monetary policy, optimal resource allocation, risk measurement, capital requirements and asset valuation. Additionally, the growing availability of high-frequency data has boosted research on intraday data which has emerged as a major area in econometrics and statistics.

However, handling high-frequency data may be especially challenging because of the idiosyncrasy of the data, which makes it crucial to consider the intraday seasonal patterns present in the volatility of financial markets before modelling the dynamics of intraday volatility.

In this article, we aim to address if the well-documented strong intraday repetitive pattern in average absolute returns is present in our data and if there is any change in volatility transmission dynamics when the intraday periodic component is considered. Regarding this, the most remarkable results may be summarised as follows: a) Noteworthy similarities are detected in the markets analysed; all of them illustrate a distorted double $U$-shape in the average absolute returns during a trading day; b) the FFF methodology used to remove the intraday periodic component considerably reduces serial autocorrelation; c) cross-correlation analysis reveals significant cross-market volatility interactions between the spot and futures markets that have also diminished noticeably after considering the seasonal pattern; d) volatility transmission differs significantly regardless of whether raw and standardized returns are considered, so that when intraday data are not standardized, the optimal number of lags in the VAR model determined by the selection criteria seems to be redundant, suggesting that if the seasonal pattern is neglected, it might result in invalid statistical inference in the spillover analysis; e) when a shock hits the system and the intraday periodic component has not been used to adjust the returns before conducting the spillover analysis, the response to 
that shock is highly persistent; and f) the directional measurement of volatility spillovers shows that the spot market is the largest net sender of volatility spillovers to the futures market and that, in terms of magnitude, the NPVS are generally greater when the intraday periodic component has been considered, which suggests, once again, that when this seasonal component is neglected, we might be losing some relevant information regarding volatility transmission.

In sum, this article highlights how high-frequency data can shed new light on issues concerning the volatility spillover between markets and why it is really important to remove the seasonal component to diminish the risk of spurious causality when using intraday data in volatility modelling. 


\section{References}

Abhyankar, A. H. (1995). Return and volatility dynamics in the FT-SE 100 stock index and stock index futures markets. Journal of Futures Markets, 15(4), 457-488.

Andersen, T. G. (2000). Some reflections on analysis of high-frequency data. Journal of Business \& Economic Statistics, 18(2), 146-153.

Andersen, T. G., and Bollerslev, T. (1997). Intraday periodicity and volatility persistence in financial markets. Journal of Empirical Finance, 4(2), 115-158.

Andersen, T. G., Bollerslev, T., and Cai, J. (2000). Intraday and interday volatility in the Japanese stock market. Journal of International Financial Markets, Institutions \& Money, 10(2), 107-130.

Andersen, T. G., Bollerslev, T., Diebold, F. X., \& Labys, P. (2001). The distribution of realized exchange rate volatility.Journal of the American Statistical Association, 96(453), 42-55.

Andersen, T. G., Bollerslev, T., Diebold, F. X., \& Labys, P. (2003). Modeling and forecasting realized volatility. Econometrica, 71(2), 579-625.

Berument, H., \& Kiymaz, H. (2001). The day of the week effect on stock market volatility. Journal of Economics \& Finance, 25(2), 181-193.

Brooks, C., Garret, I. and Hinnich, M.J. (1999). An alternative approach to investigating lead-lag relationships between stock and stock index futures markets. Applied Financial Economics, 9(6), 605-613.

Chan, K., Chan, K. C. \& Karolyi, G. A. (1991). Intraday volatility in the stock index and stock index futures markets. The Review of Financial Studies 4(4), 657-684.

Chow, Y., Yung, H., \& Zhang, H. (2003). Expiration day effects: The case of Hong Kong. Journal of Futures Markets, 23(1), 67-86.

Diebold, F. X., \& Yilmaz, K. (2009). Measuring financial asset return and volatility spillovers, with application to global equity markets. The Economic Journal, 119(534), 158-171.

Diebold, F. X., \& Yilmaz, K. (2012). Better to give than to receive: Predictive directional measurement of volatility spillovers. International Journal of Forecasting, 28(1), 57-66.

Duong, H. N., \& Kalev, P. S. (2008). The Samuelson hypothesis in futures markets: An analysis using intraday data. Journal of Banking \& Finance, 32(4), 489-500. 
Engle, R. F. (1982). Autoregressive conditional heteroscedasticity with estimates of the variance of United Kingdom inflation. Econometrica, 50(4), 987-1007.

Fung, J. K., Lien, D., Tse, Y., \& Tse, Y. K. (2005). Effects of electronic trading on the Hang Seng Index futures market. International Review of Economics \& Finance, 14(4), 415-425.

Gallant, A. R. (1981). On the bias in flexible functional forms and an essentially unbiased form: the Fourier flexible form. Journal of Econometrics, 15(2), 211-245.

Gallant, A. R. (1982). Unbiased determination of production technologies. Journal of Econometrics, 20(2), 285-323.

Goodhart, C. A., \& O'Hara, M. (1997). High frequency data in financial markets: Issues and applications. Journal of Empirical Finance, 4(2), 73-114.

Han, L. M., Kling, J. L., \& Sell, C. W. (1999). Foreign exchange futures volatility: Dayof-the-week, intraday, and maturity patterns in the presence of macroeconomic announcements. Journal of Futures Markets, 19(6), 665-693.

Hancock, G. D. (1993). Whatever happened to the triple witching hour? Financial Analysts Journal, 49(3), 66-72.

Harju,K., and Hussain, S.M. (2011). Intraday seasonalities and macroeconomic news announcements. European Financial Managament, 17(2), 367-390.

Harris, L. (1986). A transaction data study of weekly and intradaily patterns in stock returns. Journal of Financial Economics, 16(1), 99-117.

Herbst, F.A., McCormack, J.P. and West, E.N. (1987). Investigation of the lead-lag relationships between spot stock indices and their futures contracts. Journal of Futures Markets, 7(4), 373-381.

Kan, A.C.N. (2001). Expiration-day effect: evidence from high-frequency data in the Hong Kong stock market. Applied Financial Economics, 11(1), 107-118.

Karolyi, A. G. (1996) Stock market volatility around expiration days in Japan, The Journal of Derivatives, 4(2), 23-43.

Kawaller, I. G., Kock, P. D., \& Koch, T. W. (1987). The temporal relationship between S\&P 500 futures prices and the S\&P 500 index. The Journal of Finance, 42(5), 13091329.

Kawaller, I. G., Koch, P. D., \& Koch, T. W. (1990). Intraday relationships between volatility in S\&P 500 futures prices and volatility in the S\&P 500 index. Journal of Banking \& Finance, 14(2-3), 373-397. 
Kiymaz, H., \& Berument, H. (2003). The day of the week effect on stock market volatility and volume: International evidence. Review of Financial Economics, 12(4), 363-380.

Kofman, P., \& Martens, M. (1997). Interaction between stock markets: an analysis of the common trading hours at the London and New York stock exchange. Journal of International Money and Finance, 16(3), 387-414.

Koutmos, G., \& Tucker, M. (1996). Temporal relationships and dynamic interactions between spot and futures stock markets. Journal of Futures Markets, 16(1), 55-69.

Lamoureux, C. G., \& Lastrapes, W. D. (1990). Persistence in variance, structural change, and the GARCH model. Journal of Business \& Economic Statistics, 8(2), 225234.

Meneu, V., \& Torro, H. (2003). Asymmetric covariance in spot-futures markets. Journal of Futures Markets, 23(11), 1019-1046.

Merton, R. C. (1980). On estimating the expected return on the market: An exploratory investigation. Journal of Financial Economics, 8(4), 323-361.

Pesaran, H. H., \& Shin, Y. (1998). Generalized impulse response analysis in linear multivariate models, Economics Letters, 58(1), 17-29.

Ross, S. A. (1989). Information and volatility: the no-arbitrage martingale approach to timing and resolution irrelevancy. The Journal of Finance, 44(1), 1-17.

Samuelson, P. A. (1965). Proof that properly anticipated prices fluctuate randomly, Industrial Management Review, 6, 41-49.

Sims, C. A. (1980). Macroeconomics and reality. Econometrica, 48(1), 1-48.

Soriano, P., Climent, F.J., 2006. Volatility transmission models: a survey. Revista de Economía Financiera 10, 32-81.

Stoll, H. R. and Whaley, R. E. (1987). Program trading and expiration day effects. Financial Analysts Journal, March-April, 43(2), 16-28.

Stoll, H. R. and Whaley, R. E. (1991). Expiration day effects: What has changed? Financial Analysts Journal, 47(1), 58-72.

Tse, Y. (1999). Price discovery and volatility spillovers in the DJIA index and futures markets. Journal of Futures markets, 19(8), 911-930. 
Wood, R. A., McInish, T. H., \& Ord, J. K. (1985). An investigation of transactions data for NYSE stocks. The Journal of Finance, 40(3), 723-739. 


\section{CHAPTER C:}

\section{AN APPLICATION OF HIGH-FREQUENCY DATA TO OPTIMAL PORTFOLIO CHOICE}

Abstract

This article investigates the usefulness of high frequency data in optimal portfolio choice using a comprehensive listing of major stock market indexes. We construct diversified portfolios considering monthly and high frequency data in the modelling of volatility and compare the performance of these portfolios in terms of several out-ofsample metrics. Not only does the results underscore the positive performance of switching from data at lower frequencies to intraday data in the context of optimal asset allocation, but the capability of beating the equally-weighted portfolio even in presence of transaction costs. 


\subsection{Introduction}

One of the most crucial investment decisions made by investors involves the allocation of wealth among risky assets. Since the seminal paper of Markowitz (1952) the Modern Portfolio Theory has played a pivotal role in finance and has revolutionized investment management. Despite the fact that it is more than half a century since its publication, the mean-variance approach remains the major model implemented in practice in portfolio allocation. An elemental premise of economics is that, due to the lack of resources, all economic decisions are made in the face of trade-offs. In this article, Markowitz identifies that choices involve a trade-off between expected return and risk and demonstrates how the combination of assets in a portfolio could minimize portfolio risk at a given level of expected return or maximize expected return at a given level of risk. Therefore, according to this theory, there is a set of portfolios that form the efficient frontier which maximize the expected return given a certain level of risk.

Even though no question remains that Markowitz approaches are optimal theoretically, these moments are unknown in practice, and therefore, they have to be estimated using historical data of the risky assets that may lead to estimation errors in expected returns, variances and covariances. It is widely known that estimation error presents a major obstacle to successful implement portfolio optimization strategies and may undermine the performance of the selected investment portfolio suggesting portfolios weights with poor out-of-sample results. Thus, one of the main problems of the sample-based mean-variance optimization approach is that it neglects estimation error, in such a way that the usefulness of the mean-variance strategy is brought into question (Frankfurter et al. 1971). It has motivated an extensive literature suggesting different methods to reduce the impact of estimation error (see among others Jorion, 1986; James and Stein, 1961; Mackinlay and Pástor, 2000; Jagannathan and Ma, 2003; DeMiguel et al., 2009a).

Recently, a prominent strand of literature regarding portfolio choice even suggests that common portfolio optimization strategies do not beat the equally-weighted strategy 65 (DeMiguel et al., 2009b); raising a serious doubt on the usefulness of the investment theory. To challenge the findings of DeMiguel et al. (2009b), we evaluate in this article whether, by using high frequency data (HFD henceforth) in optimal portfolio asset allocation, instead of data at lower frequencies, we can improve the performance and beat the naïve rule.

Previous research has documented that covariance matrix estimates based on HFD leads to more accurate results than estimates based on lower frequencies (see among others Pooter et al., 2008). In this context, several publications have

65 Also called naïve strategy or $1 / \mathrm{N}$ rule 
appeared in recent years documenting that decision making in portfolio theory is influenced by the frequency of the data used in the estimates and that the benefit from using intraday data may be worthwhile. However, despite the widespread availability of intraday data and the latest technological and econometric advances, in the field of asset allocation, daily or monthly returns are generally used to estimate the whole covariance matrix and only a handful of studies use intraday data to estimate the variance and covariance matrix (see Fleming, Kirby and Ostdiek, 2003; Zhang et al., 2005; Liu, 2009; Hautsch, Kyj and Malec, 2015).

Thus, the main contribution of this research is to reduce the estimation error in the covariance matrix by using HFD to successfully implement portfolio optimization methodologies, while considering a comprehensive listing of major stock market indexes to build a diversified portfolio. Hence, taking as a benchmark the naïve rule strategy, we use a wide-range portfolio containing American, Asian and European stock market indexes on a five-minute interval basis and compare the out-of-sample performance of different portfolio methodologies when using the realized covariance matrix with the out-of-sample performance of those portfolio strategies that utilize the traditional way of computing the covariance matrix with monthly returns.

From the outcome of our investigation we can conclude that: a) when monthly data are introduced into the optimization problem we obtain poorer performance as reported in DeMiguel et al. (2009b), b) in the absence of transaction costs, portfolios designed using intraday data, are found to provide better performance than those that employ monthly data (the Sharpe ratios for intraday data are higher than Sharpe ratios for monthly data), and moreover they beat the equallyweighted portfolio strategy (the annualized out-of-sample certainty equivalent rate of return, CEQ, corroborates the previous conclusions drawn by the analysis of the Sharpe ratio); and c) results show evidence that the use of intraday data in optimal portfolio choice improves the performance by reducing the estimation error, which is not the primary barrier to successful optimization, but the turnover; and despite the higher turnover obtained in the HFD-based approaches, the performance, after considering transaction costs improves considerably beating the naive rule. Thus, the benefit from using intraday data in optimal portfolio choice may be worthwhile, leading to superior performance even after considering transaction costs.

Overall, this research advocates the usefulness of the investment theory and suggests that HFD may add significant value in the field of optimal asset allocation.

The remainder of this paper is organized as follows: section 4.2 contains a review of the literature, section 4.3 describes the data employed in the empirical analysis and the procedure to construct the conditional variance-covariance matrix using monthly and high-frequency data; section 4.4 explains the portfolio strategies and 
metrics of performance employed; section 4.5 is the core of the paper as it documents the results of the various out-of-sample studies, compares the performance of these models to that of $1 / \mathrm{N}$ rule and reports the error in estimating the covariance matrix depending on the returns series used; section 4.6 performs a few robustness checks; and finally, section 4.7 concludes by summarizing the main results.

\subsection{Review of literature}

During the last decades, great effort has been devoted to improve the out-ofsample performance of asset allocation strategies. To fulfill this goal, several methodologies have been proposed which involve among others: using Bayesian methods (Jorion, 1986; Pástor, 2000; James and Stein, 1961), moment restrictions (Mackinlay and Pástor, 2000), constraining short sales (Frost and Savarino, 1988; Jagannathan and Ma, 2003), constrained weights (DeMiguel et al., 2009a) and optimal combinations of portfolios (Kan and Zhou, 2007). Notwithstanding, recent research suggests that these challenging methodologies are usually unable to beat the so-called $1 / \mathrm{N}$ or naïve strategy.

The essence of the naïve formulation rule, lies in investing equally across $\mathrm{N}$ assets, therefore the investor's strategy depends on neither any data nor any statements. In terms of the out-of-sample performance, there has been a longstanding and contentious debate in portfolio optimization between the traditional Markowitz model (and its extensions) and the equally-weighted portfolio ${ }^{66}$ trying to answer the following question: Is it preferable to use the naïve rule and avoid selecting the wrong portfolio as a result of the sampling errors or is it preferable to use optimal portfolio strategies despite the probable sampling errors?. DeMiguel et al. (2009b) attempt to answer this question by comparing the $1 / \mathrm{N}$ rule with 14 different portfolio strategies using seven different empirical datasets. The results show that the naïve $1 / \mathrm{N}$ diversification rule outperforms the sample-based mean-variance optimization strategy and all the sophisticated methodologies. Likewise, Duchin and Levy (2009) use mean-variance portfolios parametrized employing monthly sample data, and find that the Markowitz theory outperforms the naïve strategy for relatively large portfolios. Furthermore, Jacobs et al. (2014) compare 11 optimization methodologies with a very broad range of straightforward heuristic allocation approaches and suggest that portfolio optimization methodologies do not beat heuristic weighting strategies.

Conversely, $\mathrm{Tu}$ and Zhou (2011) combine the $1 / \mathrm{N}$ rule with four portfolio strategies, namely, the Markowitz approach and its extensions proposed by, Jorion

${ }^{66}$ Early discussions include among others, Frankfurter et al. (1971) and Brown (1979). 
(1986), Mackinlay and Pástor (2000) and Kan and Zhou (2007) achieving better performance, beating the naïve rule and restating the profitability of the investment theory. Moreover, Kirby and Ostdiek (2012) suggest that results in DeMiguel et al. (2009b) come from their research design, which focuses on portfolio based on high estimation risk and extreme turnover. According to Kirby and Ostdiek (2012), mean-variance optimization usually outperforms the $1 / \mathrm{N}$ strategy; however, in presence of high transaction costs, turnover usually undermines its gains. To address this matter, they develop two new methodologies (volatility timing and reward-to-risk timing) that consider the most interesting characteristics of the naïve rule (no covariance matrix inversion, no short sales and no optimization) and, at the same time, benefit from sample information. Their proposed approaches outperform the $1 / \mathrm{N}$ rule even in the presence of high transaction costs.

Previous studies indicate that the estimation of covariance matrices plays a key role for determining the optimal portfolio allocation. Even though a large part of the literature on portfolio selection has focused on such an improvement (see among others, Green and Hollifield, 1992; Ledoit and Wolf 2003, 2004a; Jagannathan and $\mathrm{Ma}, 2003$ ), more effort needs to be done to improve the estimation of the second moments. Based on this premise, this paper proposes a new approach to estimate the variance-covariance matrix for portfolio optimization using a comprehensive dataset of stock market indexes on an intraday basis.

It is now beyond doubt that the economic value of high-frequency financial data is of direct practical relevance, so that its use has become very popular in recent years (Goodhart and O'Hara, 1997). HFD is "one measure of progress in empirical econometrics" (Engle, 2000) that enables us to estimate realized measures by using all available information with the added advantage of not having to estimate parametrical models commonly used, such as the ARCH and GARCH models. It was Andersen et al. $(2001,2003)$ who paved the way for the use of models that employ Realized Volatility (RV) measures.

Nevertheless, despite the widespread availability of HFD, daily returns are generally used to estimate the whole covariance matrix and there is limited research focus on the use of intraday data to estimate the variance and covariance matrix. With regard to optimal portfolio allocation literature, although the use of high-frequency data is scarce, research in this field concludes that decision making in portfolio theory is influenced by the frequency of the data used in the estimates and that the benefit from using intraday data may be worthwhile (see Fleming, Kirby and Ostdiek, 2003; Zhang et al., 2005; Liu, 2009; Hautsch, Kyj and Malec, 2015). 
As far as we are aware, Fleming, Kirby and Ostdiek (2003) were the first authors to evaluate the economic benefits of the RV in the context of portfolio choice. Their research uses a "volatility timing" approach and is based on allocations across three highly liquid futures contracts from January 3, 1984 to November 30, 2000 and comprises two sets of estimates of the conditional covariance matrix using rolling estimators. One set is based on daily returns and the other set is based on intraday returns on a five-minute interval basis. Their findings indicate that it is valuable to switch from daily to intraday data to estimate the conditional covariance matrix even in presence of transaction costs. Liu (2009) extends the findings in Fleming, Kirby and Ostdiek (2003) using the 30 DJIA stocks from January 2, 1993 to June 30, 2000. The author computes multiple covariance matrix estimators based on daily returns and high-frequency returns and for the purpose of monthly rebalancing, a monthly covariance matrix is also constructed from these estimates. The results suggest that the benefits of using high-frequency data in portfolio optimization decision depend on the rebalancing frequency and the estimation horizon. Additionally, Hautsch, Kyj and Malec (2015) construct Global Minimum Variance Portfolios using 400 assets of the S\&P 500 index during the sample period between January 2006 and December 2009 and conclude that high frequency based forecasts outperform methods employing daily returns in terms of volatility, which translate into significant utility benefits for investors with pronounced risk aversion.

Furthermore, the answer to the long-lasting question whether high frequency volatilities should be adjusted to consider microstructure noise is ambiguous. As Merton (1980) highlights, the RV computed as the sum of the squared intraday returns for the given trading day, would be an excellent estimate of the volatility in an ideal world in which prices were observed continuously and without measurement error. Thus, microstructure noise should not be neglected and it is of paramount importance the use of standardized HFD (see among others, Hansen and Lunde, 2006 and Cartea and Karyampas, 2011). Conversely, a second strand of literature concludes that noise correction does not appear to be meaningful for volatility prediction. Ghysels and Sinko (2006) examine whether the correction of $\mathrm{RV}$ for microstructure noise improves the forecast of future volatility, and they find that uncorrected volatility measures perform on average better than noiseadjusted $\mathrm{RV}^{67}$ and conclude that in terms of predicting future volatility "it appears that corrections for microstructure noise do not matter very much". Likewise, Pooter et al. (2008) try to answer the question regarding the optimal intraday sampling frequency in the context of minimum variance portfolio using intraday return frequencies ranging from 1 to 130 minutes and conclude the following: a) the conditional covariance matrix estimates based on intraday returns improves portfolio performance when compared with results obtained using returns at

67 One explanation is that "the signal-to-noise ratio is high, and, in terms of the MSE, the uncorrected measure is better than the corrected one" (Ghysels and Sinko, 2006). 
lower frequencies; and b) an appropriate return frequency is more relevant than the bias correction techniques. Furthermore, several studies suggest that "the fiveminute horizon is short enough that the accuracy of the continuous record of asymptotics underlying our realized volatility measures work well, and long enough that the confounding influences from market microstructure frictions are not overwhelming" (Andersen, T.G., Bollerslev, T., Diebold, F.X., Labys, P. ,1999; Andersen et al, 2001). Thus, based on these aforementioned ideas, we employ in this research observations on a five-minute interval basis and do not explicitly handle microstructure noise.

Seasonality has also been a critical issue when dealing with high-frequency data. Literature related to HFD has thoroughly documented a strong intraday repetitive pattern in the average absolute returns. At market opening, absolute returns usually reach the highest values, and then around lunch hour, they diminish dramatically; finally, at the end of the trading day, they rise again, what suggests a seasonal (U-shape) pattern of volatility. Such a pattern makes especially challenging deal with high-frequency data, and we should address the fact that in an intraday setting the presence of seasonality may cause problems when estimating realized measures. Thus, in this regard, the question is: Should we seasonality adjust time series? Arguments on both sides can be found in the literature related to seasonality (for further discussion on this topic see Ghysels 1996, and Ghysels and Osborn 2001). As far as this study is concerned, results seem to be consistent with the stream of literature in favour of not removing seasonality.

Thus, to shed new light into the usefulness of HFD in optimal portfolio allocation, we begin in the next section by explaining the data employed in this research.

\subsection{Data}

Quite recently, considerable attention has been paid to the improvement of the estimation of the covariance matrix in the field of asset allocation (Ledoit and Wolf 2003, 2004a; Jagannathan and Ma, 2003 among others). In this respect, the originality of our approach lies in the fact that not only do we estimate the monthly covariance matrix of stock index returns using monthly data but also HFD. Note, that in practice, as Cartea and Karyampas (2011) suggest, employing the whole dataset at HFD is not the usual option to estimate the realized variance-covariance matrix; and it is common to employ observations on a five-minute interval basis. The decision of using a five-minute frequency is also based on the research of Andersen (2000) as commented in the previous section. 
This means that, to implement this research, two datasets are needed to compute the covariance matrices. Thus, the first and the second datasets comprise respectively excess monthly ${ }^{68}$ and intraday returns on a five-minute interval basis $^{69}$ over the risk free asset ${ }^{70}$ from 8 different stock market indexes, namely CAC40, DAX30, FTSE100, KOSPI 200, NIKKEI 225, S\&P/TSX 60, S\&P 500 and SMI stock indexes from January 2, 2004 to September 30, 2016 ${ }^{71}$ which are listed in Table 1.

\footnotetext{
68 Monthly data has been obtained from Morningstar. To implement the rolling sample approach explained in section 3.2 we also used monthly returns from December, 1993 to December, 2013.

${ }^{69}$ Intraday data has been collected from Tick Data.

70 The risk free rate has been obtained from the website:

http://mba.tuck.dartmouth.edu/pages/faculty/ken.french/data_library.html

71 Our dataset comprises 153 months with 3.318 trading days in total.
} 
TABLE 1: List of the considered datasets

\begin{tabular}{|c|c|c|c|c|c|c|c|}
\hline \multirow[t]{2}{*}{ Index } & \multirow{2}{*}{$\begin{array}{c}\text { Number } \\
\text { observations }\end{array}$} & \multirow[t]{2}{*}{$\mathbf{N}$} & \multirow[t]{2}{*}{ Stock exchange } & \multicolumn{2}{|c|}{ Trading hours } & \multicolumn{2}{|c|}{ Source } \\
\hline & & & & Local Time & Central European Time & Intraday data & Monthly data \\
\hline CAC 40 & 329,967 & 40 & Euronext Paris & 09:00-17:30 & 09:00-17:30 & Tick Data & Morningstar \\
\hline DAX 30 & 327,947 & 30 & Frankfurt Stock exchange & 09:00-17:30 & 09:00-17:30 & Tick Data & Morningstar \\
\hline FTSE 100 & 325,422 & 100 & London Stock Exchange & 08:00-16:30 & 09:00-17:30 & Tick Data & Morningstar \\
\hline SMI & 212,200 & 20 & Swiss Exchange & 09:00-17:30 & $09: 00-17: 30$ & Tick Data & Morningstar \\
\hline KOSPI 200 & 317,592 & 200 & Korea Stock Exchange & 09:00-15:00 & 01:00-07:00 & Tick Data & Morningstar \\
\hline NIKKEI 225 & 222,088 & 225 & Tokyo Stock Exchange & 09:00-15:00 & 01:00-07:00 & Tick Data & Morningstar \\
\hline S\&P/TSX 60 & 247,247 & 60 & Toronto Stock Exchange & 09:30-16:00 & $15: 30-22: 00$ & Tick Data & Morningstar \\
\hline S\&P 500 & 246,708 & 500 & New York Stock Exchange & $08: 30-15: 00$ & $14: 30-21: 00$ & Tick Data & Morningstar \\
\hline
\end{tabular}

Table 1 lists the stock indexes used for the evaluation of the portfolio performance. From left to right we see their abbreviations, the number of observations, the number of assets included in each index, its corresponding Stock Exchange, the trading hours expressed in local time and in central European time and the data sources. Intraday data are expressed on a five-minute interval basis. 
Notice that monthly returns can be incorporated straightforwardly into the optimization problem to estimate the parameters needed; however, intraday returns require previous data cleaning. Therefore, in order not to mislead the statistical inference, when using intraday data, the primary step to generate the raw intraday returns is to remove the first return of the trading day, which generally reflects the adjustment to overnight information and is regarded as the highest average return variability (Andersen et al., 2000). ${ }^{72}$ The next step, in line with literature advocating that seasonality should not be neglected 73 , is to deal with the U-pattern present in the intraday data ${ }^{74}$ and calculate the so-called deseasonalized or standardized returns ${ }^{75}$, which requires computing and extracting the intraday periodic component of return volatility. To do so, we rely on the FFF methodology (Andersen and Bollerslev, 1997) ${ }^{76}$ to remove the intraday seasonality present in raw intraday returns and obtain the standardized intraday returns which. Although, Andersen and Bollerslev (1997) and Martens (2002) suggest using the FFF to remove seasonality from high frequency data, to the best of the authors' knowledge, this methodology has not been previously used in previous studies regarding optimal asset allocation. At this point; the three return series available to be used in the analysis are the following: a) monthly returns, b) raw intraday returns; and c) standardized intraday returns.

Likewise, given that the stock markets studied do not have the same time-zone and operate within different timetables, before estimating the monthly realized covariance matrices by using raw and standardized intraday returns on a fiveminute interval basis, the previous step is to organize the two series considering the Central European Time and the trading hours of each market as can be appreciated in Table 1. After that, for each index, we complete with zeros ${ }^{77}$ the non-trading periods of five minutes in such a way that each day consists of a total of 288 observations. Then, we merge data from each index to consider only the days of simultaneous operation of the markets used in this study. At this stage, we construct the whole realized covariance matrices for each month by summing the outer products of the intraday returns, starting from January, 2004 and until the end of the dataset (September, 2016), so that our dataset comprises 153 months and therefore, we generate for each data series introduced into the optimization problem 153 variance-covariance matrices. ${ }^{78}$

\footnotetext{
${ }^{72}$ We conduct additional steps to clean the raw data. They are available upon request.

73 See Bollerslev (1997) and Martens (2002) among others

74 A repetitive U-shape pattern in the sample autocorrelations which occupies exactly one day can be appreciated each day for all markets. This corroborates the evidence of intraday periodicities in return volatility and raise concern about the importance of removing the intraday seasonal component of the volatility. To keep this article to a reasonable length these results are not attached to this article but they are available upon request.

75 Returns from which the seasonality has been removed.

76 For more details about the Fourier Flexible Form methodology to remove seasonality see Andersen and Bollerslev, 1997.

${ }^{77}$ In those periods in which there is no trading we consider that return is equal to zero.

78 Thus, to do the analysis we estimate the covariance matrix in three different ways: a) using monthly returns; and b) using raw intraday returns and c) standardized intraday returns to estimate the whole realized covariance matrix.
} 
Notice that by completing with zeros the non-trading periods we are assuming that during these intervals of five minutes the estimated pair-wise correlations between the excess risky-asset returns are zero. In line with Kirby and Ostdiek (2012), we consider this a form of shrinkage for the realized covariance matrix that despite the information loss due to this assumption it might outperform the covariance matrix estimates based on data at lower frequencies. As robustness check of the effect of this assumption we implement in section 6 the same study excluding those indexes without overlapping period with any other market, that is to say, we remove the KOSPI 200 and the NIKKEI 225 stock indexes from the study.

\subsection{Methodology}

In this section, we outline the portfolio allocation strategies, the details of the estimation procedure as well as the measures to evaluate the performance.

\subsubsection{Portfolio strategies}

Before starting with a briefly overview of the methodologies used in this research we illustrate the basic framework of the Modern Portfolio Theory or meanvariance analysis. Suppose an investor who wants to allocate his wealth among N risky assets and a risk-free asset. It was Markowitz (1952) who developed the optimal rule for allocating wealth across risky assets in a static setting by choosing a portfolio on the efficient frontier. According to this author, "the investor does (or should) consider expected return a desirable thing and variance of returns an undesirable thing". Thus, consider $X_{t}$ is a N-dimensional vector of the portfolio weights invested in the $\mathrm{N}$ risky assets at time $\mathrm{t}$, investors will choose those weights that optimizes the trade-off between the mean and the variance of portfolio returns, or in other words, that maximize the following expected utility function:

$$
\max X_{t}^{T} \mu_{t}-\frac{\gamma}{2} X_{t}^{T} \sum_{t} X_{t}
$$

where $\gamma$ denotes the investor's risk aversion; T the total length of the data series; $\mu_{t}$ represents the $\mathrm{N}$-dimensional vector of expected excess returns on the risky assets over the risk-free rate; and $\sum_{\mathrm{t}}$ is the $\mathrm{N} \mathrm{X} \mathrm{N}$ variance-covariance matrix of returns . 
The solution to this optimization problem is

$$
X_{t}=(1 / \gamma) \sum_{t}^{-1} \mu
$$

If $\left(1-1_{N}^{T} X_{t}\right)$ is the amount invested in the risk-free asset, then the vector of relative weights in the portfolio with only risky assets may be expressed as follows

$$
w_{t}=\frac{X_{t}}{\left|1_{N}^{T} X_{t}\right|}
$$

Thus, from (2) and (3) can be inferred that the vector of relative portfolio weights invested in the $\mathrm{N}$ risky assets at time $t$ is as follows

$$
w_{t}=\frac{\sum_{t}^{-1} \mu_{t}}{1_{N} \sum_{t}^{-1} \mu_{t}}
$$

The essence of each portfolio optimization methodology explained below lies in the fact that each method proposes different ways to estimate parameters $\mu_{t}$ and $\sum$ t. Given that the majority of academics are familiar with these models and it is beyond the scope of this article to comprehensively explain them, we only report a succinct overview.

\subsubsection{Naïve rule}

The use of the $1 / \mathrm{N}$ policy, or also called the naïve rule, has a long-standing history in asset allocation. Indeed, this rule can be dated back to around the fourth century when this way of allocation was recommended in the Talmud. Rabbi Isaac bar-Aha gave the following asset allocation advice: "A man should always place his money, a third into land, a third into merchandise, and keep a third at hand" (Duchin and Levi, 2009). Thus, the core of this method consists of making an equal allocation to each asset; it involves neither optimization nor estimation; and completely neglects the 
data. In line with DeMiguel et al. (2009b) the naïve rule will be used in this study as benchmark to evaluate the performance of the different strategies implemented.

\subsubsection{Mean-Variance (with and without short sale constrains)}

In the mean-variance portfolio optimization theory of Markowitz (1952), the optimal portfolio weight vector, $w_{t}$, is a function of the investor's preference parameters, $\gamma$, and the first two moments of the return distribution, that it to say, the mean vector $\mu_{t}$ and the variance-covariance matrix $\sum_{\mathrm{t}}$. Given that these two moments are not directly observable, they have to be estimated, and the most straightforward method to estimate them is simply to use the sample mean and the sample covariance matrix. Thus, portfolio weights can be computed as follows:

$$
w_{t}=\frac{\widehat{\Sigma}_{t}^{-1} \widehat{\mu}_{t}}{1_{N} \widehat{\Sigma}^{-1} \widehat{\mu}_{t}}
$$

Additionally, following Frost and Savarino (1988) and Chopra (1993), who highlight the fact that short sale constraints can help reduce estimation error, we also consider the mean-variance strategy with short sale constrains, so that optimal portfolio weights have to be non-negative. Therefore, we set the following restriction $w_{t} \geq 0$.

\subsubsection{Minimum variance (with and without short sale constrains)}

It is widely known that it is more difficult to estimate means than covariances of asset returns and that errors in means estimates have greater impact on portfolio weights than errors in covariance estimates (Merton, 1980; Jorion, 1986) ${ }^{79}$. For this reason, much recent research on the minimum variance portfolios has been done (see among others Jagannathan and $\mathrm{Ma}$, 2003). Notice that the minimum variance portfolio strategy relies only on estimates of the covariance matrix and as a result of that it is deemed to be less vulnerable to estimation error than other methodologies that consider the mean as well.

Thus, this strategy selects the portfolio of risky assets that minimizes the variance of returns and ignores the estimate of the expected returns; that is,

\footnotetext{
79 Jagannathan and Ma (2003) claim that "the estimation error in the sample mean is so large that nothing much is lost in ignoring the mean altogether when no further information about the population mean is available." Their research shows that the global minimum-variance portfolio usually performs better out-of-sample with regard to the mean- variance portfolio strategy.
} 


$$
\min w_{t}^{T} \sum_{t} w_{t}, \text { s.t } 1_{N}^{T} w_{t}=1
$$

As in the previous strategy, we also consider the minimum variance methodology with short sale constraints; that is to say including the restriction $w_{t} \geq 0$.

The remaining strategies, Volatility timing (VT) and Reward-to-Risk timing (RRT), follow Kirby and Ostdiek (2012). These authors develop these two methodologies that use sample information, a tuning parameter to measure aggressiveness and at the same time exploit the most attractive aspects of the naïve rule; that is: no optimization, no covariance matrix inversion and no short sales.

\subsubsection{Volatility timing}

In this strategy portfolio weights are rebalanced based on changes in the estimated conditional matrix of returns and they are computed as follows:

$$
\widehat{W_{l t}}=\frac{\left(1 / \widehat{\sigma_{l t}^{2}}\right)^{\eta}}{\sum_{i=1}^{N}\left(1 / \widehat{\sigma_{l t}^{2}}\right)^{\eta}}, i=1,2, \ldots, N
$$

where $\eta>0$, is a tuning parameter which determines how aggressively the investor adjusts portfolio weights in response to volatility changes, and therefore enables to control turnover, and $\sigma_{i t}^{2}$ is the estimated conditional variance of the excess return on the ith risky asset. Thus, if the tuning parameter, $\eta$, tends to zero we get the equally-weighted portfolio, and when it tends towards infinity the weights on the assets with less variance approach to one.

\subsubsection{Reward-to- Risk timing}

Note that the VT strategy neglects information about conditional expected returns. The RRT method aims to improve performance considering this information, so that the weights are calculated of the form

$$
\widehat{w_{l t}}=\frac{\left({\widehat{\mu_{l t}}}^{+} /{\widehat{\sigma_{l t}^{2}}}^{\eta}{ }^{\eta}\right.}{\sum_{i=1}^{N}\left({\widehat{\mu_{l t}}}^{+} /{\widehat{\sigma_{l t}^{2}}}^{\eta}{ }^{\eta}\right.}, i=1,2, \ldots, N
$$


where ${\widehat{\mu_{l t}}}^{+}=\max \left(\widehat{\mu_{l t}}, 0\right)$. This means that the investor removes any asset with $\mu_{i t} \leq 0$. Note that the rest of parameters are the same employed in the previous methodology 80 .

\subsubsection{Performance evaluation}

In accordance with DeMiguel et al. (2009b) we employ a rolling sample approach of length $\mathrm{M}=120$ months to estimate the optimization input parameters. Portfolio weights are first based on the estimation period from January 1993 to December 2003 (that is to say, 120 months) using the monthly excess returns; and the out-ofsample period is from January, 2004 to September, 2016 (153 months), so that, the data introduced in the optimization problem are different depending on the dataset used. For dataset 1, comprised by monthly returns, we use each month, starting from $\mathrm{t}=\mathrm{M}+1$, the data in the previous $\mathrm{M}$ months to estimate the required parameters to implement the optimization strategies. With these parameters each strategy determines its optimal portfolio weights, and then the out-of-sample return in month $t+1$. We follow the same procedure by moving one month forward and dropping the earliest return until we reach the end of the period, which keeps the estimation window length fixed, so that, given a dataset with $\mathrm{N}$ risky assets of length $\mathrm{T}$ months, with the rolling sample methodology we obtain a vector of T-M monthly out-of-sample returns and a $(\mathrm{T}-\mathrm{M}) \times \mathrm{N}$ matrix of optimal portfolio weights for each strategy ${ }^{81}$. For dataset 2 the rolling sample approach is basically the same, but the difference lies in the fact that each month we introduce in the optimization procedure, on one hand the realized covariance matrices estimated using raw intraday returns, and on the other hand, the realized covariance matrices computed using standardized intraday returns as explained in section 4.3.

The out-of-sample returns are then used to measure portfolio performance in terms of two metrics: the Sharpe ratio and the certainty equivalent rate of return. Additionally the optimal portfolio asset weights are used to compute a third measure of performance: the turnover.

\subsubsection{Performance metrics: Sharpe ratio, certainty equivalent rate of return (CEQ) and turnover}

\footnotetext{
80 In line with Kirby and Ostdiek (2012) we set $\eta=1 ; \eta=2$ and $\eta=4$.

81 In this research, we use $\mathrm{N}=8$ risky assets; $\mathrm{T}=273$ months; and we obtain a vector of 153 monthly out-ofsample returns and a $153 \times 8$ matrix of optimal portfolio weights for each portfolio strategy.
} 
The out-of-sample Sharpe ratio of strategy $k$ is the most commonly used performance measure. It is defined as the sample mean of the out-of-sample excess returns (over the risk-free asset) $\hat{\mu}_{k}$, divided by their sample standard deviation $\hat{\vartheta}_{k}$,

$$
\widehat{S R_{k}}=\frac{\widehat{\mu}_{k}}{\widehat{\vartheta}_{k}}
$$

Another utility-based measure is the certainty equivalent rate of return (CEQ). The CEQ for strategy $k$ is the risk-free rate of return that the investor is willing to accept instead of undertaking the risky portfolio strategy. In the literature regarding portfolio allocation it is common to mathematically define the CEQ as:

$$
\widehat{C E Q_{k}}=\hat{\mu}_{k}-\frac{\gamma}{2} \hat{\sigma}_{k}^{2}
$$

where $\hat{\mu}_{k}$ and $\hat{\sigma}_{k}^{2}$ are the mean and variance of out-of-sample excess returns(over the risk-free asset) for strategy $\mathrm{k}$, and the parameter $\gamma$ represents the investor's risk aversion ${ }^{82}$.

The third measure of out-of-sample performance is portfolio turnover which, in terms of active management of an investment portfolio, is an important concept in finance. It is a volume based metric of the amount of trading required to implement a particular portfolio strategy that gives investors some insight into how often assets in the portfolio are bought or sold. Thus, turnover for strategy $k$ is mathematically expressed as the average sum of the absolute value of trades across the $\mathrm{N}$ risky assets:

$$
\text { Turnover }=\frac{1}{T-M} \sum_{t=1}^{T-M} \sum_{j=1}^{N}\left(\left|\widehat{w}_{k, j, t+1}-\widehat{w}_{k, j, t^{+}}\right|\right)
$$

\footnotetext{
82 The results reported are for the case of $\gamma=1$ as in DeMiguel et al. (2009b).
} 
where $\widehat{w}_{k, j, t^{+}}$and $\widehat{w}_{k, j, t+1}$ are respectively, the portfolio weight in asset $\mathrm{j}$ at time $\mathrm{t}$ under strategy $k$ before rebalancing and the desired portfolio weight at time $t+1$ after rebalancing.

\subsection{Empirical results}

In this section we comprehensively examine the performance implications of using HFD in optimal portfolio allocation throughout the various portfolio strategies implemented, taking as a benchmark the 1/N strategy. Firstly, section 4.5.1 deals with baseline results, that is to say, results without considering transaction costs (TCs), section 4.5.2 introduces TCs in the optimization problem; given that, trading costs may considerably reduce portfolio's return, in practice it is advisable to account for them at the portfolio construction stage; and finally, section 4.5.3 measures error estimate of covariance matrices.

\subsubsection{Baseline results}

We start by analyzing the first metric of performance: the Sharpe ratio. Table 2 gives the annualized Sharpe ratio ${ }^{83}$ of the optimal portfolio allocation strategies that employ monthly returns and; raw and standardized intraday data. The strategies are listed in rows (results for the benchmark 1/N strategy are reported in the leading row of the table), whereas the columns refer to the returns data series introduced in the optimization problem, namely data series A (monthly returns), data series $B$ (raw intraday data) and data series C (standardized intraday data).

${ }^{83}$ We rely on the Opdyke (2007) test to test whether the null hypothesis that the Sharpe ratio of an optimal strategy is less than or equal to that of the benchmark strategy $(1 / \mathrm{N})$. 
TABLE 2: Annualized Sharpe ratio before transaction costs

\begin{tabular}{|l|c|c|c|} 
& $\begin{array}{c}\text { Series A (monthly } \\
\text { returns) }\end{array}$ & $\begin{array}{c}\text { Series B (raw } \\
\text { intraday data) }\end{array}$ & $\begin{array}{c}\text { Series C (standardized } \\
\text { intraday data) }\end{array}$ \\
\hline $\mathbf{1}$ /N & 0.2699 & 0.2699 & 0.2699 \\
\hline Mean variance & $\mathbf{0 . 3 3 5 0}$ & 0.3461 & -0.3395 \\
& $\mathbf{( 0 . 0 0 ) ^ { * * * }}$ & $(0.00)^{* * *}$ & $(1.00)$ \\
\hline Mean Variance & 0.2047 & 0.3450 & 0.2657 \\
restricted & $(0.99)$ & $(0.00)^{* * *}$ & $(1.00)$ \\
\hline Minimum variance & -0.0007 & 0.3561 & 0.2515 \\
& $(0.96)$ & $(0.00)^{* * *}$ & $(1.00)$ \\
\hline Minimum variance & 0.2040 & 0.3450 & 0.2660 \\
\hline restricted & $(0.99)$ & $(0.00)^{* * *}$ & $(1.00)$ \\
\hline VT1 & 0.2106 & 0.3235 & 0.2823 \\
& $(1.00)$ & $(0.00)^{* * *}$ & $(0.00)^{* * *}$ \\
\hline VT2 & 0.1909 & $\mathbf{0 . 3 8 9 4}$ & 0.3281 \\
& $(1.00)$ & $(\mathbf{0 . 0 0})^{* * *}$ & $(0.2424)$ \\
\hline VT4 & 0.1680 & 0.5106 & $\mathbf{0 . 4 1 8 8}$ \\
& $(1.00)$ & $(0.50)$ & $(\mathbf{0 . 0 4})^{* *}$ \\
\hline RRT1 & 0.2882 & 0.3790 & 0.3599 \\
& $(0.00) * * *$ & $(0.00)^{* * *}$ & $(0.00)^{* * *}$ \\
\hline RRT2 & 0.2539 & 0.3641 & 0.3485 \\
& $(1.00)$ & $(0.00)^{* * *}$ & $(0.00)^{* * *}$ \\
\hline RRT4 & 0.2311 & 0.3530 & 0.3163 \\
& $(1.00)$ & $(0.00)^{* * *}$ & $(0.00)^{* * *}$ \\
\hline
\end{tabular}

Table 2 exhibits the annualized Sharpe ratio of the optimal portfolio allocation strategies. The strategies are listed in rows (results for the benchmark 1/N strategy are reported in the leading row of the table), whereas the columns refer to the returns data series introduced in the optimization problem, namely data series A (monthly returns), data series B (raw intraday data) and data series C (standardized intraday data). We rely on the Opdyke (2007) test to check whether the null hypothesis that the Sharpe ratio of an optimal strategy is less than or equal to that of the benchmark strategy $(1 / \mathrm{N})$. The associated p-values are shown below the performance metric in each case and ${ }^{* * *}, * *$ and ${ }^{*}$ denote that the null hypothesis is rejected at $1 \%, 5 \%$ and $10 \%$ significance level. The strategy with the highest Sharpe ratio for each data series is given in bold. VT1, VT2 and VT4 represent the volatility timing strategy with a tuning parameter of 1,2 and 4 respectively. In the same way RRT1, RRT2 and RRT4 represents the reward-to-risk timing strategy with a tuning parameter of 1,2 and 4 respectively. 
To assess the magnitude of the potential profit that an investor might achieve by switching from data at lower frequencies to intraday data, it is crucial to study the out-of-sample Sharpe ratio of the different strategies. As can be appreciated in Table 2, when monthly returns are used, the Sharpe ratios for the different strategies are substantially lower than the Sharpe ratio for the 1/N strategy, note that only the mean variance $(0.3350)$ and the reward-to-risk timing with a tuning parameter equal to $1(0.2882)$ beat the naïve rule $(0.2699)$. However, when intraday data are used in the optimization problem the out-of-sample performance improves considerably. The out-of-sample Sharpe ratios obtained by using raw intraday data are higher than those Sharpe ratios obtained using monthly data the estimated Sharpe ratios range from 0.3235 to $0.3894^{84}$ ), and moreover they also beat the $1 / \mathrm{N}$ rule for all the strategies (for instance for the min variance strategy the Sharpe ratio is equal to 0.3561 when using raw intraday data, whereas it is equal to -0.0007 when using monthly data). Similarly, for standardized intraday data the Sharpe ratios for the different strategies are remarkably better than those computed using monthly data (excluding the mean variance strategy), and moreover, note that the VT and the RRT strategies proposed by Kirby and Ostdiek (2012) beat the equally-weighted strategy as well.

These results suggest that, in this context, the best performance is achieved by those portfolio allocation strategies that employ raw intraday data. This result is in line with the strand of literature that advocates that seasonality does not appear to be meaningful when an appropriate return frequency is considered 85 .

Thus, in the absence of TCs, portfolios designed using HFD and, in particular raw data, are found to provide better performance than those that employ monthly data (see that the Sharpe ratios for intraday data are higher than Sharpe ratios for monthly data). To put it another way, these findings suggest that the estimate error is greater as the frequency of the observation decreases, and it worsens Sharpe ratios on the optimization strategies.

The annualized out-of-sample certainty equivalent rate of return (CEQ) corroborates the conclusions drawn by the analysis of the Sharpe ratio. This fact is already observed in previous literature (see among others DeMiguel et al. 2009b) given that, in both metrics, the higher the mean returns and the lower the variance, the greater the measure of performance. To keep this article to a reasonable length, results regarding the CER are not attached to this article, but they are available upon request.

Hence, our first observation is in good agreement with those results found by Fleming, Kirby and Ostdiek (2003); Zhang et al. (2005); Liu (2009); and Hautsch, Kyj and Malec (2015), suggesting that: a) when monthly data are introduced into

${ }^{84}$ Note that the Sharpe ratio for the VT4 strategy (0.5106) is not significant

85 See among others, Ghysels 1996, and Ghysels and Osborn 2001. 
the optimization problem we obtain poorer performance as reported in DeMiguel et al. (2009b), b) the benefit from using intraday data in optimal portfolio choice may be worthwhile, and c) considering raw intraday data leads to superior performance.

Table 3 exhibits the third measure of performance: the monthly turnover for each portfolio allocation strategy. The undisputed winner in terms of turnover, reported in the first row, is the turnover of the equally-weighted strategy in which only $0.0001(0.01 \%)$ of wealth is traded on average at each rebalancing. Obviously, this turnover is smaller because in this strategy the weight for each asset is constant and equal to $1 / \mathrm{N}$; therefore turnover is not originated by optimization decisions, but only by changes in prices. Consequently, in all cases the turnover for the portfolio from the optimization strategies is considerably greater than for the $1 / \mathrm{N}$ strategy. We also see that the mean variance strategy has the greatest turnover and as previous studies corroborate the strategies with shortsale constraints have lower turnover than the unrestricted ones (DeMiguel et al., 2009b). As far as series A is concerned (monthly returns) the best dynamic portfolio strategy with a turnover of $0.0079(0.79 \%)$ is the VT1. Moreover, for all strategies, excluding the mean variance approach, notice that when using monthly data, the turnover for the optimization strategies is lower and ranges from $0.0079(0.79 \%)$ to 0.1822 (18.22\%), whereas the turnover varies from $0.1854(18.54 \%)$ to $0.5803(58.03 \%)$ and from $0.1822(18.22 \%)$ to $0.6665(66.65 \%)$ when using raw and standardized intraday data respectively. Hence, despite the better performance of the HFDbased approaches due to the efficient use of more recent information, what leads to higher responsiveness of forecasts, the main drawback of using HFD, in line with results found by Hautsch, Kyj and Malec (2015), is the greater variability in portfolio weights that increases portfolio turnover and therefore, transaction costs. 
TABLE 3: Turnover for the asset allocation strategies

\begin{tabular}{|l|c|c|c|}
\hline & $\begin{array}{c}\text { Series A } \\
\text { (monthly returns) }\end{array}$ & $\begin{array}{c}\text { Series B (raw } \\
\text { intraday data) }\end{array}$ & $\begin{array}{c}\text { Series C (standardized } \\
\text { intraday data) }\end{array}$ \\
\hline $\mathbf{1}$ /N & 0.0001 & 0.0001 & 0.0001 \\
\hline Mean variance & 65.6150 & 7.6742 & 27.0986 \\
\hline $\begin{array}{l}\text { Mean Variance } \\
\text { restricted }\end{array}$ & 0.0903 & 0.2492 & 0.2769 \\
\hline Minimum variance & 0.1822 & 0.3309 & 0.3417 \\
\hline Minimum variance & 0.0889 & 0.2486 & 0.2760 \\
\hline restricted & $\mathbf{0 . 0 0 7 9}$ & 0.1874 & 0.1972 \\
\hline VT1 & 0.0148 & 0.3506 & 0.3733 \\
\hline VT2 & 0.0269 & 0.5803 & 0.6665 \\
\hline VT4 & 0.1084 & $\mathbf{0 . 1 8 5 4}$ & $\mathbf{0 . 1 8 2 2}$ \\
\hline RRT1 & 0.1357 & 0.2786 & 0.2612 \\
\hline RRT2 & 0.1740 & 0.3609 & 0.3267 \\
\hline RRT4 & & & \\
\hline
\end{tabular}

Table 3 reports the monthly turnover for the optimal portfolio allocation strategies, that is to say, the average percentage of wealth traded in each month (see equation 11). The strategies are listed in rows (results for the benchmark 1/N strategy are reported in the leading row of the table), whereas the columns refer to the returns data series introduced in the optimization problem, namely data series A (monthly returns), data series B (raw intraday data) and data series C (standardized intraday data). VT1, VT2 and VT4 represent the volatility timing strategy with a tuning parameter of 1,2 and 4 respectively. In the same way RRT1, RRT2 and RRT4 represents the reward-to-risk timing strategy with a tuning parameter of 1, 2 and 4 respectively. The dynamic strategy with lowest turnover for each data series is given in bold. 
Additionally, note that Table 3 shows that when using HFD the smaller turnover is obtained with the volatility timing (VT) and Reward-to-Risk timing (RRT) strategies considering a tuning parameter equal to $1(\eta=1)$, that is to say in those VT and RRT strategies in which the timing aggressiveness is lower, thus, the more risk loving the investor is the greater the turnover is.

On the basis of this evidence, it can be inferred that the use of HFD in optimal portfolio allocation improves the performance by reducing the estimation error, which is not the primary barrier to successful optimization, but the turnover. Notice that active strategies that imply high turnover are dramatically affected by transaction costs, in such a way that, as highlighted by Kirby and Ostdiek (2012), periodic rebalancing and associated TCs may dramatically undermine the benefits of portfolio optimization strategies. Hence, in the next section we assess the different portfolio performances after incorporating the transaction costs of rebalancing monthly which play a crucial role whenever we follow a dynamic strategy.

Having concluded by means of the Sharpe ratio (before TCs) that the use of HFD improves the performance, at this point, the focus is on how the higher turnover detected when using HFD affects the dynamic portfolio strategies performance.

\subsubsection{Breakeven transaction cost}

Although Markowitz (1952) demonstrated how to find the best portfolio at a specified time, his basic methodology based on the maximization of expected returns of the portfolio and the simultaneous minimization of the investment risk does not include the costs generated by changing portfolio weights. Given that, in practice, each transaction has an associated cost that must be considered in the decision investment process, we evaluate, to this extent, the impact of TCs on the utility gains reported in the above section. Thus, the role of transaction costs on portfolio selection is not trivial, so that the higher the turnover the greater the cost that the investor has to pay.

Following Pooter et al. (2008), we define transaction costs as follows;

$$
C_{t+1}=C \sum_{i=1}^{N}\left|w_{i, t+1}-w_{i, t}\right|
$$

where $C_{t+1}, C$ and $\sum_{i=1}^{N}\left|w_{i, t+1}-w_{i, t}\right|$ represents the cost of reallocating the portfolio at the point of rebalancing, a fixed TC expressed in annualized percentage, and the sum of the absolute changes in the portfolio weights respectively. Thus, the net portfolio return is computed by deducting $C_{t+1}$. 
Unfortunately, it is not easy to compute the total TCs associated to an investment. Accurate estimation of the amount of TCs is challenging because the appropriate estimates of TCs are not usually available and it requires information on the type of investor and broker. Academic research regarding TCs has employed a wide range of estimates. For instance, there are studies that apply TCs of 10 basis points (DeMiguel et al., 2014), other investigations consider TCs of 50 basis points (DeMiguel et al., 2009b), while there are those that use three levels of TCs, ranging from 10 to 100 basis points, representing low, medium, and high costs, respectively (Marquering and Verbeek, 2004). To overcome this issue and in line with Han (2006) we estimate the breakeven transaction cost (BTCs henceforth) defined as the TCs that make investors indifferent between the dynamic and the static strategies in terms of utility. In such a way that, when TCs are lower than the breakeven transaction cost, investors will follow a dynamic strategy; otherwise, they should follow the static benchmark, that is to say, the naïve rule ${ }^{86}$.

Table 4 exhibits the BTCs of the dynamic strategies. As one might expect, in presence of TCs, the performance of dynamic strategies deteriorates; nevertheless, notice that all the portfolio methodologies that use raw HFD beat the benchmark strategy when TCs are below 12.08 basis points, and moreover, for series B (raw intraday data) the maximum transaction costs possible that makes an investor indifferent between holding the equally-weighted portfolio and implementing a sophisticated strategy ranges from 12.08 to 76.43 basis points, being the best strategy to follow the RRT with a tuning parameter equal to one (RRT1).

86 Our analysis assumes that the level of transactions costs is constant across assets and throughout the whole sample period. 
TABLE 4: Breakeven transaction costs for monthly rebalancing strategies

\begin{tabular}{|l|c|c|c|}
\hline & $\begin{array}{c}\text { Series A (monthly } \\
\text { returns) }\end{array}$ & $\begin{array}{c}\text { Series B (raw } \\
\text { intraday data) }\end{array}$ & $\begin{array}{c}\text { Series C (standardized } \\
\text { intraday data) }\end{array}$ \\
\hline Mean variance & 4.70 & 12.08 & -98.60 \\
\hline $\begin{array}{l}\text { Mean Variance } \\
\text { restricted }\end{array}$ & -61.29 & 35.09 & 1.99 \\
\hline Minimum variance & -140.63 & 28.00 & -3.06 \\
\hline Minimum variance & $-63,00$ & 35.10 & 2.12 \\
\hline restricted & -672.37 & 35.50 & 12.30 \\
\hline VT1 & -482.80 & 37.27 & 20.30 \\
\hline VT2 & -344.00 & 41.90 & 26.90 \\
\hline VT4 & $\mathbf{2 9 . 7 0}$ & $\mathbf{7 6 . 4 3}$ & $\mathbf{6 7 . 0 9}$ \\
\hline RRT1 & -5.83 & 46.42 & 43.89 \\
\hline RRT2 & -20.89 & 33.58 & 23.67 \\
\hline RRT4 & & & \\
\hline
\end{tabular}

Table 4 exhibits the breakeven transaction costs expressed in basis points and computed as the maximum transaction costs possible that makes an investor indifferent between holding the equally-weighted portfolio and implementing a sophisticated strategy, thus, when TCs are lower than the breakeven transaction cost, the investor will follow a dynamic strategy; otherwise, he should follow the static benchmark (1/N rule). VT1, VT2 and VT4 represent the volatility timing strategy with a tuning parameter of 1,2 and 4 respectively. In the same way RRT1, RRT2 and RRT4 represents the reward-to-risk timing strategy with a tuning parameter of 1,2 and 4 respectively. The best portfolio for each series, defined as the one with the highest breakeven transaction costs, is shown in bold. 
As far as standardized HFD is concerned only the VT and RRT strategies outperform the equally-weighted strategy for TCs below 12.30 basis points. As can be appreciated in Table 4, for series C (standardized intraday data), the BTCs for the timing strategies vary from 12.30 to 67.09 basis points and the winner strategy is the RRT1 as well.

With regard to monthly data (series A), only the RRT1 strategy beats the naïve rule for TCs smaller than 29.70 basis points. The BTC for the mean variance strategy is 4.70 basis points and the remaining strategies have negative BTCs, obviously, because the Sharpe ratio before TCs is lower than the Sharpe ratio for the naïve strategy as can be appreciated in Table 2. Consequently, when monthly data are introduced into the optimization problem we obtain poorer performance as reported in DeMiguel et al. (2009b).

Thus, despite the higher turnover obtained in the HFD-based approaches, the performance of those strategies that use HFD to estimate the covariance matrix improves considerably beating the $1 / \mathrm{N}$ rule in the majority of cases.

Overall, these results underscore the positive performance implications of deploying HFD in the field of optimal portfolio allocation, especially raw intraday data. Likewise, in line with Kirby and Ostdiek (2012), the VT and RRT strategies seem to be two promising approaches.

\subsection{Measurement estimation error}

It is widely known that estimating the covariance matrix of returns has always been challenging. Previous studies indicate that when the number of assets considered is large in relation to the number of return observations, the sample variance-covariance matrix is estimated with a lot of error. Furthermore, provided that asset returns are independently and identically distributed, the higher the number of observations, the lower the errors in the covariance matrix estimated using historic returns (Ledoit and Wolf, 2004b). ${ }^{87}$ Thus, based on this idea and the results obtained so far, we expect that error in estimating the variance-covariance matrix to be lower when raw ${ }^{88}$ HFD are used in the analysis.

Given that, previous results suggest better performance when raw HFD are used in the optimization problem, we compare in this section the estimation error obtained when using raw intraday data (data series B) and monthly data (data

87 When the number of variables are finite and fixed, and the number of observations goes to infinity, under standard asymptotics, the sample covariance matrix is well-conditioned (in the limit) and has some appealing optimality properties.

88 Results in previous sections show that dynamic strategies that use raw intraday data outperform those dynamic strategies that use standardized intraday data. 
series A). To this end, we measure the estimation error by means of the following metrics: a) mean absolute error (MAE), b) mean squared error (MSE) and c) the Mincer-Zarnowitz regression ${ }^{89}$ expressed as follows:

$$
\tilde{\sigma}_{i t}^{2}=a_{0}+a_{1} \widehat{\sigma_{i t}^{2}}+e_{i t}, \quad t=1, \ldots, T ; i=1, \ldots, N
$$

where $\tilde{\sigma}_{i t}^{2}$ is a proxy for the ex-post volatility ${ }^{90}, \widehat{\sigma_{t t}^{2}}$ is the out-of-sample variance forecast ${ }^{91}$ and $e_{i t}$ are the residuals of the regression. Then, we compare the results of these metrics.

Table 5 exhibits the results of the metrics employed to measure errors in the estimation of the variance-covariance matrix when using monthly returns (data series A) and raw intraday returns (data series B).

${ }^{89}$ Mincer and Zarnowitz (1969).

90 We consider the realized volatility obtained with raw returns as a proxy of the ex-post volatility.

91 For each data series (monthly and raw intraday data series), we consider the variance estimated in the previous period as variance forecast 
TABLE 5: Measurement estimation error

PANEL A: Mean absolute error (MAE) and Mean squared error (MSE)

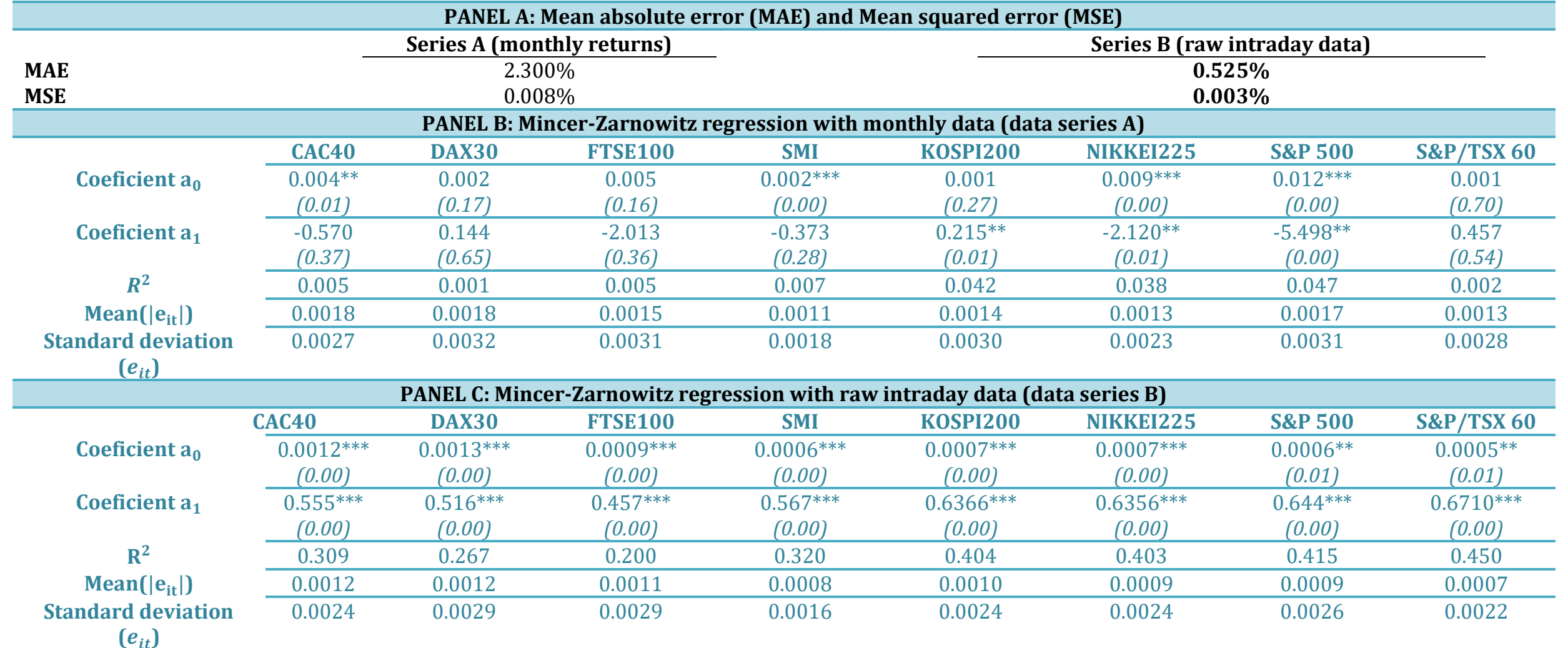

Table 5 exhibits the results of the metrics used to measure errors in the estimation of the variance-covariance matrix when using monthly returns (data series A) and raw intraday returns (data series B). Panel A shows the MAE and MSE, which are listed in rows, whereas the columns refer to the returns data series used in this research. The return series with the lowest estimation error is given in bold.

Panels B and C show the Mincer-Zarnowitz regression for data series A and B respectively, given by $\tilde{\sigma}_{i t}^{2}=a_{0}+a_{1} \widehat{\sigma_{i t}^{2}}+e_{i t}$ for $t=1, \ldots, T ; i=1, \ldots, N$, where $\tilde{\sigma}_{i t}^{2}$

is a proxy for the ex-post volatility, $\widehat{\sigma_{l t}^{2}}$ is the out-of-sample variance forecast and $e_{i t}$ are the residuals of the regression. The associated p-values are shown below the coefficients of the regression $\left(a_{0}, a_{1}\right)$ and ${ }^{* * *},{ }^{* *}$ and ${ }^{*}$ denote significance at $0.01,0.05$ and 0.1 . 
Panel A shows the mean absolute error (MAE) and the mean squared error (MSE). Note that these error estimation metrics are listed in rows, whereas the columns refer to the returns data series (monthly data and raw HFD). As can be appreciated, the lowest estimation error is obtained when raw intraday data are used in the analysis (see that MAE and MSE are equal to $0.525 \%$ and $0.003 \%$ respectively for raw intraday data).

Additionally, panel B presents the results of the Mincer-Zarnowitz regression. The regression coefficients $\left(a_{0}, a_{1}\right)$, the coefficient of determination $\left(R^{2}\right)$, the mean of the absolute errors $\left(e_{i t}\right)$ and their standard deviation are given in rows, whereas the columns show the indexes employed. Notice that when raw intraday data are used to implement the Mincer-Zarnowitz regression all the coefficients are significant, contrariwise, when monthly data are employed even no statistically significant linear dependence between $\tilde{\sigma}_{i t}^{2}$ and $\sigma_{i t}^{2}$ is detected in some indexes (DAX30, FTSE100 and S\&P/TSX 60). Likewise, the coefficient of determination for monthly data ranges from 0.001 to 0.042 , while it varies from 0.200 to 0.450 when using raw intraday data. These results suggest that the overall goodness of fit when using monthly data is really poor and it improves considerably by using raw HFD. Furthermore, see that the mean of the absolute errors and their standard deviation are lower in panel $\mathrm{C}$ than in panel $\mathrm{B}$ for all cases (see for instance that for the CAC40 index the mean absolute error is 0.0018 and 0.0012 for monthly and raw intraday data respectively, and the standard deviation is 0.0027 for monthly data and 0.0024 for raw intraday data). Thus, given that, the lower the errors the more accurate the forecast, this underscores once more the aforementioned findings.

The results thus obtained are in line with the findings in the previous sections and suggest that the performance of dynamic portfolio strategies worsens as the frequency of the observations decreases.

Therefore, this outcome is consistent with the theoretical predictions of Ledoit and Wolf (2004b) and confirms our expectations, suggesting that the use of HFD in optimal portfolio allocation, particularly raw data, leads to better performance by reducing the estimation error.

To sum up, it can be concluded that the higher the frequency of the observations the lower the estimation error and, as a consequence of that, dynamic portfolio strategies obtain better performance. 


\subsection{Additional performance results}

As explained above in section 3, by completing with zeros the non-trading periods we are assuming that during these intervals of five minutes the estimated pairwise correlations between the excess risky-asset returns are zero. Thus, as robustness check of the effect of this assumption we implement in this section the same study excluding those indexes without overlapping period with any other market, that is to say, we remove from the study the KOSPI 200 and the NIKKEI 225 stock indexes, this leaves us with a sample of six stock market indexes.

Table 6 reports the annualized Sharpe ratio before TCs considering only the six stock market indexes with overlapping period with other markets, that is to say the CAC40, DAX30, FTSE100, S\&P/TSX 60, S\&P 500 and SMI stock indexes. As can be appreciated when monthly data are considered, after having removed the NIKKEI 225 and KOSPI 200 indexes, results suggest that only the Sharpe ratio for the mean variance strategy $(0.4257)$ beats the equally-weighted portfolio (note that the Sharpe ratio for the naïve strategy is equal to 0.2598 whereas the Sharpe ratios for the remaining dynamic strategies varies from 0.1732 to 0.2473).However, the performance substantially improves by using HFD, particularly by using raw HFD. Column 2 in Table 6 shows the Sharpe ratios when raw intraday data are used in the optimization problem. See that in this case, the Sharpe ratios are greater than those ratios obtained by using monthly data (except for the mean variance approach), and moreover, they also beat the equallyweighted strategy. For instance, the Sharpe ratio for the VT4 is equal to 0.1732 and 0.5404 for monthly and raw intraday data respectively. 
TABLE 6: Annualized Sharpe ratio before transaction costs (excluding Nikkei 225 and Kospi 200 stock market indexes)

\begin{tabular}{|l|c|c|c|}
\hline & $\begin{array}{c}\text { Series A (monthly } \\
\text { returns) }\end{array}$ & $\begin{array}{c}\text { Series B (raw } \\
\text { intraday data) }\end{array}$ & $\begin{array}{c}\text { Series C (standardized } \\
\text { intraday data) }\end{array}$ \\
\hline $\mathbf{1}$ /N & 0.2598 & 0.2598 & 0.2598 \\
\hline Mean variance & $\mathbf{0 . 4 2 5 7}$ & -0.2006 & 0.1240 \\
& $(\mathbf{0 . 0 0 )} * * *$ & $(1.00)$ & $(1.00)$ \\
\hline Mean Variance & 0.2473 & 0.3575 & 0.2834 \\
\hline restricted & $(1.00)$ & $(0.00)^{* * *}$ & $(0.00)^{* * *}$ \\
\hline Mlinimum variance & 0.0357 & 0.3959 & 0.2802 \\
& $(0.99)$ & $(0.00)^{* * *}$ & $(0.00)^{* * *}$ \\
\hline Minimum variance & 0.2473 & 0.3575 & 0.2806 \\
\hline restricted & $(1.00)$ & $(0.00)^{* * *}$ & $(0.00)^{* * *}$ \\
\hline VT1 & 0.2203 & 0.3190 & 0.2740 \\
& $(1.00)$ & $(0.00)^{* * *}$ & $0.38)$ \\
\hline VT2 & 0.2023 & 0.4018 & 0.3017 \\
& $(1.00)$ & $(0.00)^{* * *}$ & $(0.15)$ \\
\hline VT4 & 0.1732 & $\mathbf{0 . 5 4 0 4}$ & 0.3561 \\
& $(1.00)$ & $(\mathbf{0 . 0 0 )} * * *$ & $(0.45)$ \\
\hline RRT1 & 0.1860 & 0.2466 & 0.2309 \\
& $(0.99)$ & $(0.99)$ & $(0.26)$ \\
\hline RRT2 & 0.1916 & 0.2882 & 0.2636 \\
& $(0.98)$ & $(0.00)^{* * *}$ & $(0.18)$ \\
\hline RRT4 & 0.1995 & 0.3274 & $\mathbf{0 . 3 0 0 3}$ \\
& $(0.87)$ & $(0.06)^{*}$ & \\
\hline
\end{tabular}

Table 6 exhibits the annualized Sharpe ratio of the optimal portfolio allocation strategies. The strategies are listed in rows (results for the benchmark 1/N strategy are reported in the leading row of the table), whereas the columns refer to the returns data series introduced in the optimization problem, namely data series A (monthly returns), data series B (raw intraday data) and data series C (standardized intraday data). We rely on the Opdyke (2007) test to test whether the null hypothesis that the Sharpe ratio of an optimal strategy is less or equal to that of the benchmark strategy $(1 / \mathrm{N})$. The associated p-values are shown below the performance metric in each case and ${ }^{* * *},{ }^{* *}$ and ${ }^{*}$ denote that the null hypothesis is rejected at $1 \%, 5 \%$ and $10 \%$ significance level. The strategy with the highest Sharpe ratio for each data series is given in bold. VT1, VT2 and VT4 represent the volatility timing strategy with a tuning parameter of 1,2 and 4 respectively. In the same way RRT1, RRT2 and RRT4 represents the reward-to-risk timing strategy with a tuning parameter of 1,2 and 4 respectively. 
Table 7 exhibits the outcome of the BTCs analysis considering only these six indexes. Notice that, similar to results found in the previous section, the majority of strategies have negative BTCs when using monthly data; however, see in column 2 that most of the strategies improve their performance when using raw HFD (for instance, see that for the VT strategies the BTCs ranges from 40 to 51 basis points for raw HFD, whereas it varies from -569 to -325 basis points when using monthly data). Therefore, these findings reinforce the positive performance of switching from data at lower frequencies to intraday data in the context of optimal asset allocation, especially when using raw data. 
TABLE 7: Breakeven transaction costs for monthly rebalancing strategies (excluding Nikkei 225 and Kospi 200 stock market indexes)

\begin{tabular}{|l|c|c|c|}
\hline & $\begin{array}{c}\text { Series A (monthly } \\
\text { returns) }\end{array}$ & $\begin{array}{c}\text { Series B (raw } \\
\text { intraday data) }\end{array}$ & $\begin{array}{c}\text { Series C (standardized } \\
\text { intraday data) }\end{array}$ \\
\hline Mean variance & $\mathbf{3 . 4 5}$ & -55.57 & -13.60 \\
\hline $\begin{array}{l}\text { Mean Variance } \\
\text { restricted }\end{array}$ & -10.32 & 42.36 & 8.78 \\
\hline Minimum variance & -115.00 & 38.00 & 6.10 \\
\hline Minimum variance & -10.00 & 42.00 & 8.90 \\
\hline restricted & -569.00 & 40.00 & 9.61 \\
\hline VT1 & -414.50 & 48.00 & 14.50 \\
\hline VT2 & -325.00 & $\mathbf{5 1 . 0 0}$ & $\mathbf{1 8 . 8 0}$ \\
\hline VT4 & -92.44 & -9.56 & -21.30 \\
\hline RRT1 & -81.97 & 13.8 & 2.65 \\
\hline RRT2 & -66.96 & 26.00 & 18.30 \\
\hline RRT4 & & & \\
\hline
\end{tabular}

Table 7 exhibits the breakeven transaction costs expressed in basis points and computed as the maximum transaction costs possible that makes an investor indifferent between holding the equally-weighted portfolio and implementing a sophisticated strategy, thus, when TCs are lower than the breakeven transaction cost, the investor will follow a dynamic strategy; otherwise, he should follow the static benchmark (1/N rule). VT1, VT2 and VT4 represent the volatility timing strategy with a tuning parameter of 1,2 and 4 respectively. In the same way RRT1, RRT2 and RRT4 represents the reward-to-risk timing strategy with a tuning parameter of 1, 2 and 4 respectively. The best portfolio for each series, defined as the one with the highest breakeven transaction costs, is shown in bold. 


\subsection{Concluding remarks}

The modern portfolio theory and its extensions have been widely used in practice. Nevertheless, as a result of estimation errors, some studies suggest that the naïve strategy beats the optimization portfolio strategies in any case. These findings have brought into question the benefits of the investment theory.

Additionally, a prominent strand of literature suggests that intraday returns may be used to construct daily volatility estimates which theoretically should be more accurate than those based on data at lower frequencies, and may minimize the portfolios tracking error volatility.

Based on this approach, the purpose of this paper is to contribute to the existing literature regarding asset allocation by studying the benefits of using intraday data in optimal portfolio choice to estimate the variance-covariance matrix, while considering at the same time, a comprehensive listing of major stock market indexes to build a diversified portfolio.

In the absence of TCs, portfolios designed using HFD and, particularly raw data, are found to provide much better performance than those that employ monthly data, and moreover they beat the equally-weighted portfolio strategy.

Furthermore, results suggest that the use of HFD in optimal portfolio allocation leads to better performance by reducing the estimation error, which is not the primary barrier to successful optimization, but the turnover. Even though, the performance of the HFD-based approaches is considerably superior before transaction costs, high turnover is the most troublesome aspect of using HFD. Notwithstanding, despite the higher turnover obtained when using HFD, the performance of those strategies based on intraday data to estimate the covariance matrix improves considerably beating the $1 / \mathrm{N}$ rule even after having considered TCs. Thus, an accurate forecast and minimization of the estimation error is paramount, and in this sense, HFD seems to play a major role.

Overall, these results underscore the positive performance implications of deploying HFD, especially raw intraday data, and suggest that the benefit from switching from data at lower frequencies to intraday data may be worthwhile in the field of optimal portfolio allocation. 


\section{References}

Andersen, T. G. (2000). Some reflections on analysis of high-frequency data. Journal of Business \& Economic Statistics, 18(2), 146-153.

Andersen, T. G., \& Bollerslev, T. (1997). Intraday periodicity and volatility persistence in financial markets. Journal of Empirical Finance, 4(2-3), 115-158.

Andersen, T.G., Bollerslev, T., Diebold, F.X., Labys, P. (1999). Microstructure bias and volatility signatures. Working Paper, Northwestern University, Duke University and University of Pennsylvania

Andersen, T. G., Bollerslev, T., and Cai, J. (2000). Intraday and interday volatility in the Japanese stock market. Journal of International Financial Markets, Institutions \& Money, 10(2), 107-130

Andersen, T. G., Bollerslev, T., Diebold, F. X., \& Labys, P. (2001). The distribution of realized exchange rate volatility.Journal of the American Statistical Association, 96(453), 42-55.

Andersen, T. G., Bollerslev, T., Diebold, F. X., \& Labys, P. (2003). Modeling and forecasting realized volatility. Econometrica, 71(2), 579-625.

Areal, N. M., \& Taylor, S. J. (2002). The realized volatility of FTSE-100 futures prices. The Journal of Futures Markets, 22(7), 627-648.

Barndorff-Nielsen, O. E., Hansen, P. R., Lunde, A., \& Shephard, N. (2011). Multivariate realised kernels: consistent positive semi-definite estimators of the covariation of equity prices with noise and non-synchronous trading. Journal of Econometrics, 162(2), 149-169.

Brown, S. (1979). The effect of estimation risk on capital market equilibrium. Journal of Financial and Quantitative Analysis, 14(2), 215-220.

Cartea, Á., \& Karyampas, D. (2011). Volatility and covariation of financial assets: A high-frequency analysis. Journal of Banking \& Finance, 35(12), 3319-3334.

Chopra, V.K. (1993). Mean-variance revisited: near optimal portfolios and sensitivity to input variations. Journal of Investing, 2(1), 51-59.

DeMiguel, V., Garlappi, L., Nogales, F. J., \& Uppal, R. (2009a). A generalized approach to portfolio optimization: Improving performance by constraining portfolio norms. Management Science, 55(5), 798-812.

DeMiguel, V., Garlappi, L., \& Uppal, R. (2009b). Optimal versus naive diversification: How inefficient is the $1 / \mathrm{N}$ portfolio strategy? The Review of Financial Studies, 22(5), 1915-1953. 
DeMiguel, V., Nogales, F. J., \& Uppal, R. (2014). Stock return serial dependence and out-of-sample portfolio performance. The Review of Financial Studies, 27(4), 10311073.

Duchin, R., \& Levy, H. (2009). Markowitz versus the Talmudic portfolio diversification strategies. The Journal of Portfolio Management, 35(2), 71-74.

Engle, R. F. (1982). Autoregressive conditional heteroscedasticity with estimates of the variance of United Kingdom inflation. Econometrica, 50(4), 987-1007.

Engle, R.F.(2000).The econometrics of ultra-high frequency data. Econometrica, 68(1), 1-22.

Fleming, J., Kirby, C., \& Ostdiek, B. (2003). The economic value of volatility timing using "realized" volatility. Journal of Financial Economics, 67(3), 473-509.

Frankfurter, G. M., Phillips, H. E., \& Seagle, J. P. (1971). Portfolio selection: the effects of uncertain means, variances, and covariances. Journal of Financial and Quantitative Analysis, 6(5), 1251-1262.

Frost, P. A., \& Savarino, J. E. (1988). For better performance: Constrain portfolio weights. The Journal of Portfolio Management, 15(1), 29-34.

Gallant, A. R. (1981). On the bias in flexible functional forms and an essentially unbiased form: the Fourier flexible form. Journal of Econometrics, 15(2), 211-245.

Gallant, A. R. (1982). Unbiased determination of production technologies. Journal of Econometrics, 20(2), 285-323.

Goodhart, C. A., \& O'Hara, M. (1997). High frequency data in financial markets: Issues and applications. Journal of Empirical Finance, 4(2-3), 73-114.

Ghysels, E. (1996). On the economics and econometrics of seasonality. Advances in Econometrics. Sixth World Congress, Vol. 1, 257-322.

Ghysels, E., \& Osborn, D. R. (2001). The econometric analysis of seasonal time series. Cambridge University Press.

Ghysels, E., \& Sinko, A. (2006). Comment. Journal of Business \& Economic Statistics, 24(2), 192-194.

Green, R., \& Hollifield, B. (1992). When Will Mean-Variance Efficient Portfolios be Well Diversified? The Journal of Finance, 47(5), 1785-1809.

Han, Y. (2006). Asset allocation with a high dimensional latent factor stochastic volatility model. The Review of Financial Studies, 19(1), 237-271.

Hansen, P. R., \& Lunde, A. (2006). Realized variance and market microstructure noise. Journal of Business \& Economic Statistics, 24(2), 127-161. 
Hautsch, N., Kyj, L. M., \& Malec, P. (2015). Do High-Frequency Data Improve HighDimensional Portfolio Allocations?.Journal of Applied Econometrics, 30(2), 263290.

Jacobs, H., Müller, S., \& Weber, M. (2014). How should individual investors diversify? An empirical evaluation of alternative asset allocation policies. Journal of Financial Markets, 19, 62-85.

Jagannathan, R., \& Ma, T. (2003). Risk reduction in large portfolios: Why imposing the wrong constraints helps. The Journal of Finance, 58(4), 1651-1684.

James, W., \& Stein, C. (1961). Estimation with quadratic loss. Proceedings of the fourth Berkeley symposium on mathematical statistics and probability, 1(1961) 361379.

Jorion, P. (1986). Bayes-Stein estimation for portfolio analysis. Journal of Financial and Quantitative Analysis, 21(3), 279-292.

Kan, R., \& Zhou, G. (2007). Optimal portfolio choice with parameter uncertainty. Journal of Financial and Quantitative Analysis, 42(3), 621-656.

Kirby, C., \& Ostdiek, B. (2012). It's all in the timing: simple active portfolio strategies that outperform naive diversification.Journal of Financial and Quantitative Analysis, 47(2), 437-467.

Ledoit, 0., \& Wolf, M. (2003). Improved estimation of the covariance matrix of stock returns with an application to portfolio selection.Journal of Empirical Finance, 10(5), 603-621.

Ledoit, 0., \& Wolf, M. (2004a). Honey, I shrunk the sample covariance matrix. The Journal of Portfolio Management, 30(4), 110-119.

Ledoit, O., \& Wolf, M. (2004b). A well-conditioned estimator for large-dimensional covariance matrices. Journal of multivariate analysis, 88(2), 365-411.

Liu, Q. (2009). On portfolio optimization: How and when do we benefit from highfrequency data?. Journal of Applied Econometrics, 24(4), 560-582.

MacKinlay, A. C., \& Pástor, L. (2000). Asset pricing models: Implications for expected returns and portfolio selection. The Review of Financial Studies, 13(4), 883-916.

Markowitz, H. (1952). Portfolio selection. The Journal of Finance, 7(1), 77-91.

Marquering, W., \& Verbeek, M. (2004). The economic value of predicting stock index returns and volatility. Journal of Financial and Quantitative Analysis, 39(2), 407-429. 
Martens, M. (2002). Measuring and forecasting S\&P 500 index-futures volatility using high-frequency data. The Journal of Futures Markets, 22(6), 497-518.

Merton, R. C. (1980). On estimating the expected return on the market: An exploratory investigation. Journal of Financial Economics, 8(4), 323-361.

Mincer, J. A., \& Zarnowitz, V. (1969). The evaluation of economic forecasts. In Economic forecasts and expectations: Analysis of forecasting behavior and performance. NBER, 3-46.

Opdyke, J. D. J. (2007). Comparing Sharpe ratios: so where are the pvalues?. Journal of Asset Management, 8(5), 308-336.

Pástor, L. (2000). Portfolio selection and asset pricing models. The Journal of Finance, 55(1), 179-223.

Pooter, M. D., Martens, M., \& Dijk, D. V. (2008). Predicting the daily covariance matrix for s\&p 100 stocks using intraday data - but which frequency to use? Econometric Reviews, 27(1-3), 199-229.

Tu, J., \& Zhou, G. (2011). Markowitz meets Talmud: A combination of sophisticated and naive diversification strategies. Journal of Financial Economics, 99(1), 204-215.

Zhang, L., Mykland, P. A., \& Aït-Sahalia, Y. (2005). A tale of two time scales: Determining integrated volatility with noisy high-frequency data.Journal of the American Statistical Association, 100(472), 1394-1411. 


\section{GENERAL CONCLUSIONS}

With the advent of the new technological era, the development of high-frequency datasets is easier than ever. It has allowed a wide range of empirical investigations regarding the financial markets to deepen the understanding on several fields. In this dissertation, three important issues, namely, the study of the lead-lag relationship, volatility transmission and optimal portfolio choice, are addressed by considering intraday data on a five-minute interval basis. Thus, the main purpose of this thesis is to provide new insights into the aforementioned aspects when high-frequency data are used in the analysis.

Chapter A is devoted to the study of the lead-lag relationship between the DAX30 stock index and DAX30 index futures. This research contributes to the existing literature by using high-frequency data and nonlinear models based on an extension of Markovian regime shifts to consider the presence of different regimes in the deviation from the long run equilibrium.

On one hand, in the short run analysis, when using linear models, results support the hypothesis of unilateral causality in such a way that the futures market leads the spot market; however, pronounced two-way causality is detected in the estimation of the MS-VECM suggesting bilateral interaction in the price discovery process, but the futures market has more predictive capability as well. These results are in good agreement with previous empirical studies that reinforce the idea of the leading role of the futures market.

On the other hand, when analysing the cointegration relationship (long run analysis), the results are completely different depending on the model used to make the estimations. The traditional VECM suggests that spot and futures prices do not follow a common long term trend; however the MS-VECM reveals that spot and futures markets are cointegrated and it is the spot price that makes the greater adjustment to re-establish the equilibrium. Moreover, spot price adjustment accelerates in states with higher ECT, suggesting that the convergence towards equilibrium is faster when arbitrage opportunities arise.

Additionally, results from the impulse response analysis reinforce the idea that the dynamic causal effect is remarkably different in regimes with different arbitrage opportunities in such a way that as the arbitrage opportunities increase, the impact of unexpected shocks on prices increases.

In sum, these results underscore the importance of considering regimes present in the error correction term and the hazards of strong linear hypothesis when analysing the lead-lag relationship. 
Chapter B studies the effect of the well-documented intraday seasonality on volatility transmission between the spot and futures markets of the CAC40, DAX30 and FTSE100.In this article, we aim to address how this strong intraday repetitive pattern in average absolute returns affects the volatility transmission dynamics. In essence, the questions that this study attempts to answer are the following: Are the results obtained in this research field the same whether raw data or standardized data are considered? Or, are the persistence of a shock on volatility return in a market and the net directional spillover effects among the spot and futures markets the same regardless of whether this seasonal component is considered?. In this respect, the most noteworthy results are that cross-market volatility interactions between the spot and futures markets have diminished noticeably after considering the seasonal pattern and that volatility transmission differs significantly whether raw and standardized returns are considered, so that when intraday data are not standardized, the optimal number of lags in the VAR model determined by the selection criteria seems to be redundant, suggesting that if the seasonal pattern is neglected, it might result in invalid statistical inference in the spillover analysis. Moreover the impulse response function analysis reveals that when a shock hits the system and the intraday periodic component has not been removed before implementing the spillover analysis, the response to that shock is highly persistent. Finally the directional measurement of volatility spillovers shows that the spot market is the largest net sender of volatility spillovers to the futures market and that, in terms of magnitude, the net pairwise volatility spillover are generally greater when the intraday periodic component has been considered, which suggests, once again, that we might be losing some relevant information regarding volatility transmission if this seasonal component is ignored.

Overall, this second chapter reveals that high-frequency data can shed new light on issues concerning the volatility spillover between spot and futures markets and the importance of removing the seasonal component to reduce the risk of spurious causality when using intraday data in volatility modelling.

The third and last chapter of this dissertation (chapter C) contributes to the existing literature regarding asset allocation by studying the benefits of using intraday data to estimate the variance-covariance matrix considering a comprehensive listing of major stock market indexes to build a diversified portfolio. From the outcome of this research can be inferred that even after considering transaction costs, not only do portfolios designed using highfrequency data, and, particularly raw data, provide much better performance than those that use monthly data, but they also beat the naïve strategy. Therefore, these results highlight the positive performance implications of deploying highfrequency data and suggest that the benefit from switching from data at lower frequencies to intraday data in the field of optimal portfolio allocation is worthy. 
Thus, what seems clear is that high-frequency data is an area of paramount importance and plays a major role in the fields studied in this dissertation. Highfrequency data provides a great potential to improve our understanding of the lead-lag relationship, as well as the volatility spillovers between the spot and futures markets. Finally, it also reveals great potential when implemented to the problem of optimal portfolio choice, showing better performance than other standard strategies that use data at lower frequencies.

To sum up, this thesis advocates that high-frequency data may add compelling value in the fields that have been covered. 


\section{RESUMEN}

\subsection{Introducción 92}

La creciente disponibilidad de datos de alta frecuencia ha impulsado un amplio abanico de investigaciones empíricas que tratan de explicar el comportamiento de los mercados financieros. Sin duda, el uso de datos de alta frecuencia puede revelar nueva información que no puede ser detectada con frecuencias menores; sin embargo, este tipo de datos también suponen un reto para académicos e investigadores debido a las regularidades presentes en los datos intradiarios (Goodhart and O’Hara, 1997).

En base a esta idea, el objetivo general de esta tesis es analizar las principales conclusiones alcanzadas cuando datos de alta frecuencia son utilizados en los siguientes estudios: a) el análisis de las relaciones de lead-lag entre los índices bursátiles de contado y futuro cuando diferentes regímenes están presentes en los datos, b) la influencia de la estacionalidad intradiaria en la transmisión de volatilidad entre los mercados de contado y futuro; y c) la selección óptima de carteras. Para ello, esta tesis se divide en tres artículos publicables, de forma que cada uno de ellos corresponde a un capítulo de tesis. Por tanto, estos tres capítulos que constituyen la esencia de esta tesis, son independientes entre sí (en el sentido de que cada uno puede ser leído y entendido de forma independiente) pero su nexo común es el uso de datos de alta frecuencia. Estos capítulos están precedidos por una breve introducción al tema que contiene la información esencial y les sigue a continuación una conclusión general.

Así pues, el punto de unión entre los tres capítulos es el uso de datos de alta frecuencia.

\subsection{Capítulos de la tesis}

Esta tesis está dividida en tres capítulos (capítulos A, B y C), además de la introducción y el último capítulo dedicado a las conclusiones generales.

El Capítulo A se titula La relación de lead-lag entre los índices bursátiles de contado y futuro: datos intradiarios y Modelos de Cambio de Régimen, e

92 Dado que ninguno de los capítulos han sido redactados en ninguna de las dos lenguas oficiales de la Universitat Jaume I, en cumplimiento de lo previsto en el artículo 27 de la Normativa de los estudios de Doctorado, regulados por el RD 99/2011, en la Universitat Jaume I, aprobada por el Consejo de Gobierno núm. 19 de 26 de enero de 2012 y en vigor desde 11 de febrero de 2012, se resumen a continuación los tres capítulos y se presentan las conclusiones de la tesis en Castellano. 
investiga la relación de lead-lag entre los índices bursátiles de contado y de futuro DAX30. Este estudio contribuye a la literatura existente utilizando datos de alta frecuencia y modelos no lineales basados en una extensión de cambio de régimen con cadenas de Markov (denominados Modelos de cambio de régimen) con el objetivo de superar las carencias derivadas de las hipótesis lineales, ampliamente utilizadas en la literatura previa, en la relación dinámica entre los precios de contado y futuro. Los resultados de este estudio muestran la importancia de tener en cuenta los diferentes regímenes detectados en el término de corrección de error para proporcionar modelos empíricos más adecuados y una mejor comprensión de la transmisión de la información de forma que los agentes participantes en el mercado pueden implementar estrategias más eficientes. Además, los resultados indican que los modelos lineales podrían estar mal especificados cuando en los datos hay cambios estructurales y estos han sido ignorados.

El capítulo B es La influencia de la estacionalidad intradiaria en el patrón de transmisión de la volatilidad y analiza el efecto de la documentada estacionalidad intradiaria en la transmisión de volatilidad entre los mercados de contado y futuro de los índices bursátiles CAC40, DAX30 y FTSE100 utilizando datos de alta frecuencia y la varianza realizada, y compara los resultados obtenidos utilizando modelos en los que el componente estacional ha sido ignorado versus los resultados obtenidos con modelos en que este componente estacional si se ha considerado. Este estudio pone de manifiesto el impacto que la estacionalidad intradiaria tiene en los resultados alcanzados sobre trasmisión de volatilidad. Los resultados muestran que los datos de alta frecuencia pueden aportar nueva información sobre cuestiones relacionadas con la transmisión de volatilidad entre mercados, y destacan la importancia de eliminar el componente estacional para reducir el riesgo de causalidad espuria cuando se utilizan datos de alta frecuencia en los modelos de volatilidad.

Por último, el Capítulo C se titula Aplicación de datos de alta frecuencia en la selección optima de carteras y estudia los beneficios de utilizar datos intradiarios en la estimación de la matriz de varianzas-covarianzas en la selección óptima de carteras, considerando al mismo tiempo una amplia lista de los principales índices bursátiles que nos permita construir una cartera diversificada. Recientemente, una importante corriente de la literatura relativa a selección de carteras muestra evidencia de que las estrategias tradicionales de optimización de carteras no superan la estrategia 1/N (DeMiguel et al., 2009b); lo que pone en cuestión la utilidad de la teoría de inversión. Estos hallazgos suponen un desafío interesante que nos llevan a evaluar en este estudio si mediante el uso de datos de alta frecuencia en la selección de carteras, en lugar de datos con frecuencias menores, podemos mejorar los resultados y batir la estrategia naïve. En este sentido, se propone la construcción de carteras diversificadas considerando datos mensuales y datos de alta frecuencia en la modelización de los segundos 
momentos, y se comparan los resultados de estas carteras en términos de varias medidas out-of-sample, concretamente el Sharpe ratio, el certainty equivalent rate of return y el turnover. Los resultados muestran las ventajas de pasar de datos con baja frecuencia a datos con alta frecuencia; y además, se concluye que los resultados obtenidos con las estrategias dinámicas que utilizan datos intradiarios son mejores que aquellos obtenidos con la estrategia $1 / \mathrm{N}$, incluso en presencia de costes de transacción.

\subsection{Conclusión}

Con la llegada de la nueva era tecnológica, el desarrollo de las bases de datos de alta frecuencia nunca fue tan fácil. Ello ha permitido un amplio abanico de investigaciones empíricas relacionadas con los mercados financieros para profundizar en la comprensión de diversos campos. En esta tesis se abordan tres cuestiones importantes utilizando datos intradiarios con una frecuencia de cinco minutos, en concreto el estudio de la relación de lead-lag y transmisión de volatilidad entre los mercados de contado y futuro, y la selección óptima de carteras. Por tanto, el principal objetivo de esta tesis es aportar nueva información relativa a estos tres aspectos cuando se utilizan datos de alta frecuencia en el análisis.

El capítulo A está dedicado al estudio de la relación de lead-lag entre los índices bursátiles de contado y futuro DAX 30. Este estudio contribuye a la literatura existente utilizando datos de alta frecuencia y modelos no lineales basados en una extensión de los modelos de cambio de régimen markovianos, los cuales nos permiten incorporar diferentes regímenes presentes en la desviación del equilibrio a largo plazo.

Por una parte, el estudio de la relación a corto plazo cuando se utilizan modelos lineales indica que existe causalidad unidireccional corroborando la hipótesis del liderazgo del mercado de futuro; sin embargo al utilizar el modelo no linear MSVECM se detecta que en el proceso de Price Discovery la interacción es bilateral, aunque el mercado de futuro sigue teniendo también más capacidad predictiva. Estos resultados son acordes con estudios previos que apoyan la idea del liderazgo del mercado de futuro.

Por otra parte, al analizar la relación de cointegración, los resultados son completamente diferentes en función del modelo utilizado para hacer las estimaciones. Las estimaciones del modelo tradicional VECM indican que los precios de contado y futuro no siguen una tendencia común a largo plazo; sin embargo, el modelo no lineal MS-VECM muestra que los precios de contado y futuro están cointegrados y que es el precio de contado el que más ajusta para 
reestablecer el equilibrio. Además, el ajuste del precio de contado se acelera en aquellos estados con mayor término de corrección de error, lo que pone de manifiesto que la convergencia hacia el equilibrio es más rápida cuanto mayor son las oportunidades de arbitraje.

Asimismo, los resultados del análisis impulso respuesta refuerzan la idea de que cuando las oportunidades de arbitraje se incrementan, el impacto en los precios de un shock inesperado aumenta.

En síntesis, los resultados de este primer capítulo subrayan la importancia de tener en cuenta los regímenes presentes en el término de corrección de error y el peligro de las hipótesis lineales en el análisis de la relación de lead-lag.

El Capítulo B analiza el efecto de la ampliamente documentada estacionalidad intradiaria en la transmisión de volatilidad entre los mercados de contado y futuro de los índices bursátiles CAC40, DAX30 a y FTSE100. En este artículo el principal objetivo es estudiar como el patrón repetitivo intradiario de los rendimientos medios absolutos puede afectar a la dinámica de transmisión de volatilidades. En esencia, las cuestiones que este estudio trata de responder son las siguientes: ¿son los resultados obtenidos es este campo de investigación los mismos si se consideran datos raw o datos estandarizados? 0 , ¿es la persistencia de un shock en la volatilidad de los rendimientos en un mercado y el efecto neto de los directional spillover entre el mercado de contado y futuro el mismo si el componente estacional es considerado o no? En este sentido, los resultados más notables muestran que las interacciones de volatilidad entre los mercados de contado y futuro disminuyen considerablemente después de eliminar el patrón estacional y que la transmisión de volatilidad difiere significativamente en función de si se utilizan datos raw o estandarizados, de forma que cuando los datos intradiarios no han sido estandarizados, el número óptimo de retardos en el modelo VAR determinado por el criterio de selección parece ser superfluo, sugiriendo que si el componente periódico es ignorado, esto podría invalidar la inferencia estadística en el análisis de spillovers. Además el análisis impulso respuesta muestra que cuando un shock llega al mercado y el componente intradiario no se ha eliminado antes de realizar el análisis de spillover, la respuesta a ese shock es altamente persistente. Finalmente, el estudio del efecto neto de los directional spillover entre el mercado de contado y futuro indica que el mercado de contado es el máximo emisor de volatility spillovers al mercado de futuro y que en términos de magnitud, la transmisión neta de volatilidades entre estos mercados es mayor cuando se tiene en cuenta el componente intradiario, poniendo de manifiesto una vez más que si no se considera este patrón intradiario podríamos estar perdiendo información relevante relativa a la transmisión de volatilidad.

En líneas generales, el segundo capítulo destaca la importancia de los datos de alta frecuencia en el estudio de la transmisión de volatilidad y la importancia de 
eliminar el componente periódico para reducir el riesgo de causalidad espuria al utilizar datos intradiarios en la modelización de la volatilidad.

Por último, el capítulo $\mathrm{C}$ de esta tesis contribuye a la literatura existente relativa a optimización de carteras estudiando los beneficios de utilizar datos intradiarios en este campo de estudio. Los resultados muestran que aquellos portfolios diseñados utilizando datos de alta frecuencia, y en particular datos raw intradiarios, arrojan mejor performance que aquellos portfolio diseñados con datos mensuales, incluso después de considerar los costes de transacción; y que además, son capaces de batir a la estrategia $1 / \mathrm{N}$.

Así pues, lo que parece claro es que el análisis de datos de alta frecuencia es interesante en muchos sentidos y que juega un papel crucial en los ámbitos de estudio abordados en esta tesis. Los datos de alta frecuencia proporcionan un gran potencial para mejorar la comprensión de las relaciones de lead-lag, así como de la transmisión de volatilidades entre los mercados de contado y futuro. Finalmente, cabe destacar su gran potencial en la selección óptima de carteras para la obtención de una mejor performance.

En síntesis, esta tesis pone de relieve que los datos de alta frecuencia son una valiosa propuesta para el estudio de los campos de investigación abarcados en este trabajo. 


\section{Referencias}

DeMiguel, V., Garlappi, L., \& Uppal, R. (2009b). Optimal versus naive diversification: How inefficient is the $1 / \mathrm{N}$ portfolio strategy? The Review of Financial Studies, 22(5), 1915-1953.

Goodhart, C. A., \& O'Hara, M. (1997). High-frequency data in financial markets: Issues and applications. Journal of Empirical Finance, 4(2), 73-114. 